This document is the accepted manuscript version of the following article:

Opris, D. M. (2018). Polar elastomers as novel materials for electromechanical actuator applications. Advanced Materials, 30(5), 1703678 (23 pp.). https:// doi .org/10.1002/adma. 201703678

DOI: 10.1002/ ((please add manuscript number))

Article type: ( Review)

\title{
Polar elastomers as novel materials for electromechanical actuator applications
}

Dorina M. Opris*

Dorina M. Opris

Swiss Federal Laboratories for Materials Science and Technology Empa, Laboratory for Functional Polymers, Überlandstr. 129, CH-8600, Dübendorf, Switzerland

E-mail: dorina.opris@empa.ch

Keywords: dielectric elastomer actuators, high permittivity elastomers, stimuli responsive polymers, artificial muscles

Dielectric elastomer actuators (DEAs) are stretchable capacitors capable of a muscle-like actuation when charged. They will one day be used to replace malfunctioning muscles supposed the driving voltage can be reduced below $24 \mathrm{~V}$. This review concentrates on polar dielectric elastomers and their behavior under an electric field. It puts emphasis on all the features that are correlated with the molecular structure, its synthetic realization, and its impact on properties. Regarding the polymer class it concentrates to some degree on polysiloxanes because of their attractively low glass transition temperatures. This enables introduction of highly polar groups to the backbone while maintaining soft elastic properties. The goal is to provide a few guidelines for future research in this emerging field which may be useful for those considering entering this fascinating endeavor. Because of the large number of materials available, a few restrictions in the selection had to be applied.

\section{Introduction}

More than 200 years ago, Galvani accidentally discovered that "whenever the nerves of a frog's leg were touched by one metal and the muscles by another, convulsions took place on bringing the two different metals in contact." ${ }^{\text {[1] }}$ Later in 1880, Röntgen observed that a stripe of natural rubber is deformed when charges are deposited on its surface. ${ }^{[2]}$ Ever since people have been fascinated by the properties of natural muscles and tried to find materials that 
mimic them. Biological muscles are fascinating soft protein tissues that change their length, shape, and stiffness upon an external stimulus. They produce displacements in the order of 20 to $40 \%$, energy densities in the range of $150 \mathrm{~J} \mathrm{~kg}^{-1}$, and stresses of up to $0.35 \mathrm{MPa}{ }^{[3]}$ Muscles have a fast response time, can be silently operated at different rates, have a high cycle life, and are able to self-heal after damage. Due to their complex hierarchical construction and intriguing operation mechanism, which involves the release of $\mathrm{Ca}^{2+}$ ions responsible for conformational changes of proteins translated in muscles striction, even today it is too challenging to mimic these highly optimized systems by synthetic analogs. ${ }^{[4]}$ The materials commonly advertised as ‘artificial muscles’ are in fact much simpler and typically use nonhierarchical bulk material deformations triggered by external stimuli. While one therefore should not expect artificial muscles to be able to fully compete with their biological analog, it is nevertheless astounding that a robotic arm the active part of which is based on polymeric matter can compete with a human opponent (Figure 1). ${ }^{[5]}$

a)

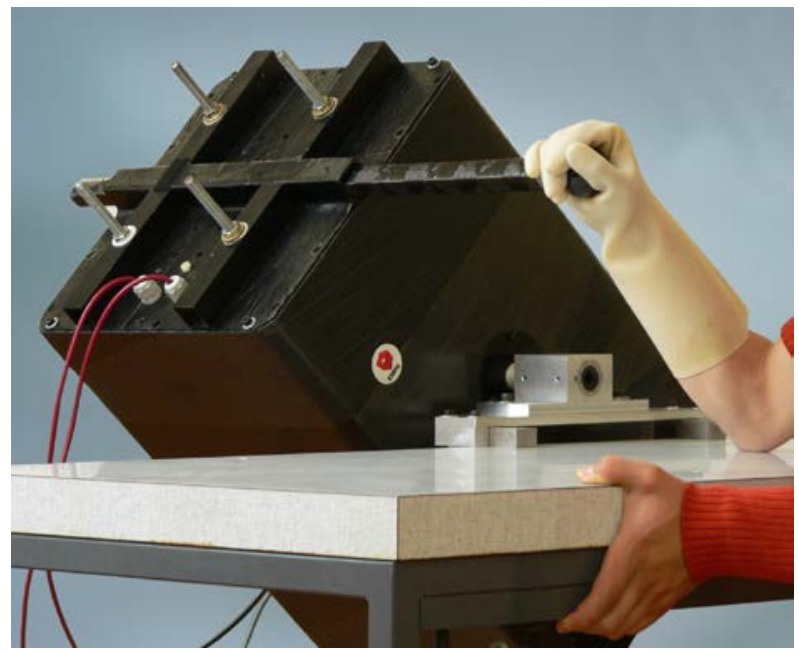

b)

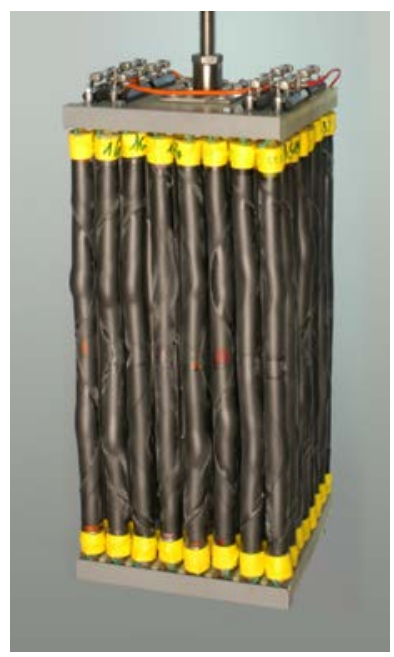

Figure 1. A robotic arm based on less than $1 \mathrm{~kg}$ of DEAs (electroactive material), constructed at Empa, effectively competing with a human demonstrated at the 2005 SPIE conference in San Diego (a) and one of the four devices, consisting of 64 roll actuators, used in the arm robot (b). The robot returns to its starting position after wrestling. Reproduced with permission from G. Kovacs, Empa.

Following the elucidation of the structure of natural rubber leading to the concept of macromolecules in the 1920 s by Staudinger, ${ }^{[6]}$ a wide variety of polymer-based materials have 
been synthesized. Many of them change their shape in response to light, $\mathrm{pH}$, temperature, humidity, electric and magnetic fields and gave rise to innovative applications. ${ }^{[7]}$ Among all, electroactive polymers (EAPs) are probably the most investigated class of responsive polymeric materials. ${ }^{[8,9]}$ They are actuated by applying an electric field, converting electrical energy directly into mechanical work. Depending on the actuation mechanism, EAPs are grouped into two classes: ionic and electronic EAPs. ${ }^{[10-12]}$ In ionic EAPs the application of an electric field results in oppositely charged ions to migrate through the polymeric film to the respective electrodes causing an up-concentration of the sterically more demanding anions on one side and of the less demanding cations on the other side of this film. ${ }^{[13]}$ This upconcentration causes the film to bend. Ionic EAPs have long response times and require the films to be embedded in electrolytes. Typical materials include ionic polymer gels, conducting polymers, carbon nanotubes, and ionic polymer-metal composites. ${ }^{[9]}$ In contrast, the electromechanical response in electronic EAPs is due to Coulombic forces that act in a material subjected to an electric field. ${ }^{[14]}$ Typical materials include dielectric, electrostrictive, liquid crystalline, and piezoelectric elastomers as well as polymer electrets. As the development currently stands, it appears that dielectric and electrostrictive elastomers have strains, actuation pressure, density, efficiency, and speed similar to natural muscles and are therefore particularly promising materials mimicking muscles. The focus of this review is therefore on these two materials which are also known as dielectric elastomer actuators (DEAs). DEAs are stretchable capacitors constructed from two compliant electrodes on a thin dielectric elastomer film, which show a muscle-like actuation when charged (Figure 2). ${ }^{[14]}$ 

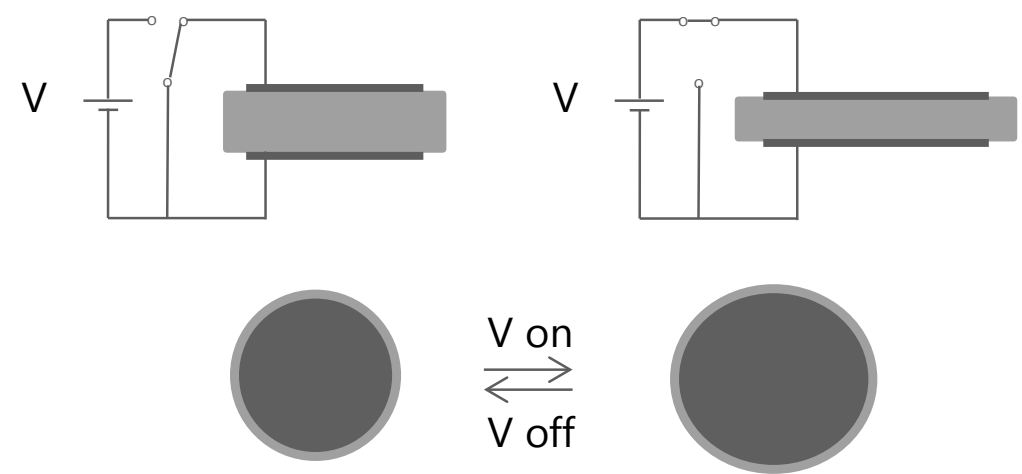

Figure 2. Cross-sectional (top) and top view (bottom) of the non-activated and the activated states of a circular membrane actuator left and right, respectively. Upon application of a voltage on the compliant electrodes the dielectric film is compressed in thickness and elongated in plane due to electrostatic forces.

A large variety of applications as actuators, generators, and sensors were proposed. ${ }^{[15-}$ ${ }^{19]}$ Despite the broad application potential of DEAs, a bottleneck in an even broader usage of these exciting materials represents the rather high driving voltages required for actuation. ${ }^{[20]}$ This is of particular concern whenever applications in the human body are foreseen. To lower the driving voltage several strategies can be followed: decreasing the elastic modulus $(Y){ }^{[21]}$ increasing the dielectric permittivity, ${ }^{[12]}$ and decreasing the film thickness ${ }^{[22]}$ of the elastomer, while keeping the dielectric breakdown as high as possible.

In recent years several excellent reviews on the topic of DEAs have appeared. They are largely complementary to the current review. Spontak et al., ${ }^{[23]}$ Pei et al., ${ }^{[12]}$ and Verdejo et al. ${ }^{[24]}$ provide overviews of the most common electrically activated EAP technologies with a special focus on DEAs. Anderson et al. ${ }^{[25]}$ and Rosser and Shea ${ }^{[26]}$ discuss different applications and recent progress in miniaturized DEAs. Skov et al. ${ }^{[27]}$ rather summarize the recent developments on high permittivity silicone elastomers and composites thereof and, finally, Biggs et al. ${ }^{[28]}$ concentrate on the different materials classes that have been evaluated for usage in DEAs. Recommended further readings include the following references. ${ }^{[4,10,29-31]}$

In all these reviews and regular articles the aspect of materials synthesis is contained, but not presented in a substantiated form that would provide a deep understanding for why 
certain molecular structures are used and how and to which level of perfection they are being synthesized. Because of the author's conviction that it is exactly the molecular structure that plays a crucial role in all materials properties, the current review tries to fill this void by putting the emphasis on all the features that are correlated with the molecular structure, its realization, and its impact on properties.

A number of materials used for DEAs are composed of different components and therefore have to be considered composites or blends. Some of these materials show rather attractive performances. ${ }^{[32-52]}$ They will nevertheless not be treated here because composites add further complexity to a system and render it more challenging to trace back which aspect is actually decisive for a particular property. The author considers a situation ideal in which a particular molecular structure and a particular mode of processing result in a particular DEA performance which can then be systematically optimized by altering these two parameters. The current article will also not consider the electrode materials themselves. To be useful in DEAs they should be stretchable to avoid delamination of the electrodes from the elastomeric part. $^{[36-38]}$ This aspect however is commonly considered an independent field of research.

The present review is structured in 7 chapters. It starts with short descriptions of the polarization mechanisms in polymers exposed to an electric field (Chapter 2) and the mechanism of actuation of electronic EAPs (Chapter 3). Another aspect the current article places emphasis on is how to design the molecular structure of an elastomer so as to increase the probability for a high dielectric breakdown. This will be delineated in Chapter 4 . In Chapter 5 the synthesis and actuation of high dielectric permittivity elastomers will be discussed. It involves considerations concerning different elastomers, the permittivity of which is altered by chemical modification with polar groups. As such modification tends to increase the glass transition temperature $\left(T_{g}\right)$ of the modified base polymer, the aspect of an as high as possible chain flexibility of the base polymer will play a significant role. This will actually lead us to concentrate the article to some degree on polysiloxanes which have 
attractively low $T_{g}$ 's as indicated for example by the $T_{g}$ of polydimethylsiloxane (PDMS) of $127^{\circ} \mathrm{C}^{[39]}$ Using such a base polymer provides the enormous opportunity even after severe structural modification to still have a material that combines useful processability with attractive elastomeric properties. Chapter 5 will also present approaches that have been used to prepare polar elastic networks, which will be explained for different materials classes. This chapter closes by comparing selected high permittivity elastomers named $\mathbf{M x}$ that show at least few $\%$ actuation at an electric field of $10 \mathrm{~V} \mu \mathrm{m}^{-1}$. As the reader will see, this comparison is complicated by the fact that every laboratory uses its own set-up for characterization.

While optimizing the molecular structures and consequently the materials properties is crucial, processing of the novel materials into very thin films is an equally important challenge. This is why Chapter 6 also treats several of these aspects with a focus on film thickness, which in light of an as low as possible driving voltage should be extremely thin, preferably below $20 \mu \mathrm{m}$.

Finally, Chapter 7 summarizes the article by providing a few guidelines for future research which may be useful for those considering entering the fascinating field of DEA.

\section{Mechanisms of polarization}

To better understand how polymers behave in an electric field, it is important to know the different mechanisms of polarization. Let us first consider a parallel plate capacitor whose dielectric is a linear dielectric material. Its capacitance $(C)$ is proportional to the dielectric permittivity $(\varepsilon)$ and the surface area $(A)$ and inversely proportional to the thickness $(d)$ of the dielectric:

$C=\frac{\varepsilon_{0} \varepsilon A}{d}$

where $\varepsilon_{0}$ is vacuum permittivity $\left(\varepsilon_{0}=8.854187817 \times 10^{-12} \mathrm{~F} \mathrm{~m}^{-1}\right)$ 
The amount of energy stored $(W)$ is given by:

$W=\frac{1}{2} C V^{2}=\frac{1}{2} \varepsilon_{0} \varepsilon A d U_{d}^{2}$

where $V$ is the maximum voltage that can be applied and $U_{b}$ is the dielectric strength. High energy density materials have a high dielectric permittivity and a high dielectric strength.

The dielectric permittivity is a measure of dielectric polarizability and increases with increasing polarizability of a material. The most important polarization mechanisms in a dielectric subjected to an electric field are: electronic, ionic, orientation, and interfacial (also called space charge) (Figure 3). ${ }^{[40]}$

Zero

Electric field

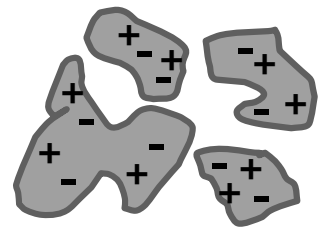

$E \widehat{T}$

Polarization:

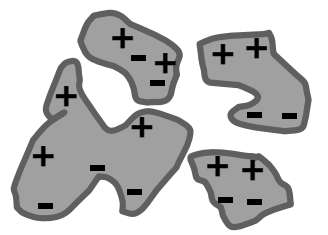

Interfacial
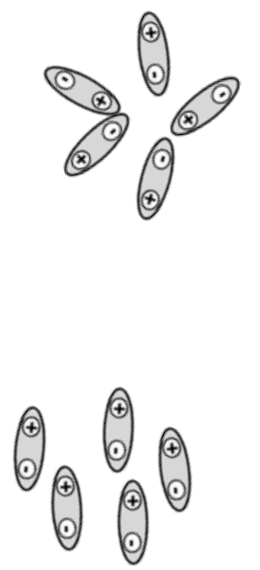

Orientation
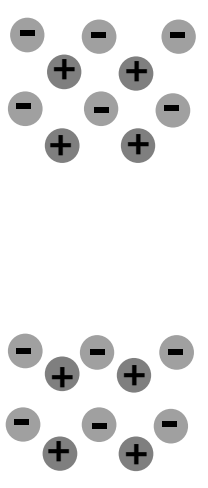

Ionic
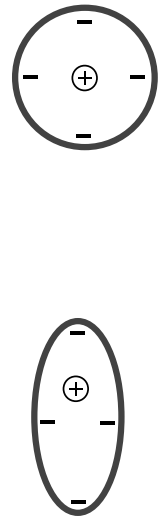

Electronic

Increasing frequency

Figure 3. Important polarization mechanisms in materials illustrated for four different starting situations which are not (yet) exposed to an electrical field and how they change upon exposure to an electrical field. For further explanations, see text.

These polarization mechanisms are shortly described below.

Electronic polarization occurs in all materials exposed to an electrical field. It is due to atom polarization upon electron displacement; the orbitals are distorted causing an induced dipole moment in the atom. This kind of polarization increases with the atomic volume. 
Ionic polarization, also referred to as vibrational polarization, occurs in all polymers and is due to displacement of atoms/ions from their equilibrium positions.

Orientation polarization is characteristic for polar molecules with permanent dipole moments that can orient in an electric field (Figure 3). This mechanism is of particular relevance to the materials presented in this article.

Interfacial polarization occurs when charges can migrate over short distances and is characterized by a local accumulation of charges at interfaces. Related to this is the effect called electrode polarization which occurs in materials that contain dissolved free ions. Under the influence of an electric field these ions tend to move towards the electrodes, resulting in ionic double layers at material/electrode interface. It causes a strong increase in permittivity at low frequencies and is to be avoided in materials for DEA applications. ${ }^{[40,44]}$ Furthermore, space charge polarization under a high electric field can allow formation of charged cellular polymer foams with positive and negative charges deposited on opposite voids. ${ }^{[45]}$

Just for the sake of completeness, it should be mentioned that beside polarization under an electric field there are also some cases where spontaneous polarization is observed in materials such as ferroelectric ceramics, poly(vinylidene fluoride) (PVDF) and its copolymers, odd numbered nylons, and cyanopolymers. ${ }^{[46-52]}$

Depending on the material used for DEAs, the polarization mechanisms manifest to a different degree. For example, when composites are used, the interfacial polarization will play an important role, while when dipoles are used, orientation polarization is important. Dielectric materials are commonly exposed to alternating electric fields when determining their permittivity. For this the frequencies are varied over a broad range. The permanent or induced dipoles orient to the electric field supposed the frequency of the electric field allows for dipole reorientation. Different polarization mechanisms have different time scales associated with dipole reorientation. It may therefore well be that at a given frequency of an alternating field some of the mechanisms are operative and, thus, contribute to permittivity, 
while others have already ceased to do so. ${ }^{[40]}$ Eventually, when the frequency of the field increases beyond $10^{15} \mathrm{~Hz}$ all polarizations turn ineffective and consequently the relative permittivity of any material equals 1 which is the value of the best dielectric, vacuum. A frequency at which a reorientation ceases is called resonance frequency. Electronic and ionic polarizations are insensitive to temperature and occur at high frequencies, while the orientation and interfacial polarizations are temperature dependent and occur at lower frequencies. Most polymers have a dielectric permittivity independent of the electric field and strain, but dependent on frequency and temperature. Therefore, it is important that the dielectric properties are provided not only in terms of permittivity but also in terms of dielectric loss and conductivity at different frequencies and preferably also at different temperatures and voltages. Only then a given material can be reasonably assessed for its suitability for a particular application.

The complex permittivity $\left(\varepsilon^{*}\right)$ is defined as:

$$
\varepsilon^{*}=\varepsilon^{\prime}-j \varepsilon^{\prime \prime}
$$

where $\varepsilon^{\prime}$ is the relative permittivity and $\varepsilon$ " is the imaginary part and represents the dielectric loss. Dielectric loss is the energy absorbed by the movement of charges in an alternating field:

$\varepsilon^{\prime \prime}=\tan \delta \times \varepsilon^{\prime}$

A drop in permittivity is accompanied by an increase in the dielectric loss. The dielectric losses are highest at the resonance frequency which causes the material to be heated. Above the resonance frequency, the dipoles do not 'feel' the alternating electric field and thus the contribution to the dielectric permittivity ceases. The optimal working frequency is where permittivity is high and losses are low. Additionally the loss tangent reaches its minimum and the contribution to the losses from the ionic conductivity is low.

The complex conductivity $\sigma^{*}$ is expressed by: 


$$
\sigma^{*}(\omega, T)=\sigma^{\prime}+i \sigma^{\prime \prime}=i \varepsilon_{0} \omega \varepsilon^{*}(\omega, T)=\varepsilon_{0} \omega \varepsilon^{\prime \prime}+\varepsilon_{0} \omega \varepsilon^{\prime}
$$

where $\sigma^{\prime}$ is the real and $\sigma^{\prime \prime}$ is the imaginary part of conductivity, while $i=\sqrt{-1}$ and the radial frequency $\omega=2 \pi v$. The imaginary part of the conductivity shows the influence of electrode polarization at low frequency.

The dielectric breakdown $\left(E_{b}\right)$ is the electric field at which a material fails as insulator:

$$
E_{b}=\frac{V}{d}
$$

where $V$ is the applied voltage and $d$ is the thickness. Dielectric breakdown occurs when the intrinsic breakdown strength of a material is too low, the mechanical forces are overcompensated by the electrostatic forces, high dielectric losses heat up the material too strongly, or defects lead to partial discharge in the dielectric. ${ }^{[53]}$ Additionally, $E_{b}$ is also influenced by other factors such as temperature, frequency, humidity, amount of stretch, as well as by electrode material, size, and shape. ${ }^{[53,54]}$ Furthermore, the presence of inhomogeneities both in material composition and in film thickness favors dielectric breakdown which typically occurs at softer and thinner parts. The dielectric breakdown in soft materials is a complex process which requests more research to understand it.

\section{Electronic EAPs}

Imagine a capacitor with compliant electrodes whose dielectric is a glassy solid with the soft segments of its rubbery phase frozen. Upon charging below $T_{g}$ only a small strain is observed since the shear modulus of a glassy solid is on the order of GPa, which is very high, and its dielectric permittivity is low, which means that not many charges can be stored. This low permittivity is a consequence of electron and ionic polarizations to be the only mechanisms contributing to the overall polarization. As long as this material is kept below $T_{g}$ the aspect of whether or not it is cross-linked does not play a role. Above $T_{g}$, cross-linking is essential to prevent the material from irreversible shape-changes caused by flow. For lightly cross-linked 
materials the shear modulus decreases by several orders of magnitudes and the soft segments are freer to move. A capacitor with such a dielectric will therefore deform much more when charged, which is exactly the effect desired for DEA applications.

When the dielectric is a nonpolar elastomer, the Coulomb interaction between the charges on the two electrodes is the main effect responsible for the observed deformation. ${ }^{[14]}$ When a capacitor with such an elastomer is charged, the like charges on individual electrodes repel each other, while the unlike ones attract each other. An additional strain is due to the electrostatic interactions between the dipoles induced by electron and ionic polarizations. The dielectric will deform until equilibrium is reached, when the electrostatic forces are balanced by the elastic forces.

The situation becomes more complex for elastomers containing polar groups. These permanent dipoles can be randomly oriented or form semicrystalline domains with the polar groups adopting either parallel or antiparallel orientation. Semicrystalline domains act as physical cross-links and mechanically reinforce the elastomer. In most cases an antiparallel orientation is found which causes the overall dipole moment to vanish. For cases with parallel orientation, however, there is an overall dipole moment of the crystalline domains and spontaneous polarization may occur even in the absence of an electric field. If this polarization can be switched between two different states by an electric field in opposite direction, the material is ferroelectric. ${ }^{[55]}$ Quasi-permanent polarization was also induced in internally charged foam polymers known as ferroelectrets ${ }^{[4,56]}$ as well as in specially designed polable elastomers recently developed in our group. ${ }^{[57,58]}$ Such materials when mechanically stressed generate an electric signal and are thus piezoelectric. While piezoelectric polymers are attractive for self-sensing, energy harvesting, and actuation these polymers will not be discussed here, the reader is referred to recent reviews in these fields. ${ }^{[59,60]}$

A capacitor whose dielectric is an amorphous polar elastomer will deform in an electric field due to Maxwell stress and electrostriction and the amount of deformation is 
proportional to the square of the field. ${ }^{[16,61,62]}$ The term electrostriction in soft materials is still debated in the literature and it appears that a commonly accepted definition has yet to be developed. ${ }^{[16,61-64]}$ According to Zhao and Suo "the electrostrictive stress results from the effect of deformation on permittivity" ${ }^{\text {[65] }}$ while others define it "as the elastic deformation of a dielectric material under the force exerted by an electric field." Since, the separation of Maxwell stress and electrostriction is rather challenging, it is questionable if it makes sense to separate the two effects. ${ }^{[66,67]}$

The electromechanical strain in amorphous polar elastomers is due to polymer backbone and dipole orientation in an electric field. Therefore, the Coulomb interactions of the charges on the electrodes, the orientation of the polar groups and the electrostatic forces between the aligned dipoles and the dipoles generated by electronic and ionic polarization are responsible for the observed actuation. ${ }^{[63]}$

The electrostatic pressure acting on the film is:

$$
p=\varepsilon_{0} \varepsilon E^{2}
$$

Thus the pressure is proportional to dielectric permittivity of the elastomer and with the square of the applied electric field.

The in-thickness strain of a material is not only influenced by its dielectric properties but also by its mechanical properties and its Poisson's ratio. ${ }^{[61]}$ The latter effect can be neglected for incompressible elastomers, but it cannot be neglected for materials with a low Poisson's ratio as is the case for some fluorinated polymers. ${ }^{[68]}$

For incompressible materials it was suggested that the in-thickness actuation strain below $10 \%$ can be predicted by: ${ }^{[14]}$

$$
s_{z}=-\frac{\varepsilon_{0} \varepsilon E^{2}}{Y}=-\frac{\varepsilon_{0} \varepsilon}{Y}\left(\frac{U}{d}\right)^{2}
$$


It should be noted that this equation is a great simplification since several parameters that affect actuation are not incorporated. Additionally, it assumes that the elastic modulus and the dielectric permittivity are not dependent on strain and electric field.

From Equation 8 it can be seen that in order to reduce the driving voltage, three parameters can be optimized: the Young's modulus should be low, the dielectric permittivity should be high, and the film thickness should be low.

Below, we will discuss approaches that have been used to lower the elastic modulus while keeping a high dielectric breakdown and approaches to increase the dielectric permittivity of an elastomer by chemical modification with polar groups.

\section{Soft elastomers with high dielectric breakdown}

The driving voltage of an actuator can be decreased when materials with low elastic moduli are used. Several approaches have been followed to reduce the elastic modulus by increasing the molar mass between the cross-links, ${ }^{[21]}$ by synthesizing bimodal heterogeneous networks, ${ }^{[69]}$ and by using plasticizers and solvents. ${ }^{[70,71]}$ While the moduli could in fact be reduced, these materials are susceptible to electromechanical instability (EMI). A soft elastomer film coated with two compliant electrodes will thin down when subjected to an electric field. As the film thins down, the electric field increases leading to a positive feedback between the reduction in thickness and the increase in electric field and may cause EMI and breakdown. ${ }^{[53,72]}$ This effect was first described by Stark and Garton who proposed that the critical electric field for pull-in instability is proportional to the square root of the elastic modulus. A significant thinning and wrinkling of the dielectric films is observed shortly before electrical breakdown. It was predicted that the electromechanical instability in an unprestrained elastomer occurs at an area actuation strain of about $40 \%$. Pelrine et al. however first showed that dielectric elastomers can achieve much higher actuation strains of over $100 \%$ when prestrained. ${ }^{[14]}$ Stimulated by this finding, extensive research to understand the 
pull-in instability and how this can be avoided or shifted to higher electric fields was conducted, e.g. the effect of prestraining on actuation strain was investigated. ${ }^{[73-76]}$ It was theoretically predicted that elastomers that strain-stiffen will give giant actuation of more than 500\%. ${ }^{[77]}$ This was confirmed experimentally by Keplinger et al., Li et al., and Huang et al. by demonstrating impressive actuation area strain of prestrained elastomers, some of which exceeded $1600 \%{ }^{[78-80]}$ The effect of prestraining on actuation will not be farther discussed here, the reader is referred to an excellent review by Zhao and Wang where the deformation and instabilities of soft dielectric elastomers under different mechanical constrains is discussed. $^{[53]}$

Despite the benefits of pre-straining a DEA, this is associated with at least three disadvantages: the need to use a rigid frame to hold the pre-strain, the danger of overstretching the film causing ruptures, the impracticability for many applications, and low fatigue strength at cyclic load. Importantly, the finding that the pull-in instability may be suppressed when the elastomers become stiffer before the actuation area reaches $40 \%$, stimulated the research for novel elastomers. As suggested by Zhao and Suo strain-stiffening may be achieved with interpenetrated polymer networks, swollen networks, and networks consisting of bottle-brush polymers (Figure 4). ${ }^{[77]}$

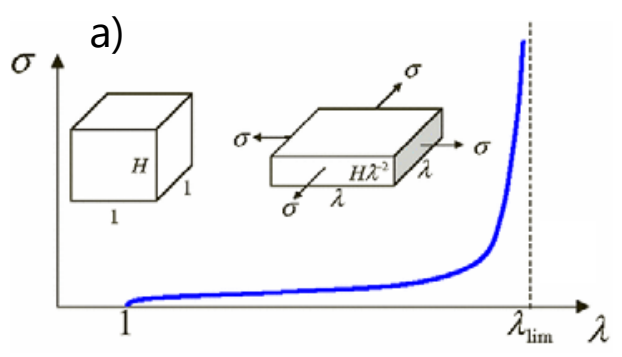

b)

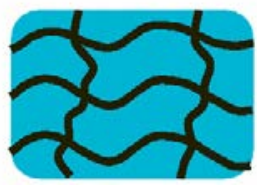

c)

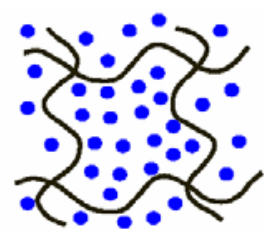

d)

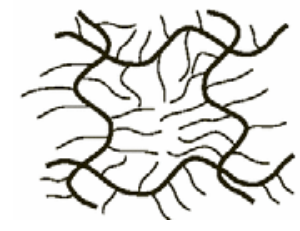

Figure 4. Stress-strain curve of an ideal elastomer for which the electromechanical instability is avoided (a). This can be achieved by using interpenetrating polymer networks (b), by swelling the network (c), and by cross-linking bottle-brush polymers (d). Adapted from Ref. 77 with permission from The American Physical Society. ${ }^{[7]}$ 
To overcome part of the above mentioned problems, Pei et al. synthesized a second network in the pre-strained film and achieved a "pre-strain-locked interpenetrating networks" which showed improved performance. ${ }^{[81]}$ A similar strategy was used by the same author for the formation of silicone films. Also here improved actuation performance and high dielectric breakdowns were reported. ${ }^{[82]}$ Despite these positive aspects, practical application of these materials may be hampered by the required pre-strain step.

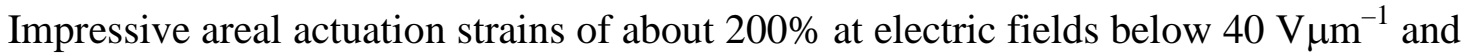
low cyclic hysteresis were achieved for a material composed of poly[styrene-b-(ethylene-copropylene)- $b$-styrene swollen with a low-volatility aliphatic-rich solvent. ${ }^{[32,83]}$ Unfortunately, such materials are susceptible to oxidation and to solvent leakage, which in turn may negatively affect the mechanical properties.

A particularly promising synthetic strategy to a single-component elastomer capable of overcoming the EMI was recently described, by incorporating bottlebrush segments into polymer networks. ${ }^{[84]}$ A mixture of monomethacryloxypropyl-terminated PDMSs and $\alpha, \gamma-$ methacryloxypropyl-terminated PDMS cross-linkers in p-xylene solvent was placed between two glass plates and then photo-polymerized. This strategy allowed tuning the bulk mechanical properties over a remarkably broad range, e.g. the elastic moduli could be varied from $1 \mathrm{MPa}$ down to $100 \mathrm{~Pa}$, by changing side-chain length of the bottlebrush polymer. Such elastomers can generate large strains of more than 300\% under relatively low electric fields ( $<10 \mathrm{~V} \mu \mathrm{m}^{-1}$ ), but because the films used are rather thick, the driving voltage was still above $1 \mathrm{kV}$. Nevertheless, supposed film thickness can be substantially reduced, bottlebrush polymers seem to be particularly promising candidates for overcoming the EMI.

While aromatic voltage stabilizers were recently proposed to increase the $E_{b}$ of an elastomer, none of the prepared materials were yet investigated in actuators. ${ }^{[85]}$

\section{Synthesis and actuation of high dielectric permittivity elastomers}




\subsection{General aspects}

The permittivity of elastomers has been increased either by blending with highly polarizable components or by chemical modification introducing polar groups. Blending was performed with ceramics, ${ }^{[86-89]}$ organic fillers ${ }^{[90-93]}$ or conductive particles. ${ }^{[21,94-97]}$ Chemical modification aimed at introducing functional groups with high dipole moment. ${ }^{[98]}$ While blending an elastomer with fillers saves synthetic effort and is a fast and easy approach which allows formation of materials with increased permittivity, other properties such as strain at break, elastic modulus, and breakdown field may be deteriorated. Additionally, phase separation during repeated actuations and the presence of interfacial phenomena which superimpose other effects, may complicate data interpretation. Furthermore, creation of ever thinner films is increasingly challenging for blends because film thicknesses eventually reaches the length scale of disperse and dispersing phases. ${ }^{[99]}$ As the current review article focusses on the chemical modification with polar groups, regarding composite dielectrics the reader is referred to a comprehensive review article. ${ }^{[27]}$

Unfortunately, the incorporation of polar groups to a polymer backbone inevitably leads to an increase in $T_{g}$. This negatively affects both the elastic properties and the useable temperature window of the modified polymer. There are two options to compensate for this undesired effect. Either plasticizers are added ${ }^{[100]}$ or the backbone of the polymers carrying the polar groups is chemically modified so as to increase its flexibility. ${ }^{[98]}$ The plasticizer approach has the downside that these low molar mass compounds tend to escape the dielectric, thus, rendering aging a great concern. For the alternative way to lower $T_{g}$ only a few cases exist. They concern polymers with carbon-carbon double bonds that were converted to their more flexible carbon-carbon single bond analogues by hydrogenation. ${ }^{[98,101]}$

In recent years a different strategy has increasingly been used which rests upon the usage of polymers with extremely low $T_{g}$ 's. The consideration here was that these polymers can tolerate the incorporation of polar groups because the unavoidable increase in $T_{g}$ 
associated with this incorporation will still result in materials with an attractive elastic behavior after cross-linking. Research in this direction concentrated on polysiloxanes known to have the lowest $T_{g}$ values of all polymers.

Regarding the molar mass of the polymer used, it should be sufficiently large to allow formation of soft elastomers as the molar mass between the cross-linking points will define the elastic properties. The polydispersity of the polymer used should be as narrow as possible because this allows for more defined networks. ${ }^{[102]}$

The introduction of polar groups should be done using efficient, easy to perform, versatile, robust, and extremely high yielding chemical reactions. As polar groups, moieties with large dipole moments such as $\mathrm{CF}_{3}, \mathrm{Cl}, \mathrm{F}, \mathrm{CN}, \mathrm{NO}_{2}$, carbonate, sulfone, sulfonic esters, or push pull moieties such as nitroaniline and 4-(4-nitrophenylazo)aniline can be used.

As low $T_{g}$ polar polymers are viscous liquids, they have to be cross-linked to be turned into elastic materials. Therefore the polar polymer should be designed to have reactive groups that can be used for cross-linking once processed into thin films. It is highly important that these groups remain intact during functionalization with polar groups, are stable in normal atmosphere, and allow for a fast and on demand cross-linking. Additionally, the formed bonds should be stable in normal conditions.

The main approaches used to high permittivity elastomers for DEAs are illustrated in Scheme 1. The most elegant approach uses a polymer that has both a high density of polar groups as well as end-groups for subsequent cross-linking (Scheme 1a). It allows both formation of polar materials that are homogenous at the molecular level and networks that have a high degree of structural control. The price to pay for these attractive advantages is, however, the sometimes tedious synthetic steps involved. Additionally, special care has to be taken of two aspects: the molar mass, which should be sufficiently high to ensure elasticity, and the end-group functionality which should be identical for all chain ends, otherwise the crosslinked material may contain polymer chains which are not incorporated into the network. 
When the molar mass of the polar polymer is too low, the cross-linked material does not exhibit the required elasticity. Therefore, in such cases the polar polymer is often used as high permittivity component in combination with a more conventional network providing the elasticity (Scheme 1b).

Another approach uses the end-groups of a PDMS in a cross-linking reaction with a polar cross-linker (Scheme 1c). The synthetic effort to such materials is generally low and elastomers with good mechanical properties are formed, but their dielectric permittivity is low because of the overall low dipole density in the materials.

Very often, in-situ processes are preferred in which both the functionalization with polar groups and the cross-linking occur simultaneously in thin films (Scheme 1d). They have the main advantage of allowing for the introduction of a large number of polar groups, however, this is compromised by a variety of limitations and disadvantages. For example, the materials obtained often contain unreacted reagents. This is a consequence of the fact that it can be difficult to drive both reactions to completion. Additionally, the cross-links are formed at completely unpredictable sites, which render molecular scale interpretation of properties practically impossible. Finally, up-scaling may pose a problem. In order to provide a homogeneous solution of all required components, the use of solvents is unavoidable. This not only raises a cost issue but more importantly the thin films formed shrink during drying which often results in fluctuations of film thickness and the formation of cracks.

There are a number of “compromise” approaches, the perhaps most important of which is shown in Scheme 1e. It uses polar polymers, whose lateral functional groups have not all been converted into polar groups. The residual groups are then being used for crosslinking once the material has been processed into thin films. Although also here the network is not particularly well defined, the formed materials have a high density of polar groups and are 'purer' as compared to the materials obtained by the in-situ processes. The latter aspect refers to the fact that the polymer can be purified before further use, which means that 
residual functionalization reagent and initiator are absent when cross-linking occurs. This is beneficial to overall process. Furthermore, this strategy allows for scaling-up because much less solvent is required for processing into thin films. This is likely a consequence of the fact the polar polymers do not need to be modified anymore (except for cross-linking). Interestingly, this strategy has only recently been used in the field of silicone-based materials, while it is routine in the synthesis of other polar elastomers as will be seen in Subchapter 5.3. The next two subchapters delineate the synthesis of polar polysiloxanes and other polar elastomers that show an increased dielectric permittivity.

a)

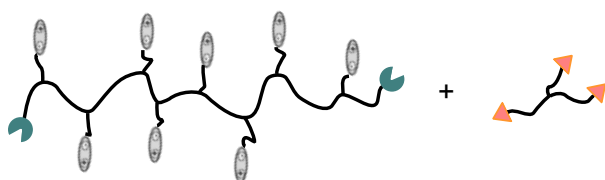

b)

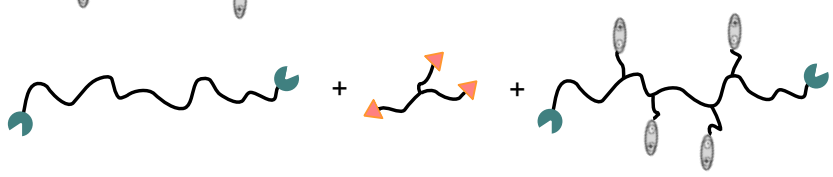

c)

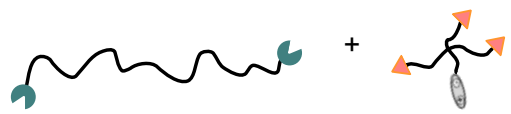

d)

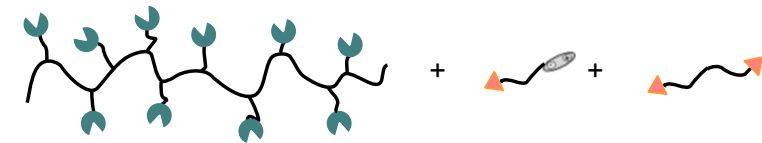

e)

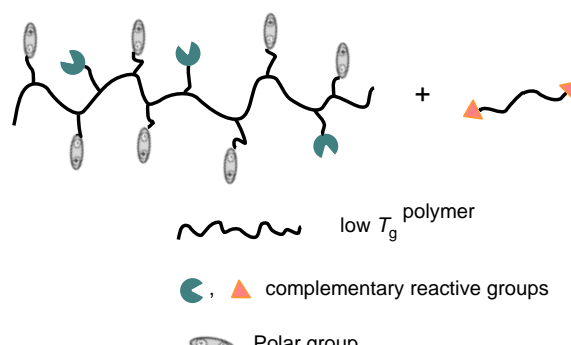

Scheme 1. Synthetic strategies used to prepare polar elastomers for DEAs starting from: a polar polymer that has a high density of polar groups and end-groups for subsequent crosslinking (a), a mixture of polar and nonpolar polymers and a cross-linker (b), an endfunctionalized non-polar polymer and a polar cross-linker (c), a prepolymer that is 
functionalized with polar groups and cross-linked simultaneously (d), and a polymer that carries both polar groups and reactive groups needed for cross-linking (e).

Therefore in order to prepare a high dielectric permittivity polymer by chemical modification with polar groups some design aspects have to be considered such as: 1) low $T_{g}$ of the base polymer, 2) range of molar masses and dispersity, 3) choice of polar groups and connection chemistry, and 4) choice of reactive groups for subsequent cross-linking.

\subsection{Polysiloxanes}

Polysiloxanes are probably one of the most investigated materials that have been used to optimize the properties for actuation. The reasons behind this may be their rather easy synthesis and the high flexibility of the siloxy backbone. ${ }^{[102]}$ Additionally, specific end-groups important for subsequent cross-linking in thin films can be introduced. First we will discuss approaches that have been used to chemically modify polysiloxanes with polar groups and the impact this chemical modification has on $T_{g}$ and on the dielectric permittivity of the resulting polymers. To access useful material for actuators consisting of polysiloxanes with polar groups in the side chains, the next step requires their cross-linking. Without this step they are basically highly viscous liquids without useful elastic properties. Therefore, a special emphasis is put on how to get polar elastomers according to Scheme 1. Despite the large number of literature dealing with increasing the dielectric permittivity of polysiloxanes, there is only limited literature available on how this increase of permittivity due to polar groups affects the electromechanical properties.

Given the complexity of the chemical transformations in many of the cases which will be presented, it is unfortunate that structural characterization is not always given the importance it deserves. Original analytical data are often not provided in the supporting information. This makes it difficult to assess the purity of the prepared polymers which is an 
important factor when it comes to investigating the dielectric properties and making a durable and powerful material.

5.2.1. Polysiloxanes with polar side groups and defined end-groups for subsequent crosslinking

Polar polysiloxanes can be prepared either by polycondensation of bifunctional silanes, by ring opening polymerization of functional cyclosiloxane, or by post-polymerization modification of polysiloxanes that carry reactive groups (Scheme 2). ${ }^{[102]}$ These three strategies are not of equal importance. The most important approach is the latter, which will be described in more detail at the end of this subchapter. Specific end-groups required for subsequent networking, such as vinyl, allyl, hydroxyl, and amino can be introduced via endblockers.

a)

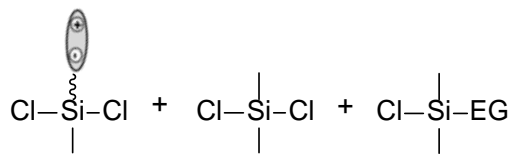

b)

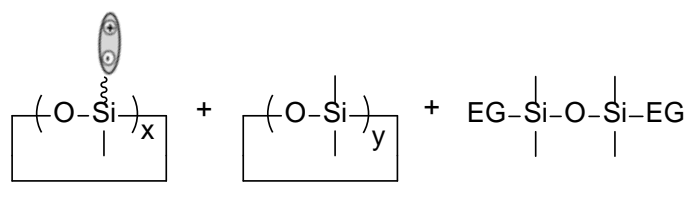

c)

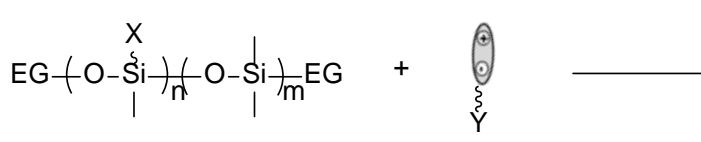

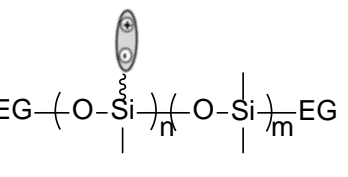

目= polar group

$\mathrm{X}$ and $\mathrm{Y}$ are complementary reactive groups EG is end-group

Scheme 2. Synthesis of polysiloxanes containing polar side groups by polycondensation of bifunctional silanes (a), by ring opening (co)polymerization of functional cyclosiloxane (b), and by post-polymerization modification of polysiloxanes that carry reactive side-groups (c). Specific end-groups can be introduced via end-blockers.

Polycondensation of dichloro(chloromethyl)methylsilane (1) and dimethyldichlorosilane (2), blocked with vinyldimethylchlorosilane (3) end-blocker was used to prepare a copolymer (P1) that carries chloromethyl side- and vinyl end-groups (Scheme 3a). ${ }^{[103]}$ The vinyl groups were subsequently used in a hydrosilylation with a multifunctional hydrosilane cross-linker. An 
elastomer with about $60 \mathrm{~mol} \%$ of the siloxy units modified with chloromethyl groups was reported to have a dielectric permittivity of 6 to 6.8 at $100 \mathrm{kHz}$, and a dielectric breakdown ranging from 50 to $60 \mathrm{~V} \mathrm{\mu m}^{-1}$.

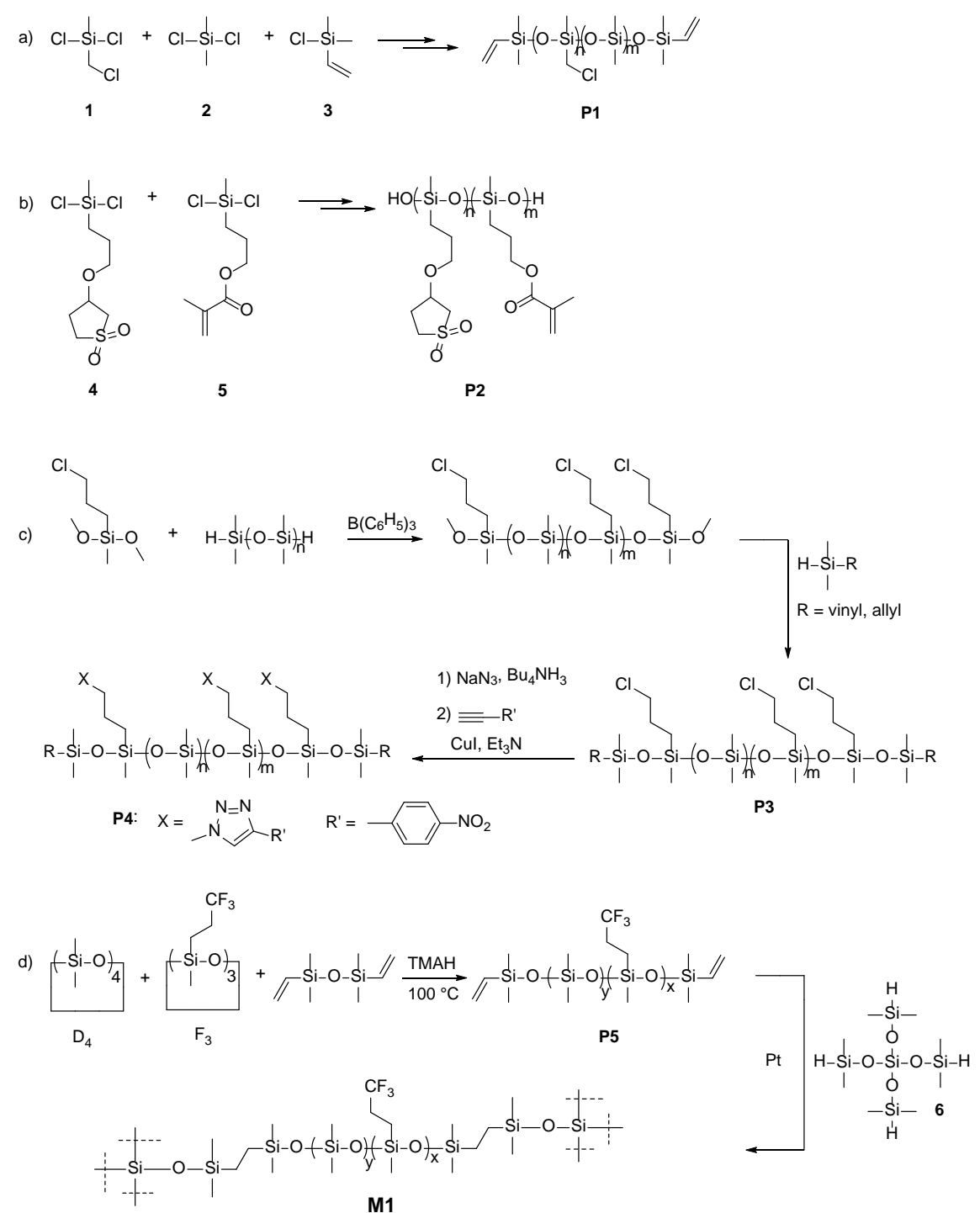

Scheme 3. Synthesis of polysiloxanes containing chloromethyl side groups (a), of polysiloxanes P2 containing propoxy-3-sulfolane groups (b), of polysiloxanes modified with chloropropyl side-groups and their post-polymerization modification with azide and nitrobenzene groups (c), and of polysiloxanes containing trifluoropropyl groups starting from $\mathrm{D}_{4}, \mathrm{~F}_{3}$, and 1,3-divinyl-1,1,3,3-tetramethyldisiloxane P5 and their cross-linking to elastic materials via a hydrosilylation reaction of the vinyl groups with tetrakis(dimethysiloxy)silane 6 (d). Note that these polymers have a random sequence of repeat units.

The same reaction was used for the synthesis of polysiloxanes containing propoxy-3-sulfolane pendant groups $\mathbf{P 2}$ (Scheme 3b). ${ }^{[104]}$ One of the monomers used, the methacryloxypropyldichloromethylsilane (4), is commercially available, while the other, monomer 5, was 
prepared using a hydrosilylation reaction between methyldichlorosilane and allyloxysulfolane. Cross-linking of the resulting polymers $\mathbf{P} 2$ by azobisisobutyronitrile gave flexible materials which showed an increase in permittivity with increasing the sulfolane content. A maximum value of $\varepsilon=11$ at $1 \mathrm{kHz}$ was reported for one of the prepared materials that contained about 60\% propoxysulfolane groups.

Polysiloxanes that carry chloropropyl side-groups and vinyl or allyl end-groups P3 were prepared through a tris(pentafluorophenyl)borane-Lewis-acid-catalyzed reaction as shown in Scheme 3c. ${ }^{[105]}$ Subsequent nucleophilic substitution of the chloride in the side chains by azide opens up the possibility of incorporating other polar groups to the polymer $\mathbf{P 4}$ via copper-catalyzed cycloaddition reactions between these azides and a variety of alkynes, while the vinyl or allyl end-groups allow for cross-linking via a hydrosilylation reaction. Elastomers containing chloride, azide, and 1-ethynyl-4-nitrobenzen were prepared. The polymers with the highest content of polar chloride, azide, and nitrobenzene showed dielectric permittivity at high frequency of $4.7,3.4$, and 8.5 , respectively. ${ }^{[105-107]}$ It shall be noted however that the reaction mechanism is rather complex, the Lewis acid may affect polysiloxane backbone resulting in chain scission and re-connection (scrambling).

Polar polysiloxanes can be also prepared by ring-opening polymerization of polar cyclosiloxane monomers (Scheme 2b). The most common polar monomers are those that carry either trifluoropropyl or nitrile groups. ${ }^{[108]}$ To tune the content of polar groups in the polymers, the ratio between the non-polar/polar monomers was changed. Polymerization of cyclic monomers modified with polar nitrile groups allows in principle access to nitrile containing polysiloxanes. Unfortunately, their molar masses could not be driven high enough so as to allow formation of materials with good elastic properties. ${ }^{[108]}$ This is why this approach is presented only briefly.

Dascalu et al. first synthesized polysiloxanes containing trifluoropropyl side-groups and vinyl end-groups by anionic co-polymerization of 1,3,5-tris(3,3,3-trifluoropropyl)-1,3,5- 
trimethylcyclosiloxane $\left(F_{3}\right)$ with octamethylcyclotetrasiloxane $\left(D_{4}\right)$ in presence of 1,3-divinyl1,1,3,3-tetramethyldisiloxane end-blocker and subsequently cross-linked them to elastomers (Scheme 3d). ${ }^{[109]}$ The content of trifluoropropyl groups in the copolymers P5 was tuned from $28 \mathrm{~mol} \%$ to $58 \mathrm{~mol} \%$ by using different $\mathrm{F}_{3}: \mathrm{D}_{4}$ ratios of monomers. The vinyl end-groups allowed cross-linking the copolymers to elastomers via a hydrosilylation reaction with tetrakis(dimethysiloxy)silane 6 in presence of Pt catalyst. By increasing the content of $\mathrm{CF}_{3}$ groups from $28 \mathrm{~mol} \%$ to $58 \mathrm{~mol} \%$, an increase in permittivity from $\varepsilon^{\prime}=5.1$ to $\varepsilon^{\prime}=6.4$ and an increase in the $T_{g}$ from $-106{ }^{\circ} \mathrm{C}$ to $-88.6^{\circ} \mathrm{C}$ was observed, respectively. A maximum lateral actuation strain of $5.4 \%$ at an electric field of $7.8 \mathrm{~V} \mu \mathrm{m}^{-1}$ was measured for a material M1 prepared by cross-linking a polymer containing 53 mol\% trifluoropropyl groups which has a $Y$ $=19 \mathrm{kPa}$ and $\varepsilon^{\prime}=6.2$.

Polar groups can be introduced on polysiloxane chain via a post-polymerization reaction. As is typical for this strategy, the reactions chosen for post-polymerization modifications must be extremely high yielding and should not cause any side reactions. ${ }^{110}$ Polymers with different degrees of substitution cannot be separated. As shown before (Scheme 3c), the presence of chloride groups in the side chains opens the possibility of replacing it by azide groups. These azides are subsequently used to introduce polar groups via aza-click chemistry. ${ }^{[105]}$ While these steps appear attractive on paper, the experimental realization is not only involved with considerable synthesis effort but also tedious purifications and considerable costs. It appears therefore that this potentially interesting approach may not be useable for large scale production despite the efficiency of aza-click chemistry. ${ }^{[111]}$ Given the complexity of this reaction, it is unfortunate that no NMR spectra are provided.

Polysiloxanes with lateral hydrosilyl or vinyl groups are attractive precursors for postpolymerization modifications using hydrosilylation and thiol-ene reactions, respectively. A large variety of functional polysiloxanes were prepared using this approach. ${ }^{[12,113]}$ For 
example, Yang and Wnek introduced silyl ketene acetal pendant groups to the polysiloxanes via hydrosilylation to obtain $\mathbf{P 6}$ (Scheme 4a). ${ }^{[114,115]}$ The formed polymers were subsequently reacted with electrophiles (E-X) such as 4-nitrobenzenesulphenyl chloride and afforded P7 in high yields. The permittivity increased from 4.83 for $\mathbf{P 6}$ to 8.96 for P7 with $70 \% p$ nitrothiophenoxy groups. When increasing the content of this polar group further to $90 \%$ the permittivity decreased to 6.52. This surprising decrease can be rationalized by the decrease in conformational mobility of the polymer with the higher content of polar groups as is reflected by its higher $T_{g}$ (Figure 5).

a) $\underset{\mathrm{H}}{(\mathrm{Si}-\mathrm{O}})_{\mathrm{n}}$<smiles>O=[N+]([O-])c1ccc(S(=O)(=O)Cl)cc1</smiles><smiles>CCOC(OC)C(C)CCC[Si](C)(C)O[Mg]</smiles><smiles></smiles>

b)

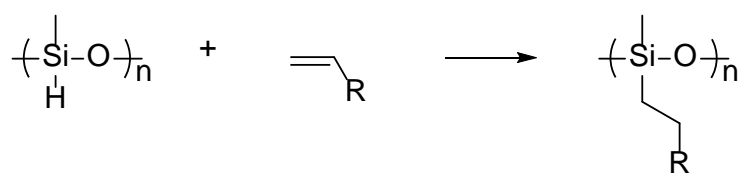<smiles>[R]C=C[C-]=C</smiles><smiles>C=CCOc1ccc(C=O)cc1</smiles>

8

10

c) $+(\mathrm{Si}-\mathrm{O})_{\mathrm{n}}+\mathrm{HS}-\mathrm{R} \longrightarrow \mathrm{S}_{-\mathrm{R}}$<smiles>CS(=O)(=O)CCS</smiles><smiles>[R]SCC[Si](C)(C)O[Ga]</smiles><smiles></smiles><smiles>C[As]([Mg])(=[Pt])SCCC#N</smiles><smiles>CS(=O)(=O)CCS[As](C)(C)=O</smiles>

Scheme 4. Synthesis of $\mathbf{P 6}$ which carries silyl ketene acetal side groups and the subsequent conversion of this polymer into P7 carrying polar 4-nitrobenzenesulphenyl groups (a), 
functionalization with pendant polar groups of poly(methylhydrosiloxane) via hydrosilylation (b), and functionalization of poly(methylvinylsiloxane) via thiol-ene addition (c).

The Si-H bonds in poly(methylhydrosiloxane) (PHMS) have been used to attach a variety of olefins by hydrosilylation. ${ }^{[112]}$ Some of them are shown in Scheme $4 \mathrm{~b}$. While hydrosilylation is an attractive tool in terms of effort and cost it bears the risk that residual Si-H bonds can hydrolyze to Si-OH groups which can cause subsequent condensation of the polymer chains into networks. This aspect was particularly well described for the cyclic carbonates $\mathbf{7}$ and $\mathbf{8}$ (Scheme 4b). The dielectric properties of the obtained polymers functionalized with carbonates 7 and 8 showed a permittivity as high as 24.1 and 46.3 at $10 \mathrm{kHz}$, respectively. ${ }^{[16]}$

Besides the aspect of (unwanted) network formation, tuning the content of polar side chains in the polysiloxanes shall be discussed. This interesting opportunity to tune permittivity was intensely studied using the allyl cyanide (9). ${ }^{[117]}$ In order to synthesize an as defined set of polysiloxanes with different ratios of nitrile groups in the side chains, the exact same starting PHMS was reacted with mixtures of allyl cyanide and 1-hexene in which these two competitive olefins were varied in a wide range. 1-Hexene was added to quench all Si-H that had not reacted with the allyl cyanide and thus to avoid the above mentioned problem with network formation of modified PHMS'. The only limitation encountered in this strategy was the inability to introduce more than $89 \%$ of nitrile groups, which likely reflects a sterical issue. A linear increase in permittivity with the nitrile content was observed culminating in the maximum value of 15.9 for a polysiloxane with 89 mol\% nitriles. All these polymers have a $T_{g}$ below $-60{ }^{\circ} \mathrm{C}$ which is a nice confirmation of the power lying in the use of polysiloxanes. Other polar olefins such as the one containing the epoxy $\mathbf{1 0}$ and the benzaldehyde $\mathbf{1 1}$ were also used. However, the amount of the polar groups introduced was too low and therefore the permittivities do not exceed $5 .^{[118]}$

Thiol-ene reactions have only recently been used for the purpose of increasing the dielectric permittivity of polysiloxanes. ${ }^{[119,120]}$ They are reliable, often near quantitative and 
fast and therefore suitable for post-polymerization modifications. Our group successfully introduced nitrile, ${ }^{[120-122]}$ sulfolane, ${ }^{[123]}$ methylsulfone, ${ }^{[123]}$ and butyl thioether groups ${ }^{[122]}$ (Scheme 4c). The polar group content was systematically varied by using two different thiols, one of which carried the polar group $(\mathbf{1 2}, \mathbf{1 3}$, or $\mathbf{1 4})$, the other a butyl group instead. Similar as in the case above where 1-hexene was used as competitive olefin, butylthiol was here employed to avoid possible cross-linking between unreacted vinyl groups. The influence the type and content of polar groups has on $T_{g}$ and permittivity was studied. The highest permittivity for the polysiloxanes with butyl thioether (P8), sulfolane (P9), nitrile (P10), and methylsulfone groups (P11) is 4.7, 13.4, 17.4, and 23, respectively. Additionally, all polymers have a $T_{g}$ below room temperature and show a linear increase in permittivity and $T_{g}$ with the polar group content. An exception is the polysiloxane that was fully functionalized with the sterically demanding sulfolane group. It has $T_{g}=9.3{ }^{\circ} \mathrm{C}$ which is high to fully exploit the polarization of all groups in an electric field at room temperature. The high $T_{g}$ is likely due to the dipolar interactions and steric hindrance of the bulky sulfolane group. Figure 5 shows the dielectric permittivity at high frequencies and the $T_{g}$ for the discussed polysiloxanes. Our attempts to cross-link P9-P11 via the end-groups were not successful.
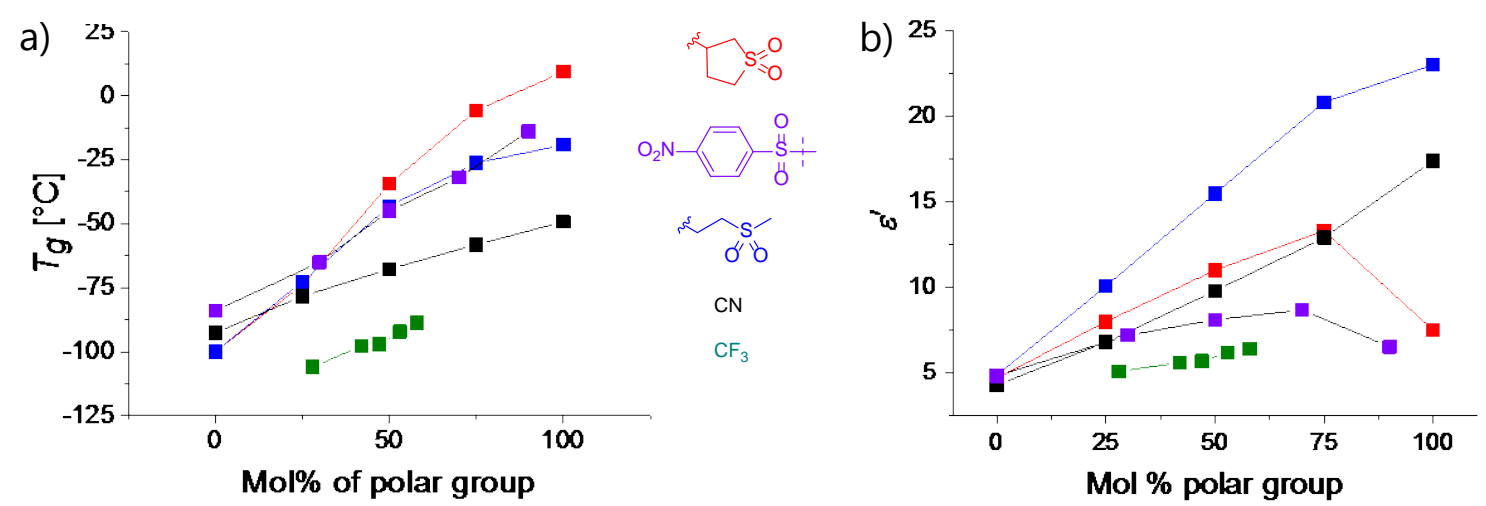

Figure 5. The glass transition temperature (left) and the dielectric permittivity of the polysiloxanes P5 and P7-P11 in dependence of amount and type of polar groups. All polymers were prepared via the thiol-ene post-polymerization modification except those that carry $\mathrm{CF}_{3}$ groups which were prepared starting from monomers. 
Using the same strategy, chlorides and carboxyl groups were also introduced on polysiloxanes using thiols 15 and 16, but because the starting polymer carried only 8\% vinyl groups, the total amount of polar groups incorporated could not exceed this number. Accordingly, the maximum achieved permittivity was 3.8 and 3.9 for polymers functionalized with 3-chloro-1propanethiol $\mathbf{1 5}^{[124]}$ and 3-mercaptopropionic acid 16, ${ }^{[118]}$ respectively.

\subsubsection{Polar-nonpolar interconnected networks}

The cases described in this chapter all use a non-polar silicone component to provide elasticity and either a polar silicone or any other polar component to provide the necessary dielectric properties. Both components are then cross-linked into the final material (Scheme 1b). Typical problems encountered relate to the required avoidance of phase segregation which can easily occur between the polar and the non-polar components simultaneously present in the mixture to be cross-linked. This requires the use of solvents and a fast crosslinking reaction and the implementation proved to be rather challenging.

There are number of publications through which polar groups such as nitrile and chloride were incorporated. To avoid phase segregation, only relatively low fractions of the polar components were used. Consequently, the permittivity of the resulting materials was always below 6. ${ }^{[126-129]}$ For the case where a nitrile-functionalized polysiloxane was used as polar component, one of the best materials has a $Y \sim 300 \mathrm{kPa}, \varepsilon^{\prime} \sim 5$, and shows an actuation strain of about $1 \%$ and $7 \%$ at an electric field of $10 \mathrm{~V} \mu \mathrm{m}^{-1}$ and $20 \mathrm{~V} \mu \mathrm{m}^{-1}$, respectively. ${ }^{[126]}$

Along the same lines, Böse et al. used the vinyl end-functionalized polysiloxane with trifluoropropyl side-groups, P5 (Scheme 3d) and formed an interconnected network with PDMS using a hydrosilylation reaction. A material containing about 45 wt $\%$ of polar polysiloxane showed a $\varepsilon^{\prime}=5.5$, a strain at break as high as $400 \%$, and a maximum actuation

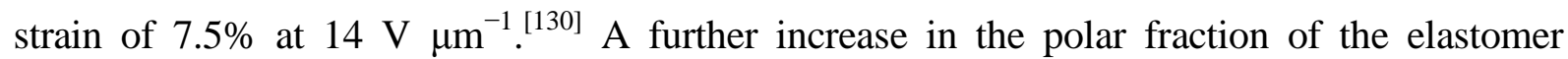
resulted in difficult to handle, very soft films. 
Dang et al. incorporated the azobenzene $\mathbf{1 7}$ in a PDMS elastomer via a condensation reaction with ethyltetraethoxy silane (Scheme 5a). ${ }^{[131]}$ The content of the polar component 17 was altered from $0 \%$ to $13.3 \mathrm{wt} \%$. Increasing the content resulted in an increase of both the permittivity (from 2.72 to 4.88 ) and the elastic modulus (from 268 to $725 \mathrm{kPa}$ ). Also the electromechanical sensitivity $\left(\varepsilon^{\prime} / Y\right)$ values increase, however, only up to a content of 10.3 wt\% (material M2). Thereafter $\varepsilon^{\prime} / Y$ decreases again because of a too high elastic modulus. Thus, the material with $10.3 \%$ polar component has the maximum performance in terms of an actuation strain of $12 \%$ at $56 \mathrm{~V} \mathrm{~m}^{-1}$.

a)

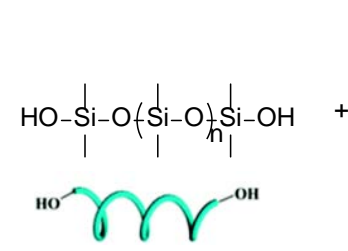

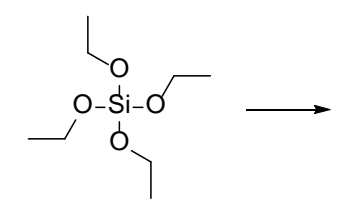

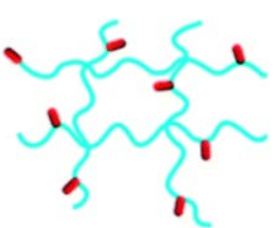

b)

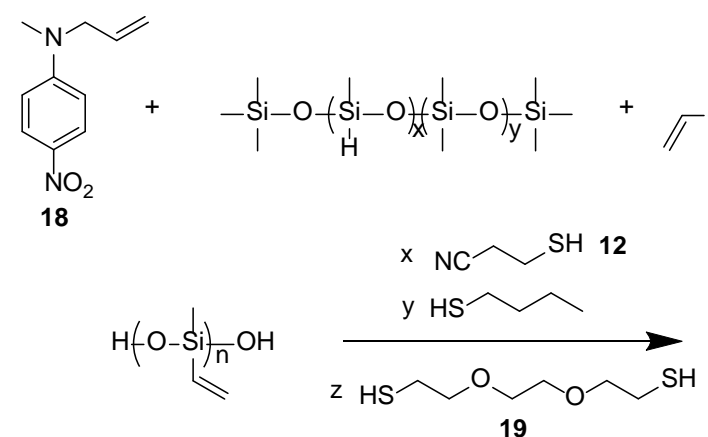

c)

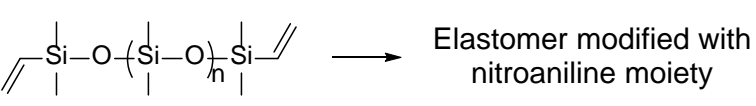
nitroaniline moiety

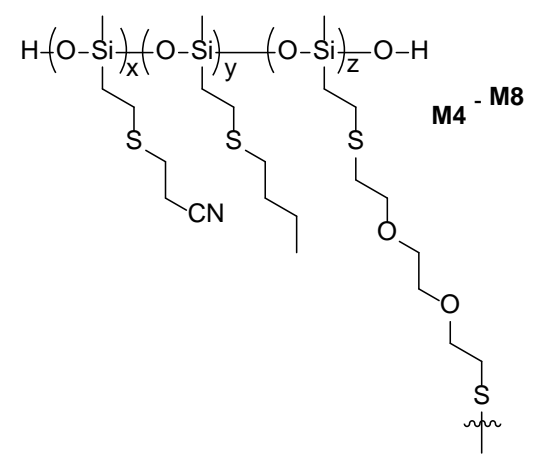

Scheme 5. Synthetic strategy to an azobenzene-grafted PDMS network (a), a one step process to polysiloxane elastomers by Kussmaul et al. starting from a 4-nitroaniline dipole, vinyl endfunctionalized PDMS, and methylhydro-co-dimethyl-polysiloxane cross-linker via hydrosilylation (b), and a one step process to silicone elastomers having different mol\% of polar CN groups prepared via thiol-ene reaction (c). Adapted from Ref. 131 and Ref. 122 with permission from The Royal Society of Chemistry.

\subsubsection{Polar networks via polar cross-linkers}

As indicated above this approach commonly suffers from the fact that the concentration of polar groups is inherently limited by the fact that they only stem from the cross-linker 
(Scheme 1c). For example, Madsen et al. used a trifunctional vinylsilane with the polar nitrobenzene as cross-linker. Although the reaction proceeded quite nicely, only modest permittivities of around 3.1 were achieved. ${ }^{[132]}$

Similarly low permittivities resulted from various trialkoxy(alkyl)silanes which carried $\mathrm{NH}_{2}$, Cl- and CN-groups in the alkyl group. ${ }^{[108,133]}$ The highest permittivity obtained for these materials was 3.7 in the case of the nitrile group. Further attempts to increase the permittivity by using excess of cross-linkers were not successful. They resulted in maximum permittivities of 3.7 and 3.9 for chloride and nitrile. The reason behind the low permittivity despite the higher content of polar cross-linker is seen by the authors in formation of silsesquioxane structures which entrap the chloride ${ }^{[133]}$ and nitrile groups ${ }^{[108]}$ hence hinder their polarization in an electric field.

\subsubsection{Networks by in-situ functionalization and cross-linking}

Another approach to synthesize polysiloxane elastomers modified with polar groups is via an in-situ process in which the functionalization with polar groups and the cross-linking occur simultaneously in thin films (Scheme 1d). When going for this synthetic strategy, it is important to implement highly efficient chemistry; otherwise the materials will contain unreacted reagents and be inhomogeneous.

Kussmaul et al. used the Si-H groups of a poly(methylhydro-co-dimethyl)siloxane for this purpose. On the one side they were partially grafted with the polar N-allyl-Nmethylaniline 18 (Scheme 5b); on the other side they were subjected to cross-linking involving the vinyl end-groups of a PDMS matrix. The content of nitroaniline precursor in the obtained elastomers was fine-tuned from 0-13 wt\%. An increase in the permittivity and a decrease in the elastic modulus with increasing nitroaniline content was observed furnishing the highest permittivity of 6 for a material with 13 wt\% dipole content. ${ }^{[134]}$ An optimized material, M3, with a polar content of $10.7 \mathrm{wt} \%$ was achieved using the commercial silicone 
Elastosil as matrix. It showed a $Y=142 \mathrm{kPa}$ and $\varepsilon^{\prime}=5.56$, and a maximum actuation strain $s_{z}$ of about $2 \%$ at an electric field of $10 \mathrm{~V}^{-1}$. $^{[135,136]}$ Unfortunately, at this voltage the actuator suffered breakdown.

The same strategy was also used by Dünki et al. for the formation of elastomers containing nitrile groups. A solution of poly(methylvinylsiloxane) in tetrahydrofuran was reacted with different ratios of 3-mercaptopropionitrile 12/butyl thiol and bifunctional thiol 19 using the efficient thiol-ene reaction (Scheme $5 c$ ). ${ }^{[120,122]}$ This allowed the preparation of elastic materials M4-M8 containing varying amounts of nitrile groups, with promising dielectric, mechanical, and electromechanical properties as well as the adjustment of the dielectric properties of the formed elastomers by using different ratios of 3mercaptopropionitrile/butyl thiol (Figure 6). ${ }^{[122]}$ All materials showed a $T_{g}$ below $-45{ }^{\circ} \mathrm{C}$. It is noteworthy that such a low $T_{g}$ should in principle allow the use of such materials under extreme environmental conditions. A linear increase in permittivity and a slight stiffening of the materials with the content of nitrile groups was observed and attributed to the dipolar interactions. The conductivity of the elastomers increased sharply for nitrile contents above 50 mol\% which did not hinder the actuation of these materials in an electric field. Despite the increase in stiffness, commonly observed for elastomers with increasing nitrile content, a decrease in the electric field required to induce a certain actuation was observed. For example, the lateral actuation strain of material M4 with no nitrile group was about $2.7 \%$ at $10 \mathrm{~V} \mu \mathrm{m}^{-1}$, while this value increased to $14 \%$ at the same field for $\mathbf{M 8}$ which has a nitrile group at every repeat unit (Figure 6). Cyclic actuation tests showed these materials to be rather robust in that thousands of cycles could be conducted without degradation. Additionally, actuators constructed from M8 were capable to self-repair after a breakdown, whereas that constructed from the material modified with butyl thioether groups were irreversibly damaged. Despite the attractively high dielectric permittivity and good electromechanical properties, it turned 
out to be challenging to process these materials into sufficiently thin films under technologically relevant conditions. Therefore further work is required in this direction.
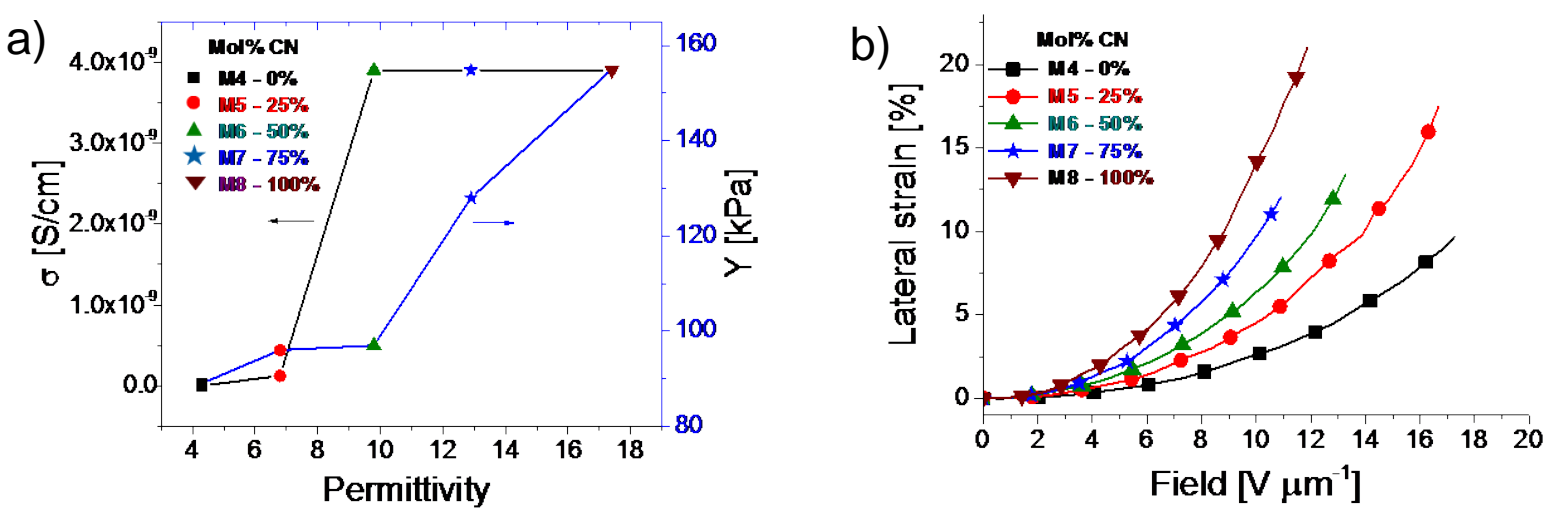

Figure 6. Conductivity and elastic modulus as function of dielectric permittivity (a) and the lateral actuation strain as function of applied electric field (b) for elastomers with different content of polar nitrile groups. Reproduced from Ref.122 with permission from The Royal Society of Chemistry.

\subsubsection{Cross-linking via side groups}

From the above examples it can be seen that it is rather challenging to prepare homogenous polysiloxane-based elastomers with high permittivity and good elastic properties. For the cases where such materials were in fact achieved, either a polar polysiloxane that carries main chain end-groups suitable for cross-linking was used or a pre-polysiloxane that carries reactive side groups which allows simultaneously dipole grafting and cross-linking in an insitu process. The first approach is time consuming, while the latter is attractively fast. On the other hand it results in less pure products as in the first approach. As discussed above a “compromise” between both approaches has been implemented. It consists in a partial dipole grafting to the pre-polymer leaving some functional groups unreacted. These groups are then subsequently used for cross-linking once the material has been processed into thin films. This approach was recently used by Sheima et al. ${ }^{[137]}$ They reacted a poly(methylvinylsiloxane) of a high molar mass with 3-mercaptopropionitrile 12 substoichiometrically and used the residual vinyl groups for thiol-ene-type cross-linking. This allowed preparing films with a 
thickness below $20 \mu \mathrm{m}$. Their properties were measured in devices and found to be favorable compared to the published DEAs. About 7\% lateral actuation strain was measured for a 35

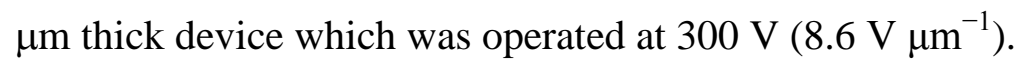

The examples presented in Subchapter 5.2 clearly show that the dielectric permittivity of polysiloxanes can be considerably increased by using polar groups. This is particularly so if the polar groups are attached in a dense sequence to the siloxane backbone. Because of the high flexibility of this backbone, typically, the functionalized polysiloxanes have a $T_{g}$ below room temperature. As pointed out in Chapter 3 this is an important characteristic whenever dielectric properties ought to be combined with elasticity. For the investigated materials a linear increase in permittivity with the content of polar groups is observed, with the stronger increase for those groups that have a stronger dipole moment. While, high permittivity values are attractive, it is equally important to keep an eye also on the conductivity, dielectric losses, relaxation times, and on how the presence of moisture may affect these properties.

\subsection{Other polar elastomers}

There are of course other low $\mathrm{T}_{\mathrm{g}}$ polymers but polysiloxanes. Also they should remain elastic when modified with polar groups. This subchapter gives an overview of those cases for which not only the chemical structures were reported but also the dielectric and electromechanical properties.

\subsubsection{Polyurethanes}

Polyurethanes were among the first polymeric materials evaluated for actuation. ${ }^{[138]}$ They are formed by reacting diisocyanates with hydroxyl end-functionalized polymers. A large variety of hydroxyl end-functionalized polymers such as polyesters, silicones, acrylics, 
poly(tetramethylene glycol), or polyethers have been used as soft segments. ${ }^{[138,139]}$ Because these end-functionalized polymers tend to have molar masses in the oligomeric regime they are often referred to as telechelics. There is a large number of publications on polyurethane elastomers used in DEA, ${ }^{[9]}$ however, their chemical composition is not always precisely known, due to insufficiently provided structural details. This unfortunately hampers establishing reliable structure/property correlations and renders it difficult to assess the potential of this class of materials for DEA applications. Furthermore, despite their good mechanical properties and increased dielectric permittivity, polyurethanes tend to be rather stiff, which is a consequence of the applied high cross-linking density. Additionally these materials have an increased sensitivity towards humidity compared to silicones. All these limitations make refrain from discussing polyurethanes further in this review. The interested reader is referred to literature. ${ }^{[9,28]}$

\subsubsection{Polyacrylates}

Polyacrylates have been extensively investigated as dielectric elastomers. The most famous example is the $\mathrm{VHB}^{\mathrm{TM}}$ film commercialized by the company 3M available in different thicknesses from $50 \mu \mathrm{m}$ to $1 \mathrm{~mm} .^{[140,141]}$

Most DEA devices reported have been constructed from these films and have a couple of rather attractive properties. ${ }^{[9]}$ For example, they exhibit exceptionally large actuation strain, high energy density, and high actuation pressure. There are however also downsides such as large viscoelastic losses which make the response time slow, modest dielectric permittivity of less than 5 , and rather high $T_{g}$. Because of the low permittivity, high driving voltages are required for bringing about actuation. The films are usually prestrained before incorporation into devices. This prestaining was found to be beneficial for achieving high actuation strains and high energy densities and stimulated considerable research that proved that electromechanical instability can be avoided in stretched films. However, in practical devices 
the use of prestrained membrane has significant drawbacks. Not only because this requires the use of frames (which increases the weight of the device), but also pre-strained films more easily suffer mechanical failure. To improve on this, interpenetrating networks were prepared. ${ }^{[142]}$ For example, acrylate monomers were embedded into highly prestrained acrylic films and reacted to form a second elastomeric network. The resulting material was allowed to relax. The formed films preserved some of the VHB prestain and were capable of actuation strains up to $300 \%$. To reduce the $T_{g}$ of the acrylate elastomers, plasticizers were used. The resulting materials actuated at temperatures as low as $-40{ }^{\circ} \mathrm{C}{ }^{[9]}$

However, up to now, only few attempts towards novel polyacrylates with defined chemical structures and for which the dielectric permittivity was given have been reported. For example, a series of polyacrylate elastomers that exhibit inter-switchable multiple states of modulus was synthesized by Pei et al. ${ }^{[143]}$ and used in capacitive sensors and actuators (Figure 7). A thermoreversible cross-linking reaction was used to switch between the different states. For this purpose the prepolymer $\mathbf{2 0}$ containing maleimine units and the multifunctional cross-linker 21 containing furan groups were used (Figure 7). Maleimine units and furan groups are known to reversibly undergo Diels-Alder cycloaddition reactions through which new cross-links can be formed and also existing cross-links can be cleaved (at higher temperature). Depending on cross-linking density the same material can either be hard (M9) or soft (M10). Also it is possible to switch back and forth between the two different states. Dielectric permittivity and elastic modulus of $\mathbf{M 9}$ and $\mathbf{M 1 0}$ were $\varepsilon^{\prime}=5.7$ and $Y^{\prime}=0.52 \mathrm{MPa}$ and $\varepsilon^{\prime}=6.3$ and $Y^{\prime}=0.26 \mathrm{MPa}$, respectively. The reason behind the observed increase in permittivity in M10 is likely related to its lower cross-link density which allows for a greater mobility of the dipoles. The somewhat higher permittivity of M9 and M10 as compared to $\mathrm{VHB}^{\mathrm{TM}}$ film is due to their polar side groups. ${ }^{[144,145]}$ Because of the decrease in elastic modulus and the slight increase in permittivity for M10, the electric field required to induce 35\% areal strain was $50 \mathrm{~V} \mu \mathrm{m}^{-1}$, while $\mathbf{M 9}$ gave the same actuation at $80 \mathrm{~V}^{-1}$ (Figure 7). 
Although, other attempts to synthesize acrylic elastomers were described in the literature, they will not be discussed here since their synthesis rests on commercial prepolymers for which the chemical composition is not precisely known. ${ }^{[146]}$ Composites of an acrylate copolymer with aluminum nanoparticles filler were also reported, however, such composites are not within the focus of this review and the reader is referred to literature. ${ }^{[97]}$

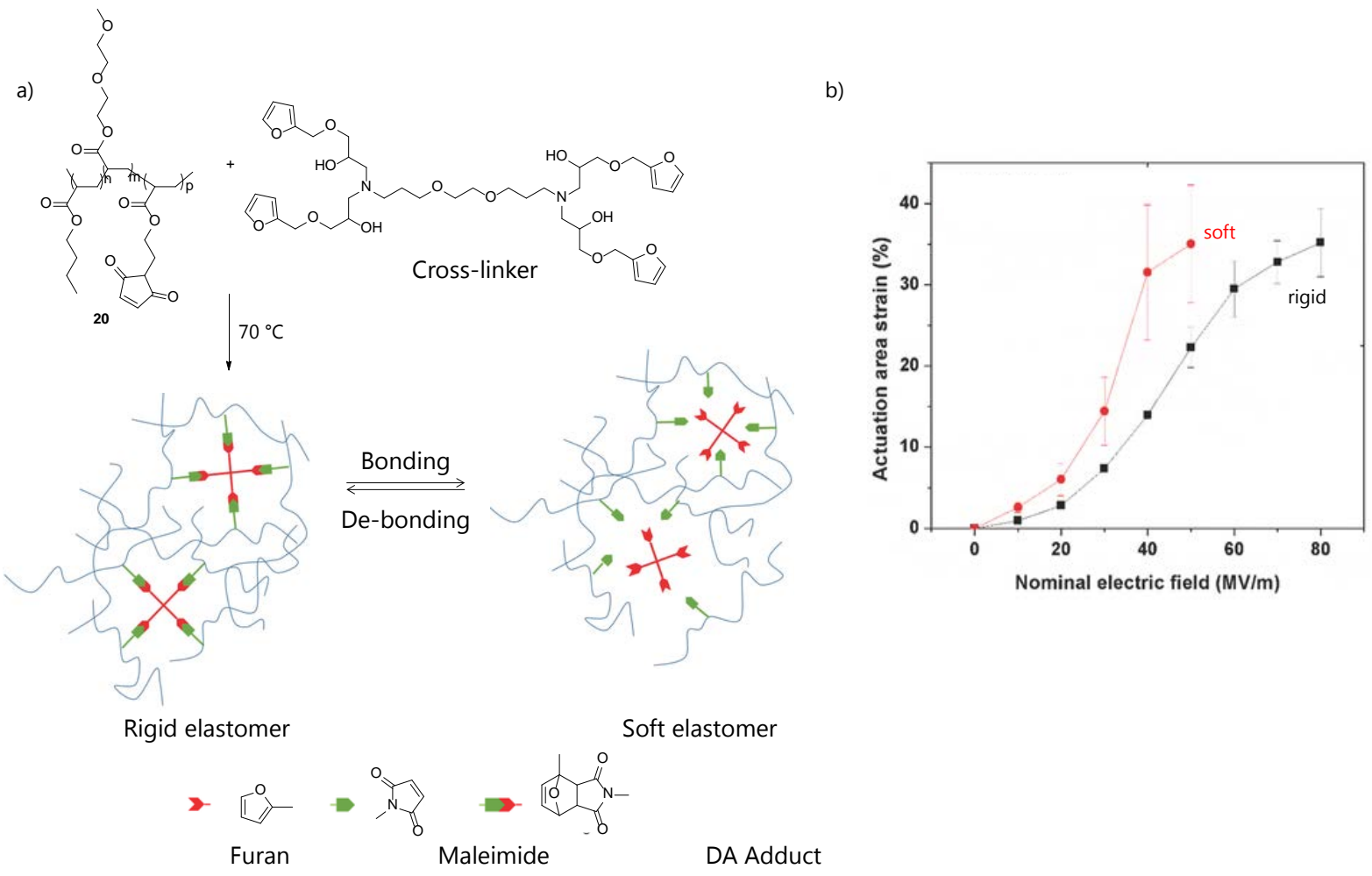

Figure 7. Synthesis of a polyacrylate cross-linked by a thermoreversible Diels-Alder reaction (a) and area actuation strain of a polyacrylate dielectric elastomer with variable moduli at different electric fields (M9 rigid and M10 soft). Both films were prestrained 5\% by 5\% (b). Adapted from Ref.143 with permission from Wiley.

\subsubsection{Polyesters}

A large variety of reagents are available to synthesize polyesters, but the most common reagents used are diols and diacids. To the best of the author's knowledge there is only one report dealing with polyester elastomers for DEA. Yang et al. applied a condensation reaction between a mixture of 1,3-propanediol and 1,4-butanediol with a mixture of sebacic acid, succinic acid, and itaconic acid (Figure 8). ${ }^{[147]}$ The formed polymers were processed into thin films using a hot press and cross-linked with dicumyl peroxide. The elastomers obtained had a 
$T_{g}$ of about $-57^{\circ} \mathrm{C}$ and a permittivity that ranged from about 5 to 8 depending on cross-linking density, whereby the stiffest material showed the highest value. These results are unexpected, as the mobility of the polymer chains decreases with cross-linking density which should also negatively affect polarizability. The strain at break of these elastomers was varied from $100 \%$ to $1100 \%$. One of the best materials, M11, has $\varepsilon=5$ and $Y=97 \mathrm{kPa}$ and an area actuation strain of $11.9 \%$ at $15.6 \mathrm{~V} \mu \mathrm{m}^{-1}$ (Figure 8).
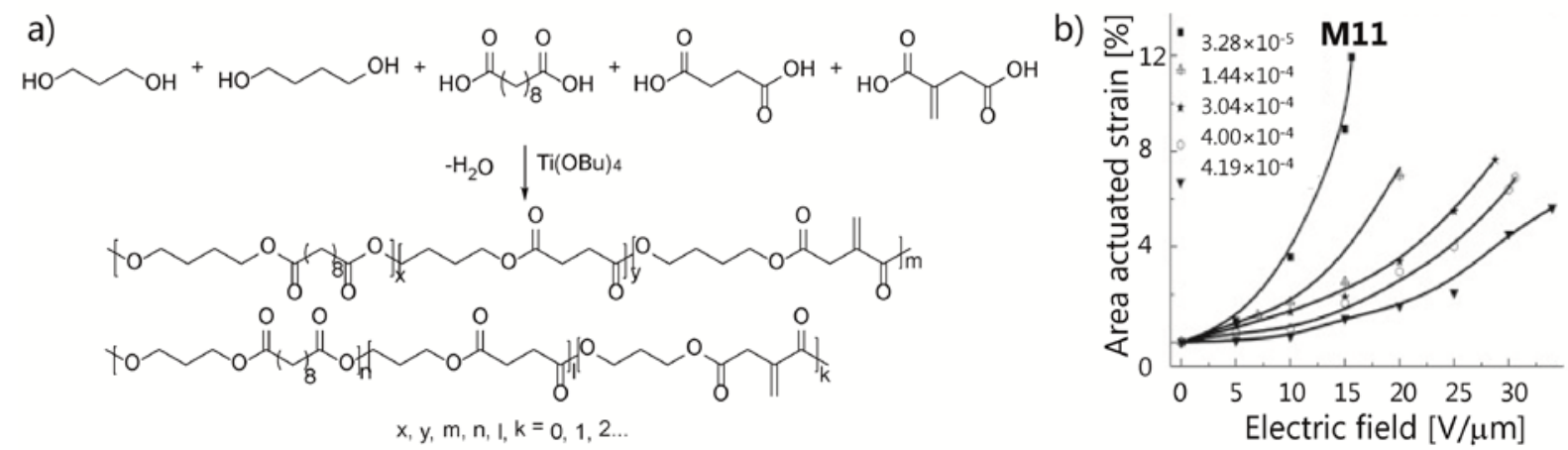

Figure 8. Large scale synthesis of polyesters starting from a mixture of diols and a mixture of dicarboxylic acids via a classical ester condensation reaction (a) and area actuated strain as function of electric field of the polyester elastomers with different cross-link densities. Adapted from Ref.147 with permission from with permission from Elsevier.

\subsubsection{Poly(di-n-butyl itaconate-co-isoprene)}

Poly(di-n-butyl itaconate-co-isoprene)s (P12) with different compositions were prepared by radical emulsion polymerization and cross-linked using dicumyl peroxide (DCP) at $165{ }^{\circ} \mathrm{C}$ after processing into films with thicknesses of about $0.4 \mathrm{~mm}$ (Figure 9). ${ }^{[148]}$ With increasing ester content (0-70\%) both the $T_{g}$ increased from -60 to $-38^{\circ} \mathrm{C}$ as well as the permittivity from 2 to 5.5. The highest actuation strain was measured for the highest ester content due to this composition's increased permittivity and lower cross-link density. This material shows a

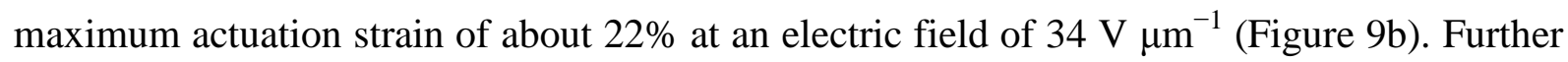
improvements by adjusting the cross-linking density using different amounts of DCP was possible (Figure 9c,d). As expected, the actuation strain at a certain electric field increased 
with decreasing DCP content. For an area actuation strain of $10 \%$, the driving voltage

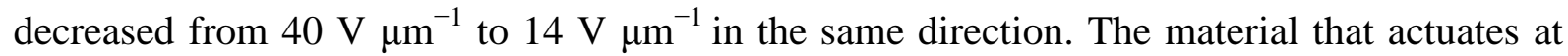
lowest electric field, M12, gave an area actuation of about $5 \%$ at $10 \mathrm{~V} \mathrm{\mu m}^{-1}$. While these properties may not be sufficient for a major breakthrough it is worth noting that because of the ample and cheap availability of the starting materials, large scale production should be possible.

a)

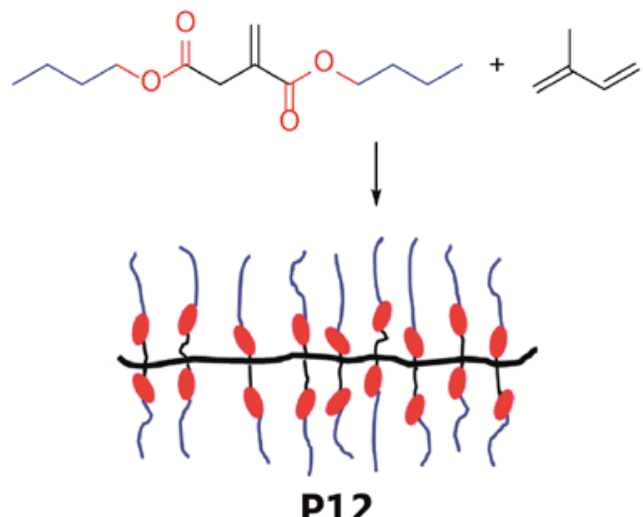

c)

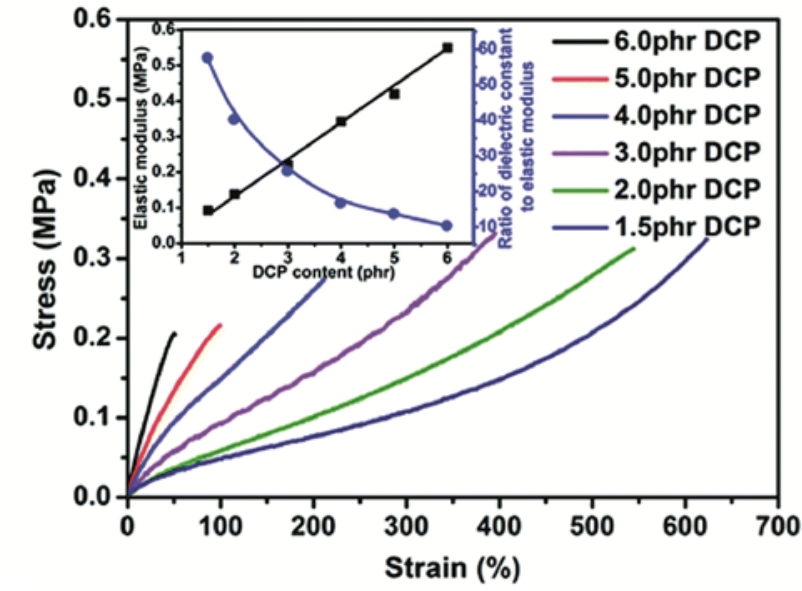

b)

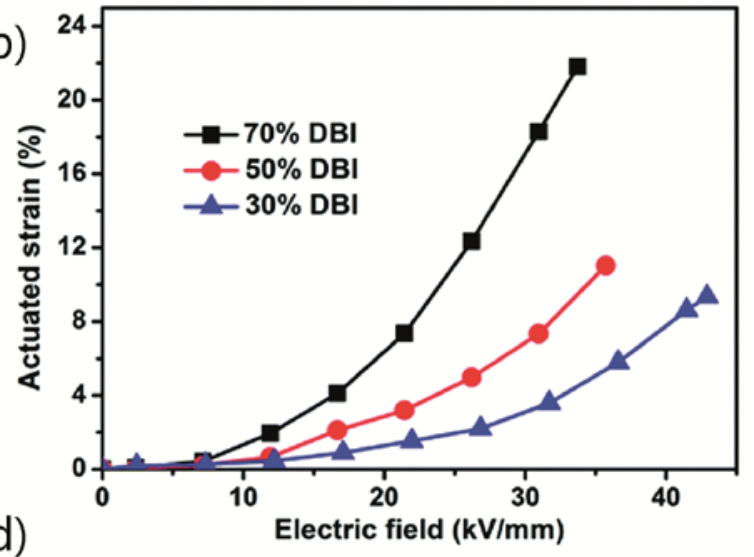

d)

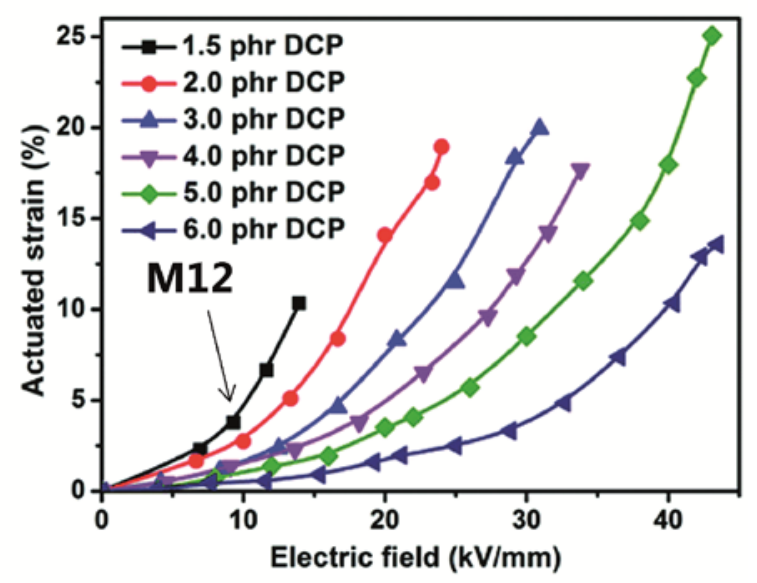

Figure 9. Poly(di-n-butyl itaconate-co-isoprene) P12 and its properties. (a) Synthesis starting from di-n-butyl itaconate (DBI) and isoprene (top left). (b) Actuation strain versus electric field of cross-linked P12 with different DBI contents. (c) Stress-strain curves of P12 (70\% DBI) cross-linked with different amounts of DCP. Insert: Plots of elastic modulus and ratio of permittivity to elastic modulus versus DCP. (d) Actuation strain of cross-linked P12 (70\% DBI) as function of applied electric field. Adapted from Ref.148 with permission from The Royal Society of Chemistry.

\subsubsection{Acrylonitrile rubbers}

Three hydrogenated acrylonitrile-butadiene rubbers with nitrile contents of $25 \%$, 36\%, and $44 \%$ were evaluated as dielectrics in DEA. ${ }^{[149]}$ Films with a thickness of $0.15 \mathrm{~mm}$ were 
processed by melt-pressing at $170{ }^{\circ} \mathrm{C}$ and then cross-linked by DCP. Their dielectric permittivity increased from 13.1 via 18.8 to 22.6, respectively, which was also associated with an increase in both dielectric loss and elastic modulus from 2.17 via 2.28 to $2.74 \mathrm{MPa}$. Despite the high elastic modulus of the material with the highest nitrile content, M13, it actuates at lower electric fields as compared to all others. For example, an area actuation strain of $12 \%$ was measured at $35 \mathrm{~V} \mathrm{\mu m}^{-1}$. This improved performance is due to the combination of high dielectric permittivity and high $\varepsilon^{\prime} / Y$ value. As in the case of polysiloxanes modified with nitrile groups (Subchapter 5.2), also here a decrease of the dielectric breakdown with increasing nitrile content is observed.

\subsubsection{Modified styrene-butadiene-styrene triblock copolymer}

A styrene-butadiene-styrene triblock copolymer (SBS) was modified with different amounts of methylthioglycolate (22) or thioglycolic acid (23) by using thiol-ene click chemistry (Figure 10). ${ }^{[150,151]}$ As expected the $T_{g}$ 's increased with the amount of incorporated polar groups. While the parent polymer SBS has $T_{g}=-89{ }^{\circ} \mathrm{C}$ the materials with $40 \%$ and $81 \%$ ester groups attached showed $T_{g}$ values of $-38{ }^{\circ} \mathrm{C}$ and $-36{ }^{\circ} \mathrm{C}$, respectively (Figure 10). The surprisingly small difference between the $T_{g}$ values of these last two samples has not yet been explained. Increasing ester content also increases permittivity. While the parent material has 3.9 the other two samples had 6.4 and 12.2, respectively. The best material in this series, M14,

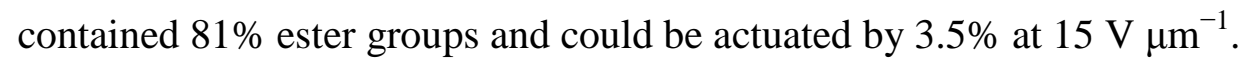

When the chemical modification of SBS was conducted with the acid 23, the $T_{\mathrm{g}}$ of the obtained polymers increased significantly and reached values near room temperature. Since these materials did not perform particularly well in actuators, they will not be further discussed here. 
a)

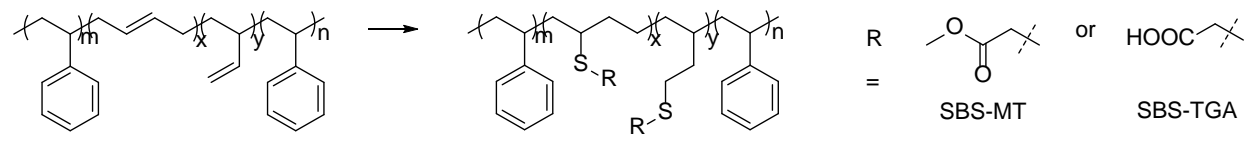

b)

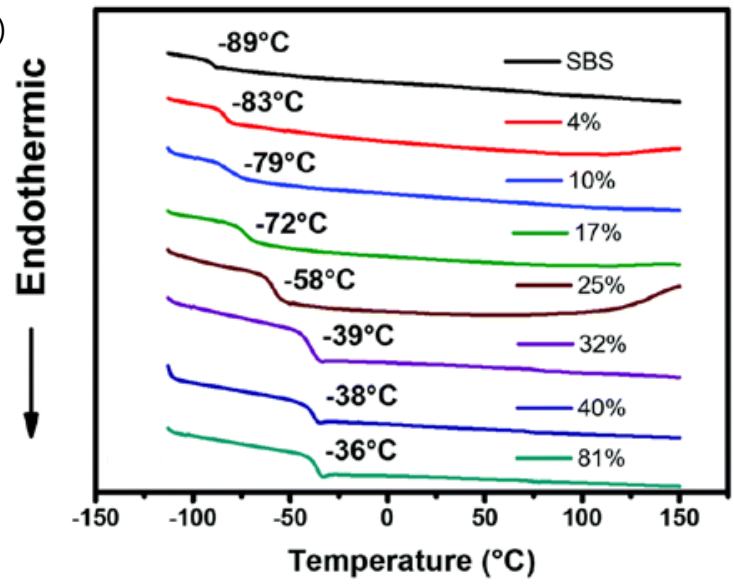

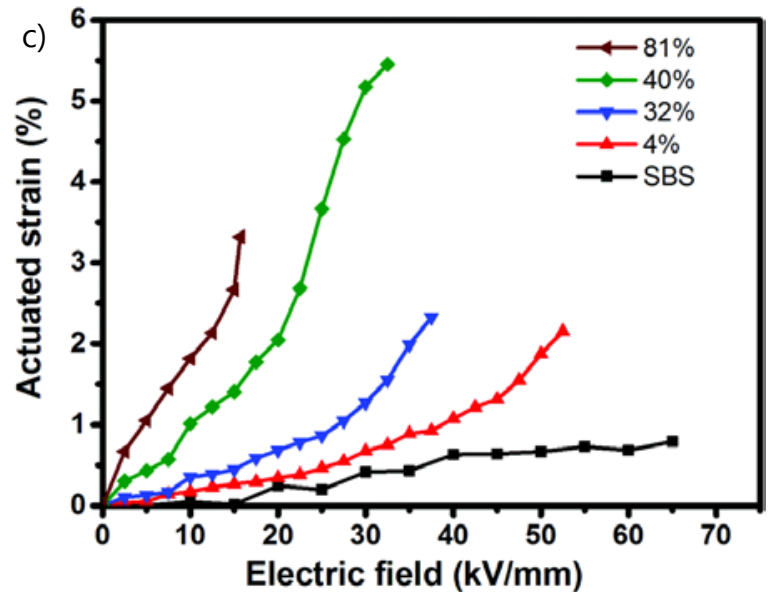

Figure 10. Thiol-ene addition of methylthioglycolate (22) and thioglycolic acid (23) to styrene-butadiene-styrene triblock copolymer following anti-Markovnicov regiochemistry. Markovnicov products are not shown for clarity (a). Properties of styrene-butadiene-styrene triblock copolymers modified with different amounts of methylthioglycolate: DSC curves (b) and actuation strain as function of electric field (c). Reproduced from Ref. 150 with permission from The Royal Society of Chemistry.

\subsubsection{Polychloroprene}

Polychloroprene is commonly synthesized by free-radical polymerization of chloroprene.

Despite of its good availability, only a single preliminary report was found concerning its behavior in DEAs. ${ }^{[152]}$ This polymer has a $\varepsilon^{\prime}=10$, a rather low conductivity of $10^{-11} \mathrm{~S} / \mathrm{cm}$, a $T_{g}$ below $-30{ }^{\circ} \mathrm{C}$, and a strain at break above $1000 \%$. Actuators gave $2 \%$ actuation at an

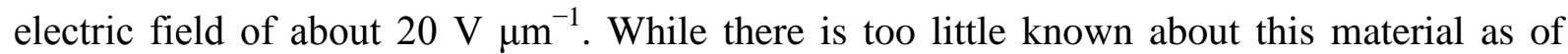
today it appears that further development could pay off in attractive properties.

\subsection{Actuation}

Now that several cases were identified where actuation is possible at low voltages, for those materials marked by the symbol $\mathbf{M}$, which concerns $\mathbf{M 1 - M 1 4}$, an attempt will be made to compare them and their performances with one another (Table 1). This is a challenging goal and a number of issues need to be considered. The first to mention is the selection criterion of 
an actuation voltage of $10 \mathrm{~V} \mathrm{\mu m}^{-1}$, as was mentioned in the Introduction. While this particular value is of course an arbitrary choice, given the fact that the ultimate goal of high permittivity DEA is low voltage actuation, it appears a reasonable threshold value. M1 will not be considered for the comparison because it suffers a dielectric breakdown already below the threshold electrical field of $10 \mathrm{~V} \mu \mathrm{m}^{-1}$. Further issues include the unfortunate fact that standardized procedures regarding how to perform electromechanical measurements were only recently introduced by Carpi et al. ${ }^{[29]}$ and thus each laboratory has its own set-up and uses different prestrains, voltage ramp rates, dead loads which is an obvious disadvantage when it comes to comparisons. Whether or not a particular sample is pre-strained before the actual measurement will influence the actuation strain and the dielectric breakdown. For

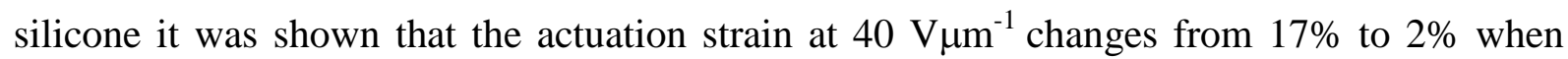
increasing the pre-strain from $40 \%$ to $82 \% .{ }^{[153]}$ A reduction of actuation strain at a certain electric field with increasing pre-strain was also reported by Pei et al. ${ }^{[154]}$ Additionally, as discussed in Chapter 4, the amount of pre-strain and the ratio between the passive area and electrode area of the tested device influence the dielectric breakdown and actuation. While these effects can be considerable, they were neglected here because the amount of pre-strain was kept low and the actuation of interest is obtained at electric fields below the threshold value. Furthermore, different laboratories report either the area $s_{a c t}$ or the lateral $s_{x y}\left(s_{x y}=s_{x}=s_{y}\right)$ actuation strain. To be able to compare different materials and their performance, the in thickness actuation strain $\left(s_{z}\right)$ will be calculated considering an isotropic in plane deformation: ${ }^{[155-157]}$

$S_{z}=\left(1+s_{x y}\right)^{-2}-1$

using the lateral actuation strain $s_{x y}$, or

$S_{z}=\left(1+s_{a c t}\right)^{-1}-1$

using the area actuation strain $s_{a c t}$. 
Table 1 compiles for M1-M14 the nature of the active group, film thickness, $T_{g}, \varepsilon^{\prime}, E_{\max }$, and other relevant properties. We will first enter into a discussion of the data in columns 2-5. The data in the remaining columns are the basis for the graphical representations in Figure 11 and will be discussed there.

The thickness data in column 3 range from 100-500 $\mu \mathrm{m}$, which independent of all other aspects, may it be molecular structure or the breakdown field, shows a general problem with these materials for DEA applications: the films are too thick! As the electric field required for actuation inversely relates with film thickness enormous positive effects are expected if film thickness can be reduced, say by a factor of 10 . Such endeavor is a real challenge but it appears worth going for it. Moving now to the $T_{g}$-values in column 4 , they all are in a more or less attractive range for room temperature applications, which means that they are well below $0{ }^{\circ} \mathrm{C}$. Unfortunately, not in all cases $T_{\mathrm{g}}$ values were reported. The permittivity values in column 5 , finally, look rather interesting. There are already 5 different cases with $\varepsilon^{\prime}$ values of approximately 10 and higher. Because four of them (M6-8, M13) carry nitrile groups it appears safe to conclude that this group is a good choice. This conclusion is not compromised by the fact that the material M5, which has much lower $\varepsilon$ ' values, also contain nitriles. In this case the concentration of the nitrile groups is so low that one cannot expect the permittivity to be high. As long as the aspect of how to achieve extremely thin films is out of consideration, the only important criterion appears to be to achieve an as high as possible concentration of polar groups contained in a matrix still providing sufficient elasticity. While the approaches that led to materials M6-M8 are not particularly elegant under synthetic considerations, they exactly serve this very purpose. We will have to come back to this issue, however, when discussing the challenge of creating ultrathin and nevertheless homogenous films (Chapter 6). 
Table 1 contains the actuators dielectric breakdown $E_{\max }$. The actuator measurements on Mx were conducted on films that were either not pre-strained or the amount of pre-strain was rather low. The area actuation strain of materials M5, M8, M9, and M10 approached the critical value of about $40 \%$ and therefore, it is likely that the actuators suffered EMI. The elastic energy density for $\mathbf{M x}$ was calculated at an electric field of $10 \mathrm{~V} / \mu \mathrm{m}$ and at $E_{\text {max }}{ }^{.158]}$

$$
e_{e}=1 / 2 Y s_{z}^{2}=1 / 2 p s_{z}
$$

The highest elastic energy density was found for materials M9 and M10 that have rather high dielectric breakdown, followed by $\mathbf{M 1 3}$ which has the highest dielectric permittivity and an acceptable dielectric breakdown. Material M8 shows the highest elastic energy density as well as the highest actuation strain at $10 \mathrm{~V} / \mu \mathrm{m}$.

Figure 11 plots $\varepsilon^{\prime}$ (red dots) and $\varepsilon^{\prime} / Y$ values (blue dots) as function of $s_{Z}$ at $10{\mathrm{~V} \mu \mathrm{m}^{-1}}^{-1}$ for different materials. While the first relation appears to be more or less linear, the second seems to level off for high $s_{z}$ values. Concerning the first relation it appears that at this low electric field the actuation is governed by the orientation polarization. This is in agreement with previous observations by Zhang et al., who suggested that the activation energy for the mechanical related segment motions is higher as compared to polarization related segment motion due to dipolar response. ${ }^{[66]}$ Unfortunately, up to date little is known regarding the electric field at which the saturation of polarization in polar elastomers occurs. Further work is required in this direction according to the lines already published for fluorinated polymers and ceramics. ${ }^{[55]}$ Material M14 is an exception in that it shows a rather low actuation given its high permittivity value. The reason for this is unclear. Concerning the second relation, while there is same scatter of data it seems that the influence of the elastic moduli on actuation is less important at low electric fields as compared to permittivity. If this data interpretation holds, increasing the permittivity and optimizing the mechanical properties of elastomers to 
overcome EMI will allow achieving reliable actuators with reasonable actuation at low electric fields. 
Table 1. Structure, film thickness $d, T_{g}$, dielectric permittivity, actuator breakdown field $E_{\max }$, actuation $s_{\max }$ at $E_{\max }$, elastic modulus at low strain, electromechanical sensitivity $\varepsilon^{\prime} / Y$, actuation $s$ from the measurement and the calculated $s_{z}$ at $10 \mathrm{~V} \mu \mathrm{m}^{-1}$, maximum actuation pressure $p_{\max }$, the maximum elastic energy density and elastic energy density at $10 \mathrm{~V} / \mu \mathrm{m}$ of materials M1-M14.

\begin{tabular}{|c|c|c|c|c|c|c|c|c|c|c|c|c|c|c|c|}
\hline Entry & Polar group & $\begin{array}{c}d \\
{[\mu \mathrm{m}]}\end{array}$ & $\begin{array}{c}T_{g} \\
{\left[{ }^{\circ} \mathrm{C}\right]}\end{array}$ & $\varepsilon^{t}$ & $\begin{array}{c}E_{\max } \\
{\left[\mathrm{V}^{-1} \mathrm{~m}^{-1}\right]}\end{array}$ & $\begin{array}{l}S_{\max } \\
{[\%]}\end{array}$ & $\begin{array}{c}s_{z, \max } \\
{[\%]}\end{array}$ & $\begin{array}{c}Y \\
{[\mathrm{MPa}]}\end{array}$ & $\begin{array}{c}\varepsilon / Y \\
{\left[\mathrm{MPa}^{-1}\right]}\end{array}$ & $\begin{array}{c}s @ 10 \\
\vee \mu m^{-1} \\
{[\%]}\end{array}$ & $\begin{array}{c}s_{z} @ 10 \\
V \mu m^{-1} \\
{[\%]}\end{array}$ & $\begin{array}{c}p_{\max } \\
{[\mathrm{kPa}]}\end{array}$ & $\begin{array}{c}p @ 10 V / \mu m \\
{[\mathrm{kPa}]}\end{array}$ & $\begin{array}{c}e_{e} @ E_{\max } \\
{\left[\mathrm{J} / \mathrm{cm}^{3}\right]}\end{array}$ & $\begin{array}{c}e_{e} @ 10 \mathrm{~V} / \mu \mathrm{m} \\
{\left[\mathrm{J} / \mathrm{cm}^{3}\right]}\end{array}$ \\
\hline $\mathbf{M 1}^{1099]}$ & $\mathrm{CF}_{3}$ & 320 & -92.2 & 6.2. & 7.8 & ${ }^{a} 5.4$ & 10 & 0.019 & 326 & - & - & 3.34 & - & $0.17 \times 10^{-3}$ & 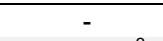 \\
\hline $\mathbf{M} 2^{[131]}$ & & 170 & - & 4.82 & 58 & ${ }^{b} 12$ & 10.7 & 0.368 & 13.1 & $<1.5$ & $<1.5$ & 143 & 4.27 & $7.68 \times 10^{-3}$ & $0.03 \times 10^{-3}$ \\
\hline $\mathbf{M} 3^{[135]}$ & & - & -71 & 5.56 & 10 & ${ }^{\mathrm{c}} 2$ & ${ }^{\mathrm{c}} 2$ & 0.142 & 39.2 & ${ }^{\mathrm{c}} 2$ & ${ }^{\mathrm{c}} 2$ & 4.92 & 4.92 & $0.05 \times 10^{-3}$ & $0.05 \times 10^{-3}$ \\
\hline $\mathbf{M} 4^{[122]}$ & & 150 & -92.6 & 4.3 & 23 & ${ }^{\mathrm{a}} 9.7$ & 16.9 & 0.089 & 48.3 & ${ }^{\mathrm{a}} 2.7$ & 5.2 & 20.14 & 3.81 & $1.70 \times 10^{-3}$ & $0.10 \times 10^{-3}$ \\
\hline $\mathbf{M}^{[122]}$ & & 150 & -78.3 & 6.8 & 18 & ${ }^{\mathrm{a}} 17.5$ & 27.6 & 0.096 & 70.8 & ${ }^{\mathrm{a}} 4.6$ & 8.6 & 19.51 & 6.02 & $2.69 \times 10^{-3}$ & $0.26 \times 10^{-3}$ \\
\hline$M 6^{[122]}$ & & 150 & -67.7 & 9.8 & 13 & ${ }^{\mathrm{a}} 13.5$ & 22.4 & 0.097 & 101 & ${ }^{\mathrm{a}} 6.4$ & 11.7 & 14.66 & 8.68 & $1.64 \times 10^{-3}$ & $0.51 \times 10^{-3}$ \\
\hline$M 7^{[122]}$ & & 150 & -58.2 & 12.9 & 11 & ${ }^{\mathrm{a}} 12.0$ & 20.3 & 0.128 & 100.8 & ${ }^{\mathrm{a}} 9.6$ & 16.8 & 13.82 & 11.42 & $1.40 \times 10^{-3}$ & $0.96 \times 10^{-3}$ \\
\hline $\mathbf{M 8}^{[122]}$ & & 150 & -49.2 & 17.4 & 12 & ${ }^{\mathrm{a}} 21.0$ & 31.7 & 0.155 & 112.3 & ${ }^{\mathrm{a}} 14.1$ & 23.2 & 22.18 & 15.41 & $3.52 \times 10^{-3}$ & $1.79 \times 10^{-3}$ \\
\hline $\mathbf{M} \mathbf{9}^{[143]}$ & & 100 & - & 5.7 & 80 & ${ }^{b} 35$ & 25.9 & 0.52 & 11.0 & ${ }^{b} 1$ & 1 & 323.00 & 5.05 & $41.83 \times 10^{-3}$ & $0.03 \times 10^{-3}$ \\
\hline $\mathrm{M} 10^{[143]}$ & & 100 & - & 6.3 & 50 & ${ }^{b} 35$ & 25.9 & 0.26 & 24.2 & ${ }^{b} 2.5$ & 2.4 & 139.45 & 5.58 & $20.22 \times 10^{-3}$ & $0.07 \times 10^{-3}$ \\
\hline $\operatorname{M11}^{[147]}$ & & - & -57 & 5.6 & 15.6 & ${ }^{b} 11.9$ & 10.6 & 0.097 & 57.7 & ${ }^{\mathrm{b}} 4$ & 3.8 & 12.06 & 4.96 & $0.64 \times 10^{-3}$ & $0.09 \times 10^{-3}$ \\
\hline $\mathrm{M} 12^{[148]}$ & & 400 & -38 & 5.6 & 14 & ${ }^{b} 11$ & 9.9 & 0.092 & 60.9 & $b_{5}$ & 4.8 & 9.72 & 4.96 & $0.48 \times 10^{-3}$ & $0.12 \times 10^{-3}$ \\
\hline $\mathrm{M} \mathbf{3}^{[149]}$ & & 150 & - & 22.6 & 34 & ${ }^{b} 12$ & 10.7 & 2.74 & 8.2 & - & - & 231.32 & 20.01 & $12.38 \times 10^{-3}$ & - \\
\hline M14 ${ }^{[150]}$ & & 500 & -36 & 12.2 & 15 & ${ }^{\mathrm{b}} 2.7$ & 2.6 & 0.34 & 35.9 & ${ }^{\mathrm{b}} 2$ & 2 & 24.39 & 10.8 & $0.32 \times 10^{-3}$ & $0.11 \times 10^{-3}$ \\
\hline
\end{tabular}

${ }^{\mathrm{a}} \boldsymbol{S}_{x y}$ or ${ }^{\mathrm{b}} \boldsymbol{S}_{\text {act }}$ as reported; ${ }^{\mathrm{c}}$ actuators measured in pure shear configuration. Where M1-M8 have a polysiloxan backbone; M9, M10, M12-M14 have a C-C backbone, and M11 has a polyester backbone. 


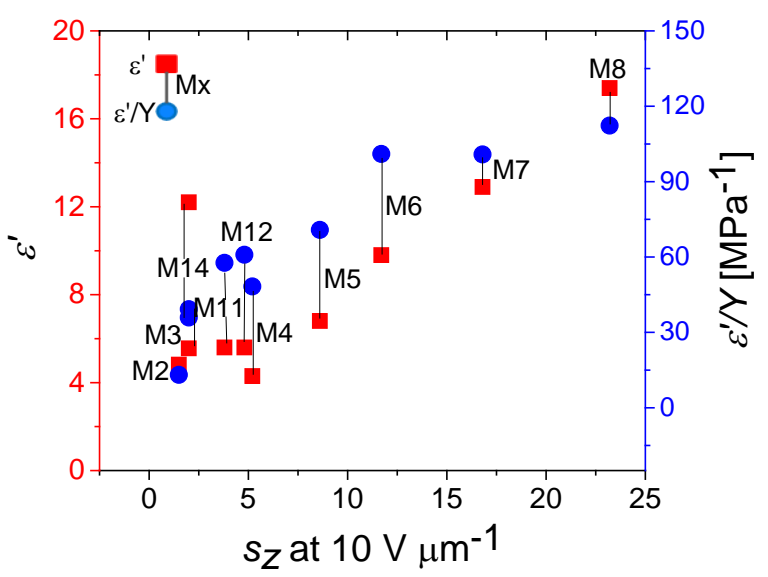

Figure 11. Dielectric permittivity $\varepsilon^{\prime}$ and $\varepsilon^{\prime} / Y$ as function of thickness actuation strain $s_{Z}$ for

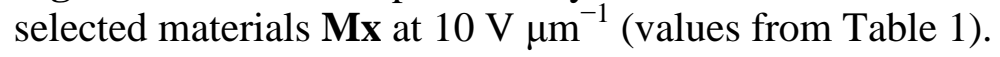

\section{Thin film formation}

Reducing thickness of a dielectric film is highly attractive as the actuation strain increases with the square of the thickness. ${ }^{[14]}$ Thin films can be prepared by spin coating, doctor blading, sputtering, melt pressing, printing or electro-spraying. ${ }^{[160-162]}$ However, for large scale production, reducing the thickness of films below $10 \mu \mathrm{m}$ turned out to be rather challenging. ${ }^{[36,161]}$ The thinnest free-standing dielectric actuator with a silicone dielectric, 3 $\mu \mathrm{m}$ thick film was recently reported by Shea et. al. ${ }^{[22,163]}$ Such device gave a lateral actuation strain of $7.5 \%$ at only $245 \mathrm{~V}$. Using a polar silicone, about the same actuation was measured at $300 \mathrm{~V}$, but the thickness of the dielectric layer was $35 \mu \mathrm{m} .{ }^{[137]}$ Comparing these two outcomes it appears that the latter material has a greater chance to eventually be successful because it has a similar actuation at a similar voltage, yet it is thicker and therefore opens the potential opportunity to reduce the voltage by making the films thinner. Future will show whether this expectation is realistic. Most recently, actuators with silicone dielectric layers of about $200 \mathrm{~nm}$ thickness were prepared by molecular beam deposition (MBD). Despite of the very low driving voltage of $12 \mathrm{~V}$ with actuation strains of $10 \%,{ }^{[164]}$ the rather complex set-up 
and the required ultra-high vacuum $\left(10^{-8} \mathrm{mbar}\right)$ conditions needed for film formation make this process less attractive for large scale production, but may be attractive for high endapplications. ${ }^{[164]}$ Contrary to MBD, thin film formation by electro-spraying is rather fast, cheap, and has a high potential for industrial implementation. ${ }^{[165,166]}$

Such single-membrane devices do not have the required force needed in many applications. To prepare powerful DEAs, the single-membrane is either rolled up to form a linear roll actuator ${ }^{[155]}$ or piled up to form a stack actuator. ${ }^{[167,168]}$ Upon application of a voltage, the roll actuator elongates, while the stack actuator contracts. When the voltage is removed, the actuators recover their original shape. While single membrane can be easily prepared from practically any thermoplastic and thermoset elastomers, for the construction of stack actuators, the processability of the dielectric layers is crucial. For this, a low viscosity formulation that can be cross-linked on demand in normal atmosphere should be used. It is also considered important that the formulation is solvent free, elsewise the layers may swell and delaminate.

Several groups reported on different processing technologies to stack actuators such as spin-coating, spray-coating, molecular beam deposition, and electro-spray deposition. ${ }^{[169-171]}$ From a practical point of view, the most attractive way to produce stack actuators is by blade coating/printing. This allows high speed production (up to $500 \mathrm{~mm} / \mathrm{s}$ ) of actuators of different sizes and shapes as well as stacking of actuators in a continuous process. ${ }^{[172]}$ Such a process was recently co-developed by Kovacs et al. at Empa and CT Systems, a start-up Swiss company and Empa spin-off. ${ }^{[168]}$ Using a fully automated process, they produce stack actuators $(15 \mathrm{~mm} \times 15 \mathrm{~mm} \times 30 \mathrm{~mm})$ with regular silicone consisting of over 1500 dielectric layers of $20 \mu \mathrm{m}$ that operate at about $1000 \mathrm{~V}$ which contract by $5 \%$, and have a cyclic life of more than 50 million cycles at $2.5 \mathrm{~Hz}$ (Figure 12). Reducing the driving voltage of such devices to $600 \mathrm{~V}$ would significantly lower the costs and also increase the application potential of these devices. This is however challenging since reducing the dielectric film 
thickness below 5-10 $\mu \mathrm{m}$ is difficult. Up to date, most of the stack actuators are constructed from regular silicone elastomers. Recently, a stack actuator consisting of a polyacrylate as dielectric with a thickness of $37.7 \mu \mathrm{m}$ was achieved, yet its driving voltage was still in the $\mathrm{kV}$ range since the permittivity of the dielectric was likely below $5 .^{[146]}$ By using a high permittivity dielectric material processable in films the thickness of which is below $10 \mu \mathrm{m}$, low voltage stack actuators should be accessible.

a)

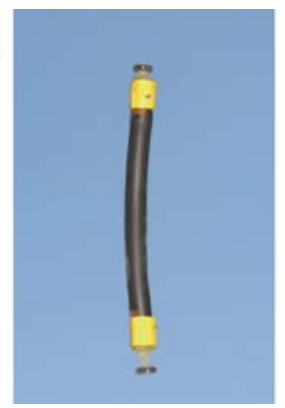

b)

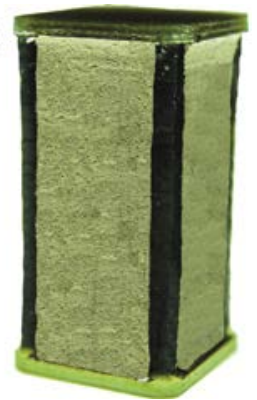

Figure 12. Photographs of a roll actuator (a) and of a stack actuator manufactured by CT Systems (b). The stack actuator contracts by $5 \%$ at $1000 \mathrm{~V}$. Reproduced with permission from G. Kovacs, CT-Systems.

\section{Summary and Outlook}

Research on DEA has started more than 15 years ago stimulated by the impressive actuation of $\mathrm{VHB}^{\mathrm{TM}}$ films commercialized by $3 \mathrm{M}^{\mathrm{TM}}$. Since then, many innovative applications and actuator designs were proposed and the first products are presently entering the market. Interestingly, all commercial products use PDMS elastomers as dielectric. A reason for this selection is the low $T_{g}$ which allows its use in different environmental conditions without compromising key mechanical properties too much. Additionally, PDMS is inert to chemical oxidation and is hydrophobic. Furthermore, it can be easily processed into thin films by conventional techniques with subsequent cross-linking. This cross-linking step in certain cases proceeds fast enough to be attractive for a technological process. Therefore, PDMSbased materials found their way into both single membrane actuators as well as stack actuators. Because PDMS has excellent gas permeability, changes in the humidity may affect 
actuators lifetime and therefore they have to be encapsulated. For example, CT Systems, a Swiss start-up company and Empa spin-off, produces such actuators which operate at about $1000 \mathrm{~V}$. They deform to about 5\% and have a cycle life of more than 50 million cycles at 2.5 Hz. While all these features are highly attractive for DEA technology, there is a major deficiency with the currently available materials which hinders the use of DEAs for high-end applications in particular in the field of medical implants. For those, the driving voltage still required today is far too high. It needs to be lowered to at least $24 \mathrm{~V}$. This quest for low driving voltages has initiated an entire research field, the current article tried to cover.

From the aspects discussed in particular in Chapters 4-6 a few guidelines can be extracted which those researchers interested in joining the field may consider. They include:

(a) The backbone of the base polymer should be as flexible as possible.

(b) The backbone should carry side groups that allow incorporating polar substituents by post-polymerization modifications. These reactions need to proceed with as high as possible conversion.

(c) The polymer backbones should be narrowly distributed in order to be able to correlate properties with molecular structure.

(d) The base polymers should carry defined end groups so as to allow for an optimum cross-linking reaction once the material has been processed into thin films.

(e) The cross-linking reaction required to transform the polar polymer into the final active material ideally should be performed under solvent-free conditions. This ensures that there are no large-scale defects caused e.g. by bubbles that would deteriorate the electromechanical properties. As is explained above, this is easiest achieved by using cross-linkers that are soluble in the base polymer which obsoletes the use of solvents.

(f) The chemical design of both polar polymer and cross-linker should not only allow for efficient cross-linking in general but also for cross-linking on demand. While 
there are several external stimuli that could in principle be used to trigger the coupling, it appears that for simplicity and practicability reasons photochemical triggers are the preferred ones.

The article will be wrapped up by two more general recommendations:

Firstly, the above small 'wish list' should not only be understood as guidelines for materials development but can also be considered a pleading for what will increasingly be needed in the field. In the author's opinion an in-depth understanding of chemical structure and its precise control is the key to creating novel functional materials.

Secondly, most novel materials developed up to date for DEA applications are evaluated in single membrane devices. While this characterization is crucial to prove potential functionality, many applications require using the dielectric material in stack or roll actuators. Because it is practically impossible to predict the behavior of a material in a real device just from knowing its properties in a single membrane, it should increasingly be turned into a routine procedure to perform tests of new materials under conditions as close as possible to reality. Additionally, the characterization of the novel materials should be done following the standards recently introduced by the European Scientific Network for Artificial Muscles. ${ }^{[29]}$ Only then the findings of different laboratories can be directly compared with one another, which the author considers an essential prerequisite for a rapid and finally successful development of the field. The author is convinced that the ultimate goal of low voltage actuators will be achieved only with a material of carefully designed molecular structure for which all the other parameters that influence the actuation are properly optimized.

\section{Acknowledgements}

The author wishes to cordially thank Prof. F. Nüesch, Empa, Dübendorf, for the freedom to perform research in the DEA field, generous support and helpful advice. The author also gratefully acknowledges A. D. Schlüter for valuable discussions and M. Alexandru, P. Caspari, E. Cuervo-Reyes, S. J. Dünki, L. Düring, Y. S. Ko, G. Kovacs, E. Perju, J. E. Quinsaat, and Y. Sheima for the various creative inputs. Financial support by the Swiss 
National Science Foundation (IZER0_142215 and 200020_172693) and the Swiss Federal Laboratories for Materials Science and Technology Empa is gratefully acknowledged.

Received: ((will be filled in by the editorial staff))

Revised: ((will be filled in by the editorial staff))

Published online: ((will be filled in by the editorial staff))

\section{References}

[1] http://bennetdictionary.com/galvanism/

[2] W. C. Röntgen, Ann. Phys. 1880, 247, 771.

[3] Y. Bar-Cohen, Electroactive Polymers (EAP) Actuators as Artificial Muscles, SPIE Press, 2001.

[4] M. C. Schaub, Swiss Med. Wkly, 2011, 141, w13319.

[5] G. Kovacs, P. Lochmatter, M. Wissler, Smart Mater. Struct. 2007, 16, S306.

[6] H. Staudinger, Ber. Dtsch. Chem. Ges. 1920, 53, 1073.

[7] M. Wei, Y. Gao, X. Li, M. J. Serpe, Polym. Chem. 2017, 8, 127.

[8] Q. M. Zhang, M. J. Serpe, ChemPhysChem, 2017, 18, 1451.

[9] F. Carpi, Electromechanically active polymers, Springer, 2016.

[10] T. Wang, M. Farajollahi, Y. S. Choi, I.-T. Lin, J. E. Marshall, N. M.

Thompson, S. Kar-Narayan, J. D. W. Madden, S. K. Smoukov, Interface Focus, 2016, 6, 20160026.

[11] T. F. Otero, J. Mater. Chem. 2009, 19, 681.

[12] P. Brochu, Q. Pei, Macromol. Rapid Commun. 2010, 31, 10.

[13] R. H. Baughman, Synth. Metals, 1996, 78, 339.

[14] R. Pelrine, R. Kornbluh, Q. Pei, J. Joseph, Science, 2000, 287, 836.

[15] A. O’Halloran, F. O’Malley, P. McHugh, J. Appl. Phys. 2008, 104, 071101.

[16] R. E. Perline, R. D. Kornbluh, J. P. Joseph, Sens. Actuat. A, 1998, 64, 77.

[17] F. Carpi, G. Frediani, S. Turco, D. De Rossi, Adv. Funct. Mater. 2011, 21, 4152. 
[18] A. Anderson, E. P. Calius, T. Gisby, T. Hale, T. McKay, B. O'Brien, S.

Walbran, Proc. SPIE, 2009, 7287, 72871H/1.

[19] S. Shian, J. Huang, S. Zhu, D. R. Clarke, Adv. Mater. 2014, 26, 6617.

[20] F. Carpi, S. Bauer, D. De Rossi, Science, 2010, 330, 1759.

[21] D. M. Opris, M. Molberg, C. Walder, Y. S. Ko, B. Fischer, F. A. Nüesch, Adv.

Funct. Mater. 2011, 21, 3531.

[22] A. Poulin, S. Rosset, H. R. Shea, Appl. Phys. Lett. 2015, 107, 244104.

[23] R. Shankar, T. K. Ghosh, R. J. Spontak, Soft Matter, 2007, 3, 1116.

[24] L.J. Romasanta, M.A. Lopez-Manchado, R. Verdejo, Prog. Polym. Sci. 2015, $51,188$.

[25] I. A. Anderson, T. A. Gisby, T. G. McKay, B. M. O’Brien, E. P. Calius, J. Appl. Phys. 2012, 112, 041101.

[26] S. Rosset, H. R. Shea, Appl. Phys. Rev. 2016, 3, 031105.

[27] F. B. Madsen, A. E. Daugaard, S. Hvilsted, A. L. Skov, Macromol. Rapid Commun. 2016, 37, 378.

[28] J. Biggs, K. Danielmeier, J. Hitzbleck, J. Krause, T. Kridl, S. Nowak, E. Orselli, X. Quan, D. Schapeler,W. Sutherland, J. Wagner, Angew. Chem. Int. Ed. 2013, 52, 9409.

[29] F. Carpi, I. Anderson, S. Bauer, G. Frediani, G. Gallone, M. Gei, C. Graaf, C. Jean-Mistral, W. Kaa, G. Kofod, M. Kollosche, R. Kornbluh, B. Lassen, M. Matysek, S. Michel, S. Nowak, B. O’Brien, Q. Pei, R. Pelrine, B. Rechenbach, S. Rosset, H. Shea, Smart Mater. Struct. 2015, 24, 105025.

[30] R. D. Kornbluh, R. Pelrine, Q. Pei, R. Heydt, S. Stanford, S. Oh, J. Eckerle, Proc. SPIE, 2002, 4698, 254.

[31] F. Carpi, G. Frediani, D. De Rossi, Proc. SPIE, 2007, 6524, 65240D/1.

[32] R. Shankar, T. K. Ghosh, R. J. Spontak, Adv. Mater. 2007, 19, 2218. 
[33] P. H. Vargantwar, A. E. Özçam, T. K. Ghosh, R. J. Spontak, Adv. Funct. Mater. 2012, 22, 2100.

[34] T. Hirai, H. Sadatoh, T. Ueda, T. Kasazaki, Y. Kurita, M. Hirai, S. Hayashi, Angew. Makromolek. Chemie, 1996, 240, 221.

[35] B. Kim, Y. D. Park, Y. Min, J. H. Lee, S. S. Hwang, S. M. Hong, B. H. Lim, S. O. Kim, C. M. Koo, Adv. Funct. Mater. 2011, 21, 3242.

[36] S. Rosset, H. R. Shea, Appl. Phys. A, 2013, 110, 281.

[37] M. G. Urdaneta, R. Delille, E. Smela, Adv. Mater. 2007, 19, 2629.

[38] S. Michel, B. T. T. Chu, S. Grimm, F. A. Nüesch, A. Borgschulte, D. M.

Opris, J. Mater. Chem. 2012, 22, 20736.

[39] M. I. Aranguren, Polymer, 1998, 39, 4897.

[40] F. Kremer, A. Schönhals, Broadband Dielectric Spectroscopy, Springer, 2003.

[41] A. G. Webb, Concepts Magn. Reson. A, 2011, 38A, 148.

[42] R. von Hippel, Dielectrics and Waves, John Wiley \& Sons, 1956.

[43] P. Hedvig, Dielectric spectroscopy of Polymers, Hilger, 1977.

[44] P. B. Ishai, M. S. Talary, A. Caduff, E. Levy, Y. Feldman, Meas. Sci. Technol. 2013, 24, 102001.

[45] S. Bauer, R. Gerhard-Multhaupt, G. M. Sessler, Physics Today, 2004, 57, 37.

[46] L. Zhu, Q. Wang, Macromolecules, 2012, 45, 2937;

[47] Q. Chen, K. Ren, B. Chu, Y. Liu, Q. M. Zhang, V. Bobnar, A. Levstik, Ferroelectrics, 2007, 354, 178.

[48] S. L. Wu, J. I. Scheinbeim, B. A. Newman, J. Polym. Sci., Part B: Polym. Phys. 1999, 37, 2737.

[49] H. Hirschmann, W. Meier, H. Finkelmann, SPIE, 1991, 1559, 27.

[50] M. Mauzac, H. T. Nguyen, F. -G. Tournilhac, S. -V. Yablonsky, Chem. Phys. Lett. 1995, 240, 461. 
[51] A. Schönfeld, F. Kremer, S. U. Vallerien, H. Poths, R. Zentel, Ferroelectrics, 1991, 121, 69.

[52] R. Zentel, M. Brehmer, Adv. Mater. 1994, 6, 598.

[53] X. Zhao, Q. Wang, Appl. Phys. Rev. 2014, 1, 021304.

[54] A. Tröls, A. Kogler, R. Baumgartner, R. Kaltseis, C. Keplinger, R.

Schwödiauer, I. Graz, S. Bauer, Smart. Mater. Struct. 2013, 22, 104012.

[55] A. J. Lovinger, Science, 1983, 220, 1115.

[56] R. Gerhard, Proc. SPIE, 2016, 9798, 97980T.

[57] Y. S. Ko, F. A. Nüesch, D. M. Opris, J. Mater. Chem. C, 2017, 5, 1826.

[58] Y. S. Ko, F. A. Nüesch, D. Damjanovic, D. M. Opris, Adv. Mater. 2017, 29, 1603813.

[59] C. Ohm, M. Brehmer, R. Zentel, Adv. Polym. Sci. 2012, 250, 49.

[60] K. S. Ramadan, D. Sameoto, S. Evoy, Smart Mater. Struct. 2014, 23, 033001.

[61] I. Krakovsky, T. Romijn, A. Posthuma de Boer, J. Appl. Phys. 1999, 85, 628.

[62] R. Yimnirum, S. M.-L. Eury, V. Sundar, P. J. Moses, S.-J. Jang, R. E.

Newnham, J. Europ. Ceram. Soc. 1999, 19, 1269.

[63] R. E. Newnham, V. Sundar, R. Yimnirun, J. Su, Q. M. Zhang, J. Phys. Chem. B, 1997, 101, 10141.

[64] Y. M. Shkel, D. J. Klingenberg, J. Appl. Phys. 1996, 80, 4566.

[65] X. Zhao, Z. Suo, J. Appl. Phys. 2008, 104, 123530

[66] Q. M. Zhang, J. Su, C. H. Kim, R. Capps, J. Appl. Phys. 1997, 81, 2770.

[67] T. Yamwong, A. M. Voice, G. R. Davies, J. Appl. Phys. 2002, 91, 1472. ,

[68] D. A. Porter, T. V. T. Hoang, T. A. Berfield, Addit. Manuf., 2017, 13, 81.

[69] A. G. Bejenariu, L. Yu, A. L. Skov, Soft Matter, 2012, 8, 3917.

[70] P. Mazurek, L. Yu, R. Gerhard, W. Wirges, A. L. Skov, J. Appl. Polym. Sci. 2016, 133, 44153. 
[71] Y. Jang, T. Hirai, T. Uekia, T. Kato, Polym. Int. 2012, 61, 228.

[72] X. Zhao, Z. Suo, Appl. Phys. Lett. 2007, 91, 061921.

[73] S. J. A. Koh, T. Li, J. Zhou, X. Zhao, W. Hong, J. Zhu, Z. Suo, J. Polym. Sci., Part B: Polym. Phys. 2011, 49, 504.

[74] S. M. Ha, W. Yuan, Q. Pei, R. Pelrine, S. Stanford, Adv. Mater. 2006, 18, 887.

[75] G. Kofod, P. Sommer-Larsen, R. Kronbluh, R. Pelrine, J. Intell. Mater. Syst. Struct. 2003, 14, 787.

[76] J.-S. Plante, S. Dubowsky, Int. J. Solids Struct. 2006, 43, 7727.

[77] X. Zhao, Z. Suo, Phys. Rev. Lett. 2010, 104, 178302.

[78] J. Huang, T. Li, C. C. Foo, J. Zhu, D. R. Clarke, Z. Suo, Appl. Phys. Lett. 2012, 100, 041911.

[79] C. Keplinger, T. Li, R. Baumgartner, Z. Suo, S. Bauer, Soft Matter, 2012, 8, 285.

[80] T. Li, C. Keplinger, R. Baumgartner, S. Bauer, W. Yang, Z. Suo, J. Mech. Phys. Solids, 2013, 61, 611.

[81] X. Niu, H. Stoyanov, W. Hu, R. Leo, P. Brochu, Q. Pei, J. Polym. Sci., Part B: Polym. Phys. 2013, 51, 197.

[82] P. Brochu, H. Stoyanov, X. Niu, Q. Pei, Smart Mater. Struct. 2013, 22, 055022.

[83] R. Shankar, T. K. Ghosh, R. J. Spontak, Macromol. Rapid Commun. 2007, 28, 1142.

[84] M. Vatankhah-Varnoosfaderani, W. F. M. Daniel, A. P. Zhushma, Q. Li, B. J. Morgan, K. Matyjaszewski, D. P. Armstrong, R. J. Spontak, A. V. Dobrynin, S. S. Sheiko, Adv. Mater. 2017, 29, 1604209.

[85] A. H. A. Razak, A. L. Skov, RSC Adv. 2017, 7, 467. 
[86] G. Gallone, F. Carpi, D. De Rossi, G. Levita, A. Marchetti, Mater. Sci. Eng. A, 2007, 27, 110.

[87] H. Stoyanov, M. Kollosche, S. Risse, D. N. McCarthy, G. Kofod, Soft Matter. 2011, 7, 194.

[88] L. J. Romasanta, P. Leret, L. Casaban, M. Hernandez, M. A. de la Rubia, J. F. Fernandez, J. M. Kenny, M. A. Lopez-Manchado, R. Verdejo, J. Mater. Chem. 2012, 22, 24705.

[89] F. Carpi, D. De Rossi, IEEE, 2005, 12, 835.

[90] Q. M. Zhang, H. Li, M. Poh, F. Xia, Z. -Y. Cheng, H. Xu, C. Huang, Nature, 2002, 419, 284.

[91] D. M. Opris, F. Nüesch, C. Löwe, M. Molberg, M. Nagel, Chem. Mater. 2008, 20, 6889.

[92] P. Mazurek, L. Yu, R. Gerhard, W. Wirges, A. L. Skov, J. Appl. Polym. Sci. 2016, 133, 44153.

[93] Y. Jang, T. Hirai, T. Uekia, T. Kato, Polym. Int. 2012, 61, 228.

[94] Stoyanov, M. Kollosche, D. N. McCarthy, G. Kofod, J. Mater. Chem. 2010, 20, 7558.

[95] F. Carpi, G. Gallone, F. Galantini, D. De Rossi, Adv. Funct. Mater. 2008, 18, 235.

[96] C. Huang, Q. Zhang, Adv. Mater. 2005, 17, 1153.

[97] W. Hu, S. N. Zhang, X. Niu, C. Liu, Q. Pei, J. Mater. Chem. C, 2014, 2, 1658.

[98] W. J. Feast, M. Gimeno, E. Khosravi, Polymer, 2003, 44, 6111.

[99] J.-W. Wang, Q. -D. Shen, H. -M. Bao, C. -Z. Yang, Q. M. Zhang, Macromolecules, 2005, 38, 2247.

[100] M.F. Bukhina, S.K. Kurlyand, Low-Temperature Behaviour of Elasomers, Taylor \& Francis Group, 2007. 
[101] G. R. Davies, H. V. St A. Hubbard, I. M. Ward, W. J. Feast, V. C. Gibson, E. Khosravi, E. L. Marshall, Polymer, 1995, 36, 235.

[102] S. J. Clarson, J. J. Fitzgerald, M. J. Owen, S. D. Smith, Silicones and SiliconeModified Materials, American Chemical Society, 2000.

[103] M. Stepp, F. Achenbach, A. Koellnberger, Wacker Chemie AG, WO 2015/121261 Al.

[104] A. P. Purdy, A. Hwang, Polym. Mater. Sci. Eng. 2001, 84, 641.

[105] F. B. Madsen, I. Javakhishvili, R. E. Jensen, A. E. Daugaard, S. Hvilsted, A. L. Skov, Polym. Chem. 2014, 5, 7054.

[106] F. B. Madsen, L. Yu, A. E. Daugaard, S. Hvilsted, A. L. Skov, RSC Adv. 2015, $5,10254$.

[107] F. B. Madsen, L. Yu, A. E. Daugaard, S. Hvilsted, A. L. Skov, Polymer, 2014, 55, 6212.

[108] S. J. Dünki, M. Dascalu, F. A. Nüesch, D. M. Opris, Proc. SPIE. 2016, 9798, 97982K.

[109] M. Dascalu, S. J. Dünki, J.-E. Q. Quinsaat, Y. S. Ko, F. A. Nüesch, D. M. Opris, RSC Adv. 2015, 5, 104516.

[110] P. Theato, H.-A. Klok, Functional Polymers by Post-Polymerization Modification: Concepts, Guidelines, and Applications, Wiley-VCH, 2013.

[111] H. C. Kolb, M. G. Finn, K. B. Sharpless, Angew. Chem. Int. Ed. 2001, 40, 2004

[112] S. Putzien, O. Nuyken, F. E. Kühn, Prog. Polym. Sci. 2010, 35, 687.

[113] A. B. Lowe, Polymer Chem. 2014, 5, 4820.

[114] C.-Y. Yang, G. E. Wnek, Polym. Mater. Sci. Eng. 1990, 62, 601.

[115] C. Y. Yang, G. E. Wnek, Polymer, 1992, 33, 4191. 
[116] Z. Zhu, A. G. Einset, C.-Y. Yang, W.-X. Chen, G. E. Wnek, Macromolecules, 1994, 27, 4076.

[117] C. Racles, M. Alexandru, A. Bele, V. E. Musteata, M. Cazacu, D. M. Opris, RSC Adv. 2014, 4, 37620.

[118] C. Racles, V. Cozan, A. Bele, M. Dascalu, Designed Monomers Polym. 2016, 19, 496.

[119] M. Le Neindre, R. Nicolay, Polym. Chem. 2014, 5, 4601.

[120] S. J. Dünki, Y. S. Ko, F. A. Nüesch, D. M. Opris, Adv. Funct. Mater. 2015, 25, 2467.

[121] S. J. Dünki, M. Tress, F. Kremer, S. Y. Ko, F. A. Nüesch, C.-D. Varganici, C. Racles, D. M. Opris, RSC Adv. 2015, 5, 50054.

[122] S. J. Dünki, F. A. Nüesch, D. M. Opris, J. Mater. Chem. C, 2016, 4, 10545.

[123] S. J. Dünki, E. Cuervo-Reyes, D. M. Opris, Polym. Chem. 2017, 8, 715.

[124] D. M. Opris, S. Dünki, C Racles, A. Bele, M. Cazacu, PCT Int. Appl. 2015, WO 2015135086 A1 20150917.

[125] C. Racles, V. Cozan, A. Bele, M. Dascalu, Designed Monomers Polym. 2016, 19, 496.

[126] S. Risse, B. Kussmaul, H. Krüger, G. Kofod, Adv. Funct. Mater. 2012, 22, 3958

[127] C. Tugui, M. Cazacu, L. Sacarescu, A. Bele, G. Stiubianu, C. Ursu, C. Racles, Polymer, 2015, 77, 312.

[128] C. Racles, A. Bele, M. Dascalu, V. E. Musteata, C. D. Varganici, D. Ionita, S. Vlad, M. Cazacu, S. J. Dünki, D. M. Opris, RSC Adv. 2015, 5, 58428.

[129] C. Racles, M. Cazacu, B. Fischer, D. M. Opris, Smart Mater. Struct. 2013, 22, 104004.

[130] H. Böse, D. Uhl, R. Rabindranath, Proc. of SPIE, 2012, 8340, 83402E-1. 
[131] L. Zhang, D. Wang, P. Hu, J.-W. Zha, F. You, S.-T. Lib, Z.-M. Dang, J. Mater. Chem. C, 2015, 3, 4883.

[132] F. B. Madsen, I. Dimitrov, A. E. Daugaard, S. Hvilsted, A. L. Skov, Polym. Chem. 2013, 4, 1700.

[133] A. Bele, M. Cazacu, C. Racles, G. Stiubianu, D. Ovezea, M. Ignat, Adv. Eng. Mater. 2015, 17, 1302.

[134] A. Kussmaul, S. Risse, G. Kofod, R. Wache, M. Wegener, D. N. McCarthy, H. Krüger, R. Gergard, Adv. Funct. Mater. 2011, 21, 4589.

[135] S. Risse, B. Kussmaul, H. Krüger, G. Kofod, RSC Adv. 2012, 2, 9029.

[136] B. Kussmaul, S. Risse, M. Wegener, G. Kofod, H. Krüger, Smart Mater. Struct. 2012, 21, 064005.

[137] Y. Sheima, High permittivity thin elastomer films for artificial muscles, Master thesis, 2017.

[138] M. Zhenyi, J. I. Scheinbeim, J. W. Lee, B. A. Newman, J. Polym. Sci., Part B: Polym. Phys. 1994, 32, 2721.

[139] M. Watanabe, N. Wakimoto, T. Hirai, M. Yokoyama, J. Appl. Polym. Sci. 2005, 95, 1566.

[140] F. Carpi, P. Chiarelli, A. Mazzoldi, D. De Rossi, Sens. Actuators A, 2003, 107, 85.

[141] S. Shian, K. Bertoldi , D. R. Clarke, Adv. Mater. 2015, 27, 6814.

[142] S. M. Ha, M. Wissler, R. Pelrine, S. Stanford, G. Kovacs, Q. Pei, Proc. SPIE 2007, 6524, 652408.

[143] W. Hu, Z. Ren, J. Li, E. Askounis, Z. Xie, Q. Pei, Adv. Funct. Mater. 2015, 25, 4827.

[144] M. Molberg, Y. Leterrier, C. J. G. Plummer, C. Walder. C. Löwe, D. M. Opris, F. A. Nüesch, J.-A. E. Manson, J. Appl. Phys. 2009, 106, 054112. 
[145] L. Di Lillo, A. Schmidt, D. A. Carnelli, P. Ermanni, G. Kovacs, E. Mazza, A. Bergamin, J. Appl. Phys. 2012, 111, 024904.

[146] M. Duduta, R. J. Wood, D. R. Clarke, Adv. Mater. 2016, 28, 8058.

[147] D. Yang, M. Tian, H. Kang, Y. Dong, H. Liu, Y. Yu, L. Zhang, Mater. Lett. 2012, 76, 229.

[148] W. Lei, R. Wang, D. Yang, G. Hou, X. Zhou, H. Qiao, W. Wang, M. Tian, L. Zhang, RSC Adv. 2015, 5, 47429.

[149] D. Yang, M. Tian, Y. Dong, H. Liu, Y. Yu, L. Zhang, Smart Mater. Struct. 2012, 21, 035017.

[150] H. Sun, C. Jian, N. Ning, L. Zhang, M. Tian, S. Yuan, Polym. Chem. 2016, 7, 4072.

[151] M. Tian, H. Yan, H. Sun, L. Zhang, N. Ning, RSC Adv. 2016, 6, 96190.

[152] R. Waché, S. Risse, M. Schulze, G. Kofod, Mater. Res. Soc. Symp. Proc. 2011, 1325, 123.

[153] X. Q. Zhang, M. Wissler, B. Jaehne, R. Brönnimann, G. Kovacs, SPIE, 2004, 5385, 78.

[154] W. Hu, X. Niu, X. Yang, N. Zhang, Q. Pei, SPIE, 2013, 8687, 86872U-1.

[155] R. Kornbluh, R. Pelrine, J. Joseph, R. Heydt, Q. Pei, S. Chiba, SPIE, 1999, 3669, 149.

[156] R. Shankar, A. K. Krishnan, T. K. Ghosh, R. J. Spontak, Macromolecules, 2008, 41, 6100.

[157] R. Pelrine, R. Kornbluh, G. Kofod, Adv. Mater. 2000, 12, 1223.

[158] R. Pelrine, R. Kornbluh, J. Joseph, R. Heydt, Q. Pei, S. Chiba, Mater. Sci. Eng. C, 2000, 11, 89.

[159] Q. M. Zhang, J. Su, C. H. Kim, R. Capps, J. Appl. Phys. 1997, 81, 2770.

[160] R. Vendamme, S. Y. Onoue, A. Nakao, T. Kunitake, Nat. Mater. 2006, 5, 494. 
[161] E. Kang, J. Ryoo, G. S. Jeong, Y. Y. Choi, S. M. Jeong, J. Ju, S. Chung, S.

Takayama, S. H. Lee, Adv. Mater. 2013, 25, 2167.

[162] M. Matysek, P. Lotz, K. Flittner, H. F. Schlaak, Proc. SPIE, 2008, 6927, 692722.

[163] S. Akbari, S. Rosset, H. R. Shea, Appl. Phys. Lett. 2013, 102, 071906.

[164] T. Töpper, F. Weiss, B. Osmani, C. Bippes, Sens. Actuators A, 2015, 233, 32.

[165] F. M. Weiss, F. B. Madsen, T. Töpper, B. Osmani, V. Leung, B. Müller, Mater. Des. 2016, 105, 106.

[166] F. Weiss, T. Töpper, B. Osmani, H. Deyhle, G. Kovacs, B. Müller, Langmuir, 2016, 32, 3276.

[167] F. Carpi, A. Migliore, G. Serra, D. De Ross, Smart Mater. Struct. 2005, 14, 1210

[168] G. Kovacs, L. Düring, S. Michel, G. Terrasi, Sens. Actuators A, 2009, 155, 299.

[169] F. Klug, S. Solano-Arana, H. Mößinger, F. Förster-Zügel, H. F. Schlaak, Proc. SPIE, 2017, 10163, 101632Q.

[170] A. Araromi, A. T. Conn, C. S. Ling, J. M. Rossiter, R. Vaidyanathan, S. C. Burgess, Sens. Actuators, A: Phys. 2011, 167, 459.

[171] D. Tepel, T. Hoffstadt, J. Maas, Proc. SPIE, 2014, 9056, 905627.

[172] G. Kovacs, 2014, CH 706837 A1 20140228.

[173] G. Kovacs, L. Düring, S. Michel, G. Terrasi, Sens. Actuators A, 2009, 155, 299. 
a)

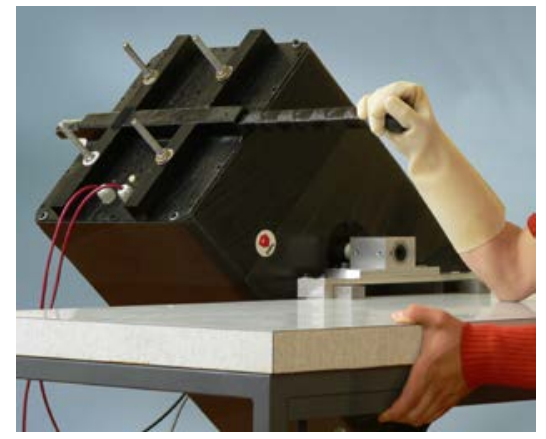

b)

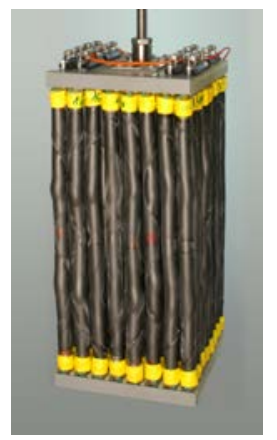

Figure 1. An arm robot based on less than $1 \mathrm{~kg}$ of DEAs (electroactive material), constructed at Empa, effectively competing with a human demonstrated at the 2005 SPIE conference in San Diego (a) and one of the four devices device, consisting of 64 roll actuators, used in the arm robot (b). The robot returns to its starting position after wrestling. Reproduced with permission from G. Kovacs, Empa.
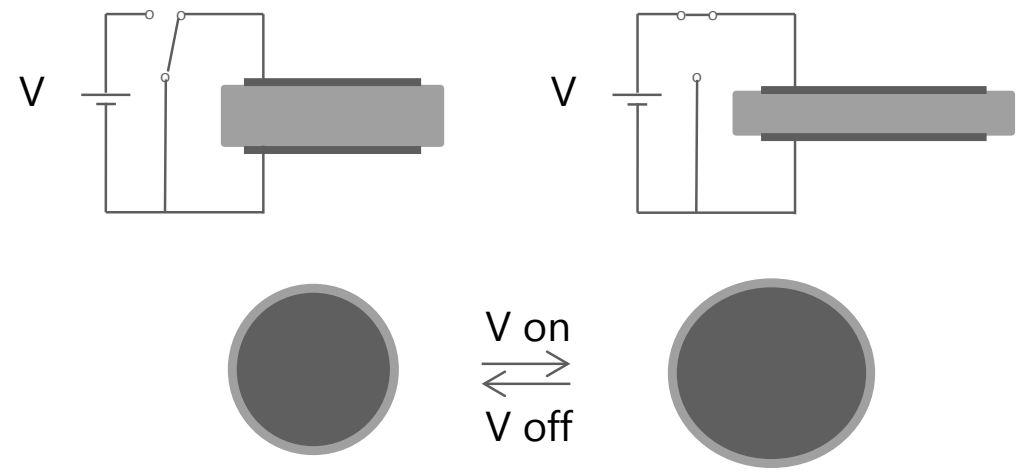

Figure 2. Cross-sectional (top) and top view (bottom) of the non-activated and the activated states of a circular membrane actuator left and right, respectively. Upon application of a voltage on the compliant electrodes the dielectric film is compressed in thickness and elongated in plane due to electrostatic forces. 
Zero

Electric field

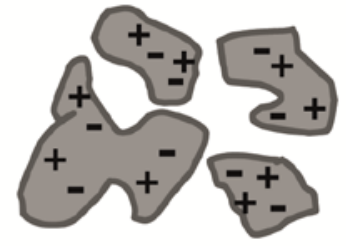

$\mathrm{E}$

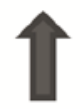

Polarization:

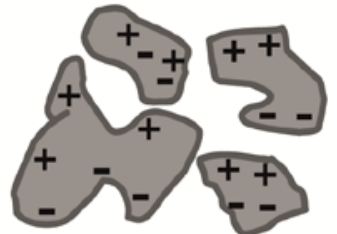

Interfacial
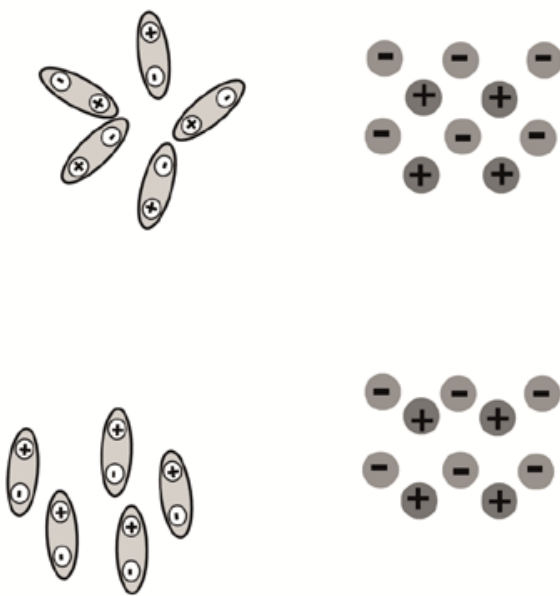

Ionic
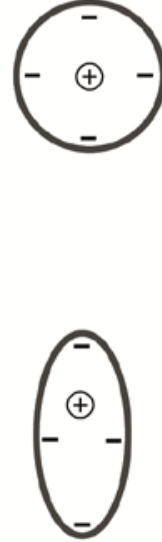

Electronic

\section{Increasing frequency}

Figure 3. Important polarization mechanisms in materials illustrated for four different starting situations which are not (yet) exposed to an electrical field and how they change upon exposure to an electrical field. For further explanations, see text.

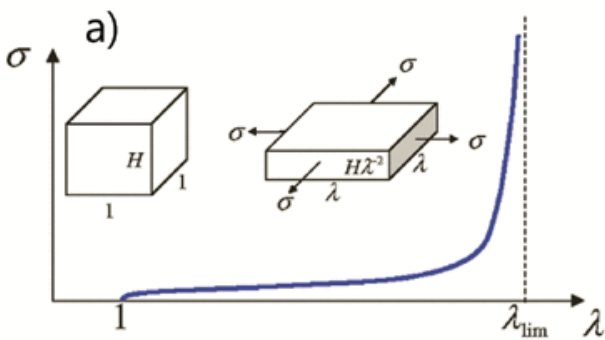

b)

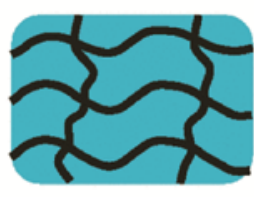

c)

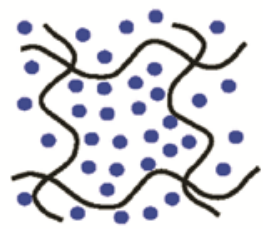

d)

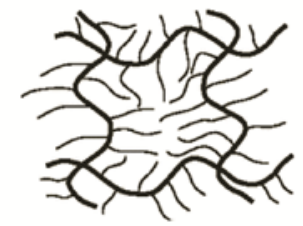

Figure 4. Stress-strain curve of an ideal elastomer for which the electromechanical instability is avoided (a). This can be achieved by using interpenetrating polymer networks (b), by swelling the network (c), and by cross-linking bottle-brush polymers (d). Adapted from Ref. 77 with permission from The American Physical Society. ${ }^{77}$
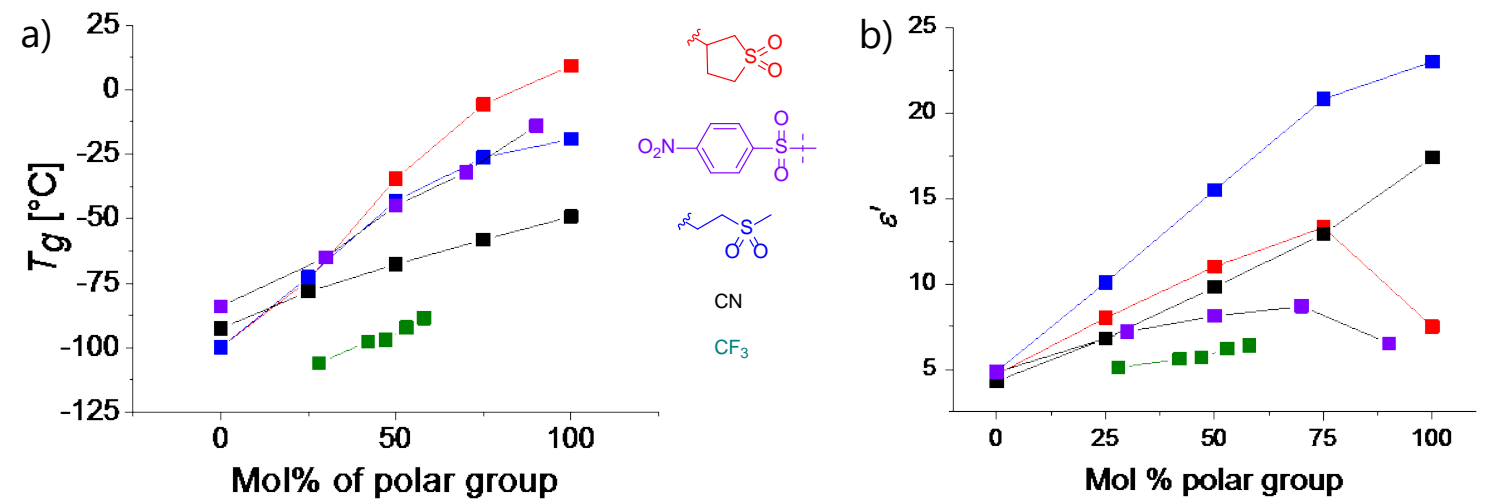

Figure 5. The glass transition temperature (left) and the dielectric permittivity of the polysiloxanes P5 and P8-P11 in dependence of amount and type of polar groups. All polymers were prepared via the thiol-ene post-polymerization modification except those that carry $\mathrm{CF}_{3}$ groups which were prepared starting from monomers. 
a)

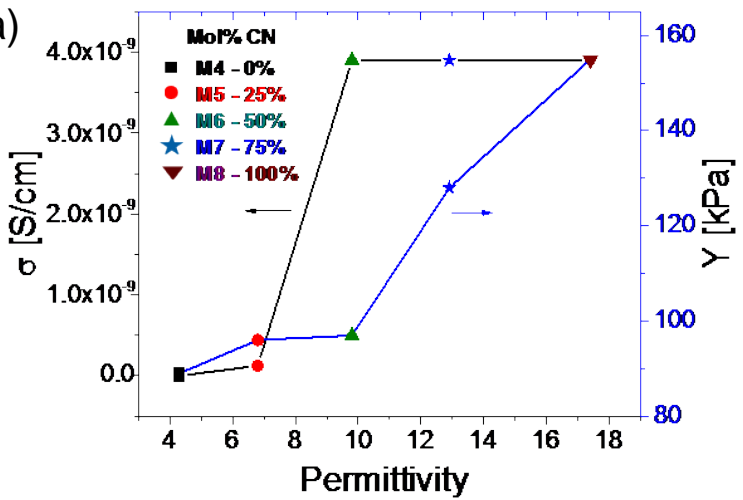

b)

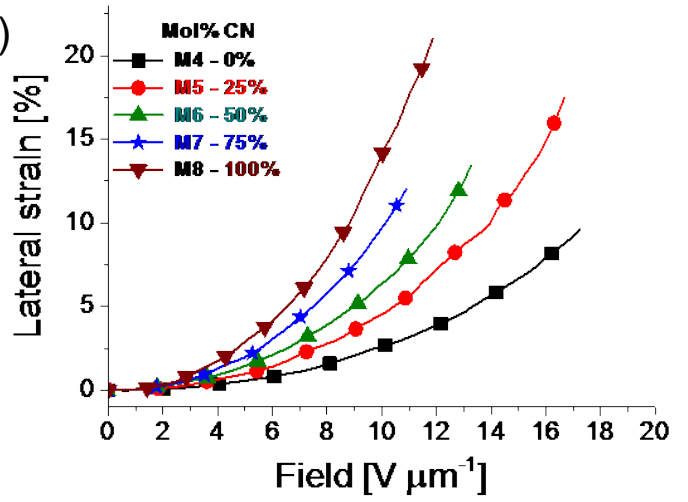

Figure 6. Conductivity and elastic modulus as function of dielectric permittivity (a) and the lateral actuation strain as function of applied electric field (b) for elastomers with different content of polar nitrile groups. Reproduced from Ref.122 with permission from The Royal Society of Chemistry.

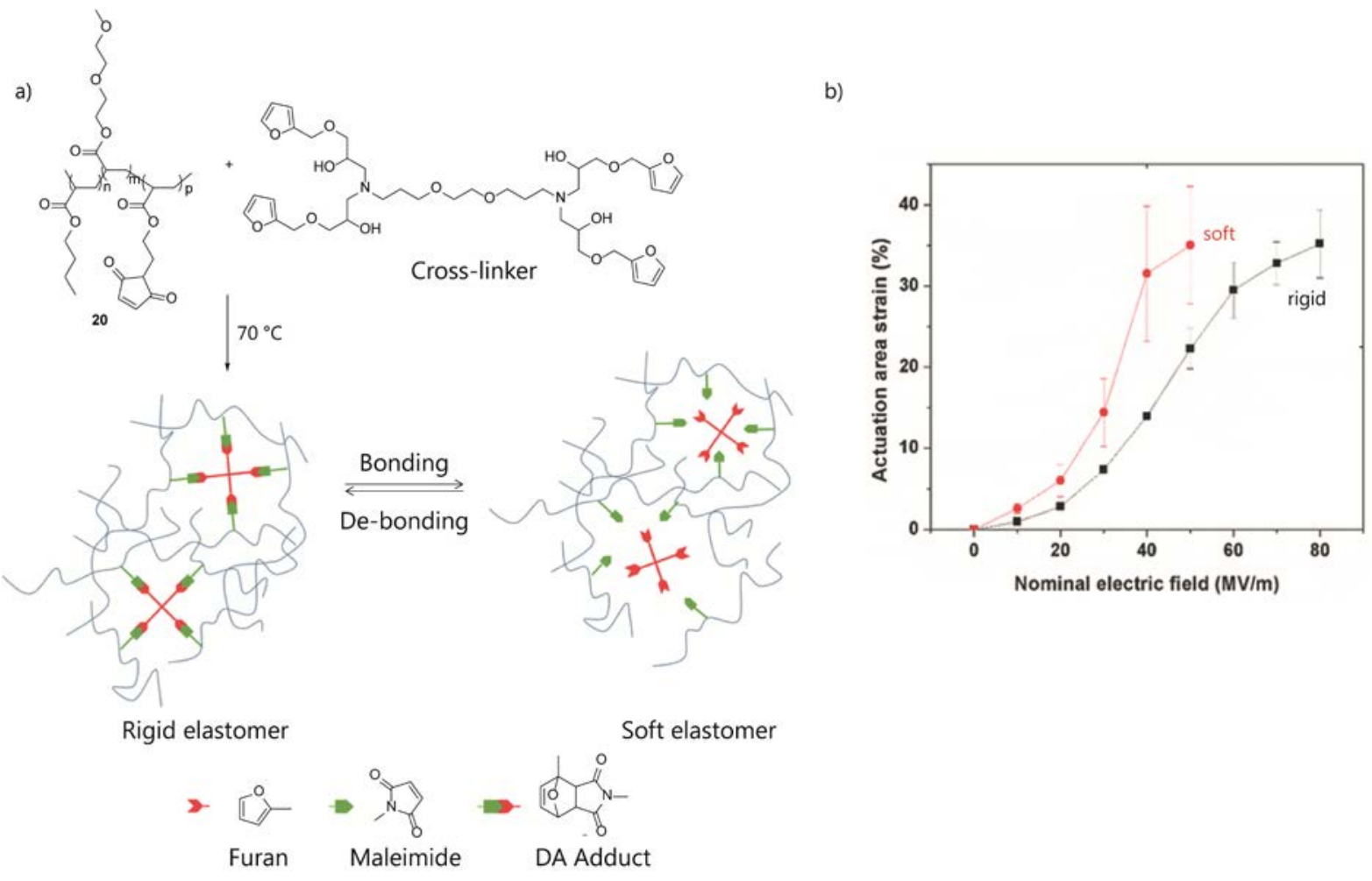

Figure 7. Synthesis of a polyacrylate cross-linked by a thermoreversible Diels-Alder reaction (a) and area actuation strain of a polyacrylate dielectric elastomer with variable moduli at different electric fields (M9 rigid and M10 soft). Both films were prestrained 5\% by 5\% (b). Adapted from Ref.143 with permission from Wiley. 

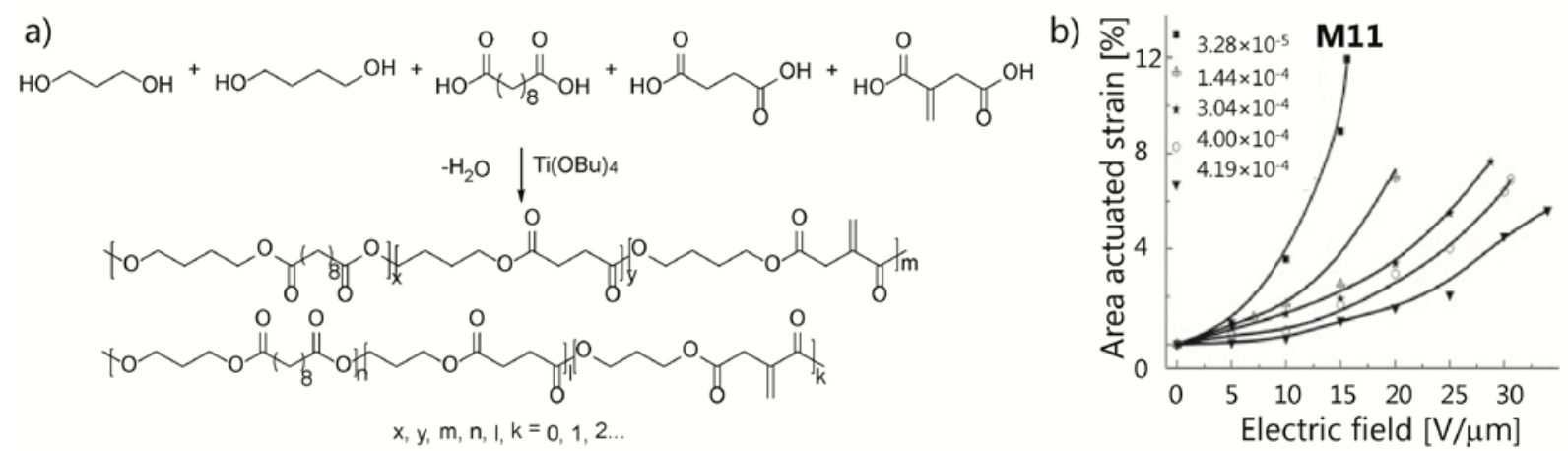

Figure 8. Large scale synthesis of polyesters starting from a mixture of diols and a mixture of dicarboxylic acids via a classical ester condensation reaction (a) and area actuated strain as function of electric field of the polyester elastomers with different cross-link densities. Adapted from Ref.147 with permission from with permission from Elsevier.

a)

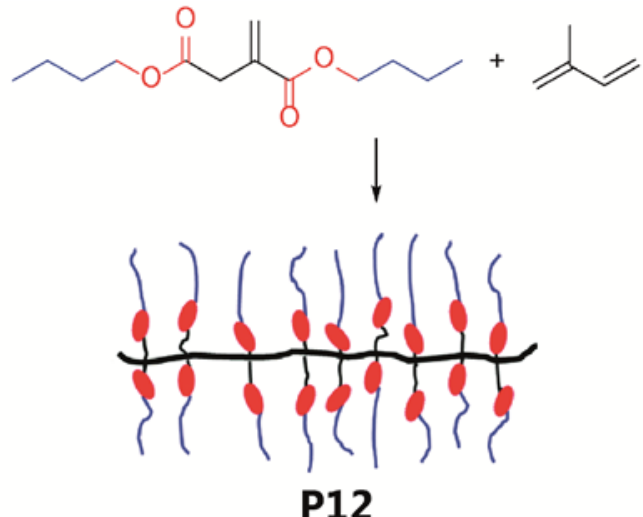

c)

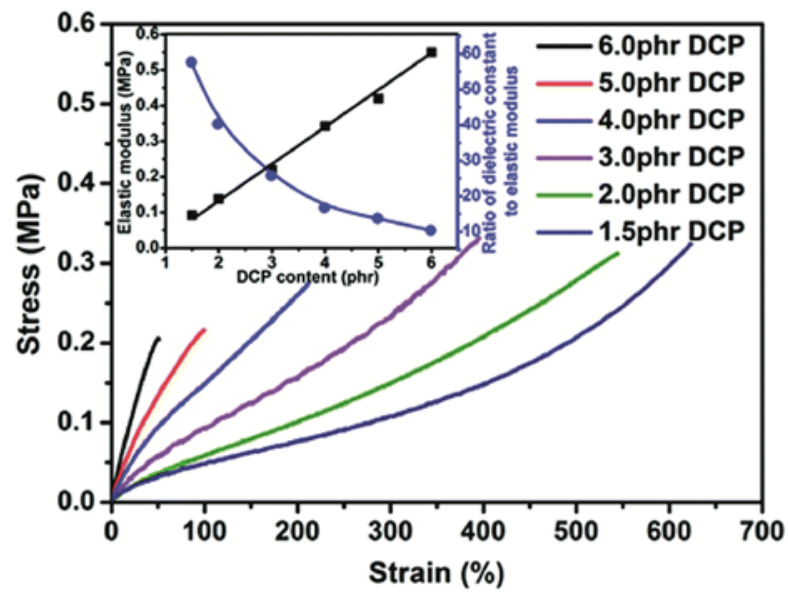

b)
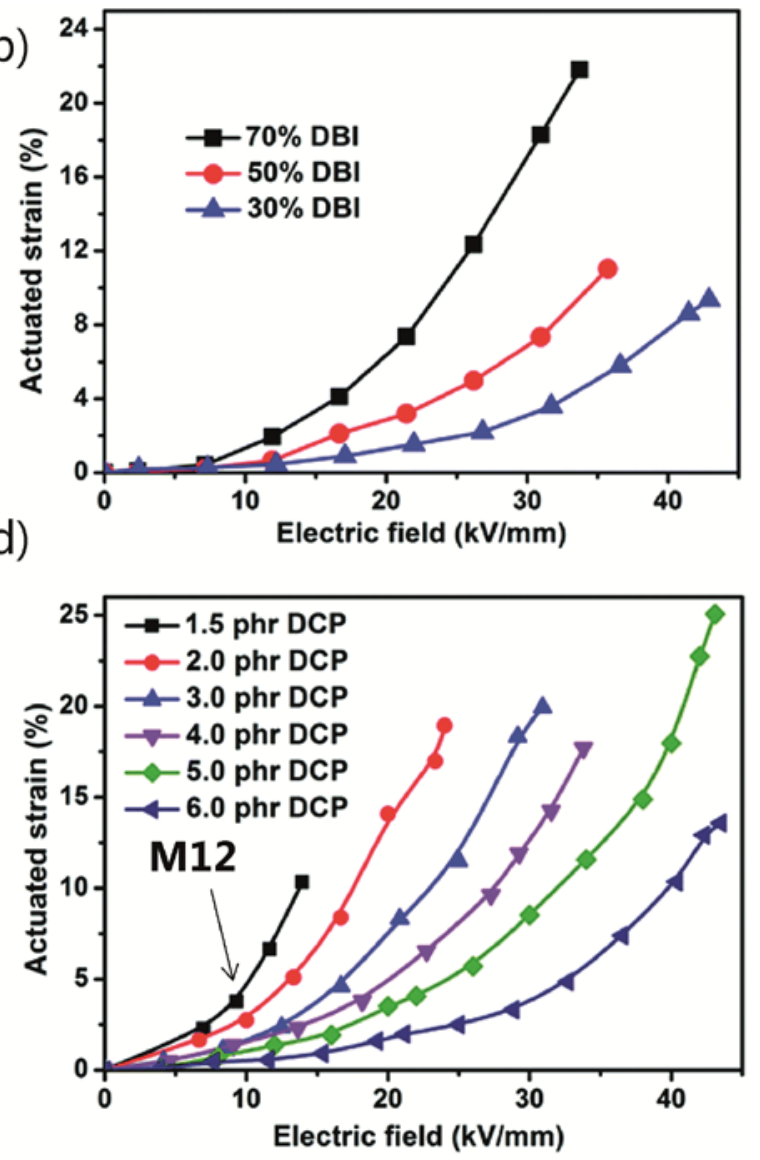

Figure 9. Poly(di-n-butyl itaconate-co-isoprene) P12 and its properties. (a) Synthesis starting from di-n-butyl itaconate (DBI) and isoprene (top left). (b) Actuation strain versus electric field of cross-linked P12 with different DBI contents. (c) Stress-strain curves of P12 (70\% DBI) cross-linked with different amounts of DCP. Insert: Plots of elastic modulus and ratio of permittivity to elastic modulus versus DCP. (d) Actuation strain of cross-linked P12 (70\% DBI) as function of applied electric field. Adapted from Ref. 148 with permission from The Royal Society of Chemistry. 
a)

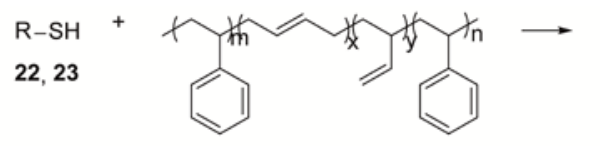

b)

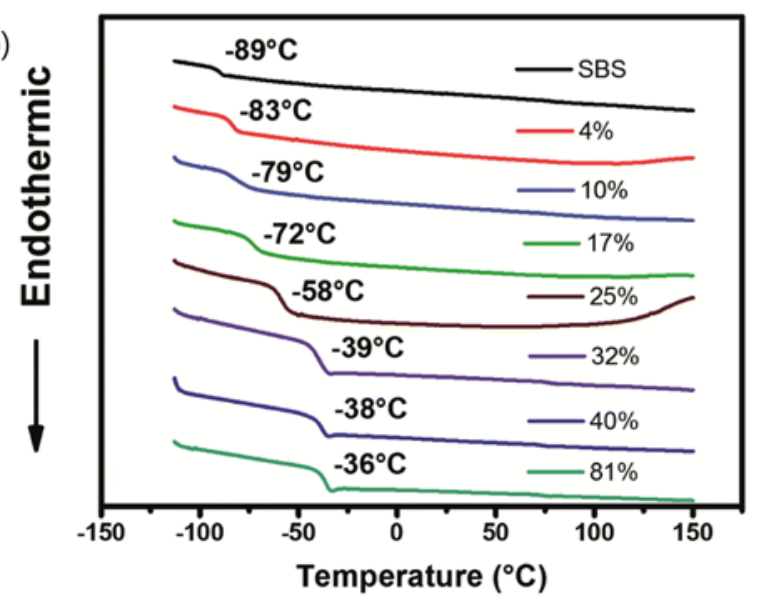

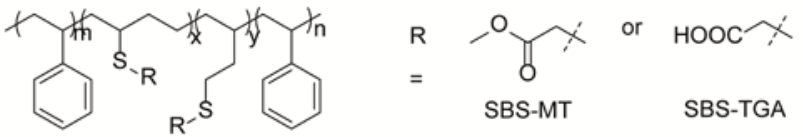

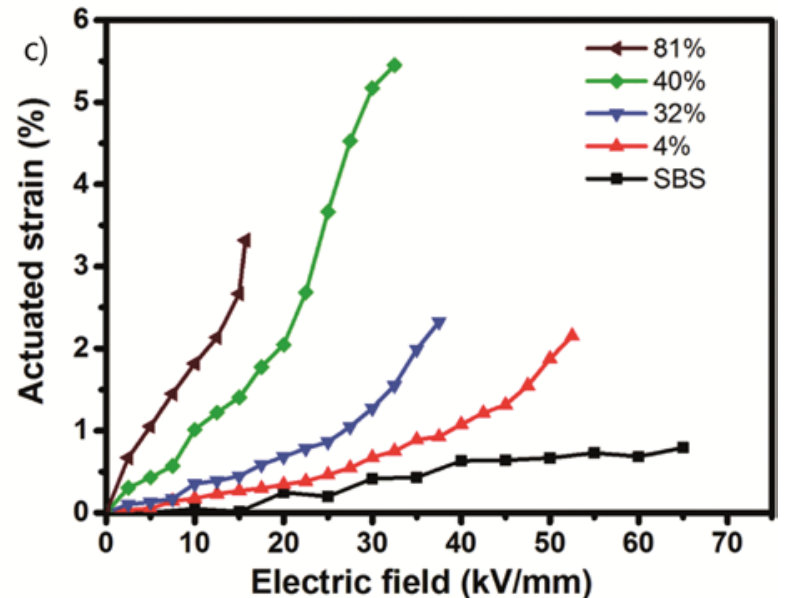

Figure 10. Thiol-ene addition of methylthioglycolate (22) and thioglycolic acid (23) to styrene-butadiene-styrene triblock copolymer following anti-Markovnicov regiochemistry. Markovnicov products are not shown for clarity (a). Properties of styrene-butadiene-styrene triblock copolymers modified with different amounts of methylthioglycolate: DSC curves (b) and actuation strain as function of electric field (c). Reproduced from Ref. 150 with permission from The Royal Society of Chemistry.

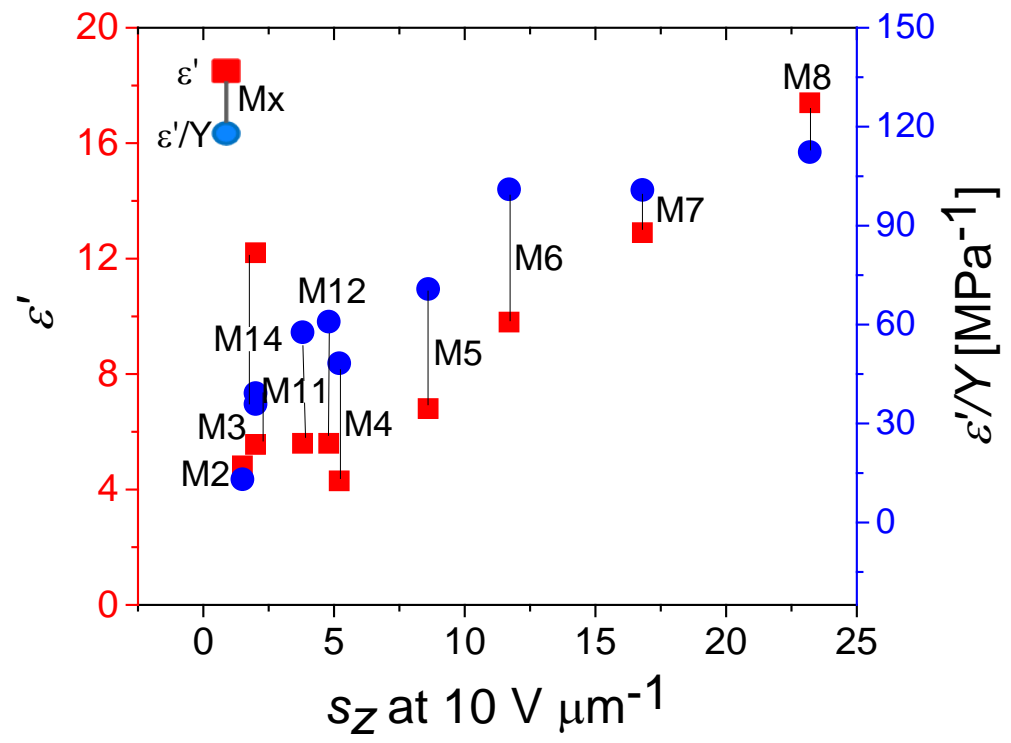

Figure 11. Dielectric permittivity $\varepsilon^{\prime}$ and $\varepsilon^{\prime} / Y$ as function of thickness actuation strain $s_{Z}$ for selected materials at $10 \mathrm{~V} \mathrm{\mu m}^{-1}$ (values from Table 1 ). 
a)

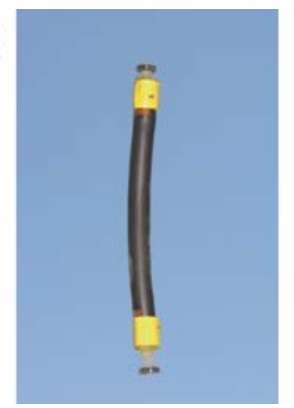

b)

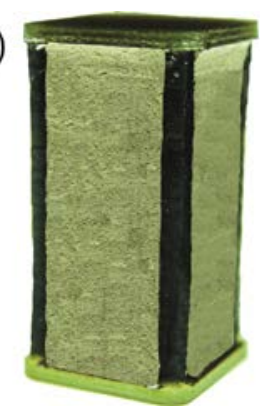

Figure 12. Photographs of a roll actuator (a) and of a stack actuator manufactured by CT Systems (b). The stack actuator contracts by $5 \%$ at $1000 \mathrm{~V}$. Reproduced with permission from G. Kovacs, CT-Systems.

a)

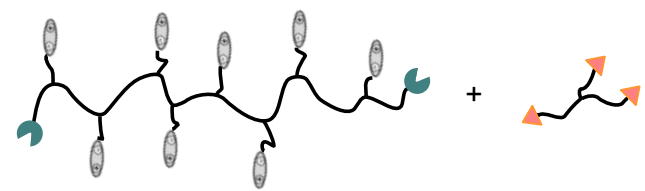

b)

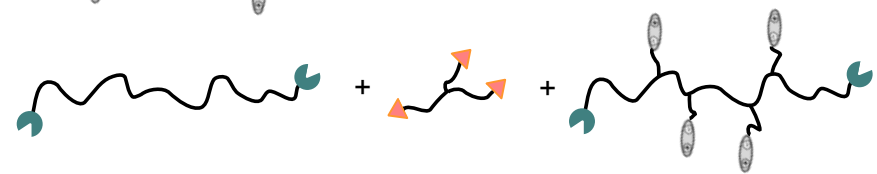

c)<smiles>CCCCCCCCCCCCC(C)(C)C(C)(C)C</smiles>

d)

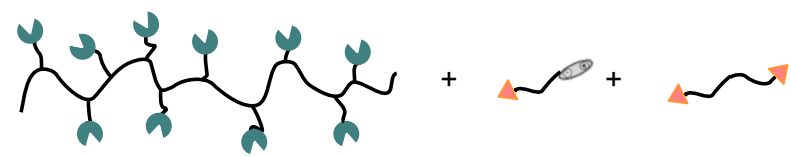

e)

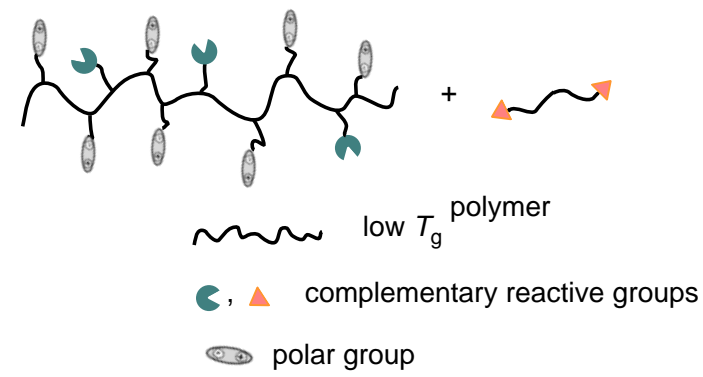

Scheme 1. Synthetic strategies used to prepare polar elastomers for DEAs starting from: a polar polymer that has a high density of polar groups and end-groups for subsequent crosslinking (a), a mixture of polar and nonpolar polymers and a cross-linker (b), an endfunctionalized non-polar polymer and a polar cross-linker (c), a prepolymer that is functionalized with polar groups and cross-linked simultaneously (d), and a polymer that carries both polar groups and reactive groups needed for cross-linking (e). 
a)

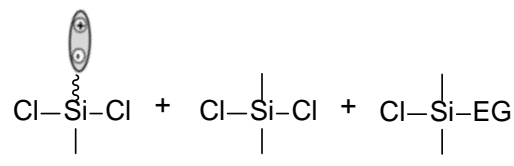

b)

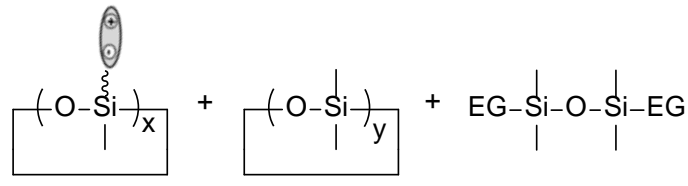

c)

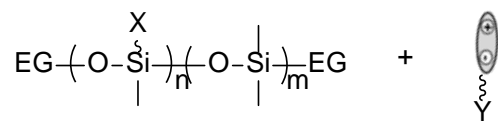

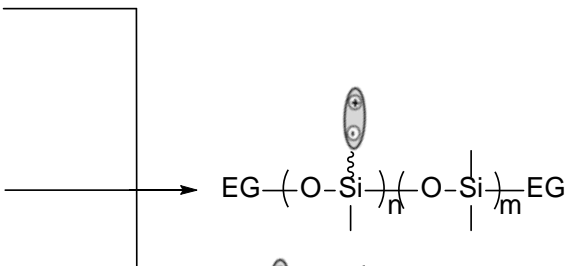

. $=$ polar group

$\mathrm{X}$ and $\mathrm{Y}$ are complementary reactive groups EG is end-group

Scheme 2. Synthesis of polysiloxanes containing polar side groups by polycondensation of bifunctional silanes (a), by ring opening (co)polymerization of functional cyclosiloxane (b), and by post-polymerization modification of polysiloxanes that carry reactive side-groups (c). Specific end-groups can be introduced via end-blockers.

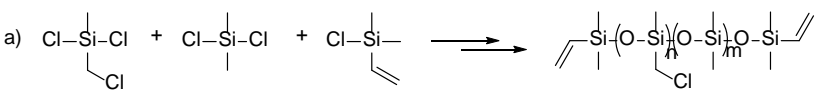
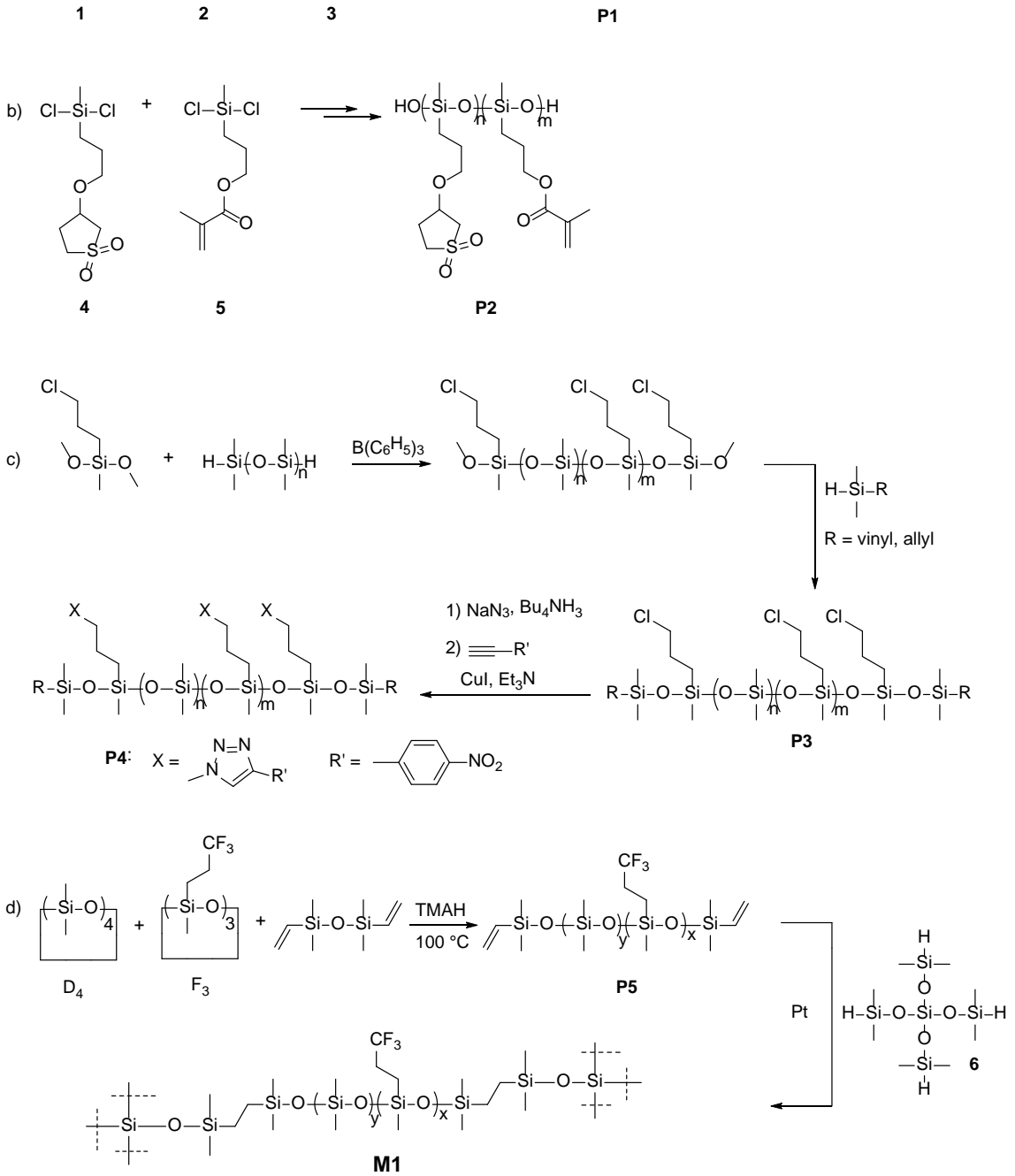
Scheme 3. Synthesis of polysiloxanes containing chloromethyl side groups (a), of polysiloxanes P2 containing propoxy-3-sulfolane groups (b), of polysiloxanes modified with chloropropyl side-groups and their post-polymerization modification with azide and nitrobenzene groups (c), and of polysiloxanes containing trifluoropropyl groups starting from $\mathrm{D}_{4}, \mathrm{~F}_{3}$, and 1,3-divinyl-1,1,3,3-tetramethyldisiloxane $\mathbf{P 5}$ and their cross-linking to elastic materials via a hydrosilylation reaction of the vinyl groups with tetrakis(dimethysiloxy)silane 6 (d). Note that these polymers have a random sequence of repeat units.

a)

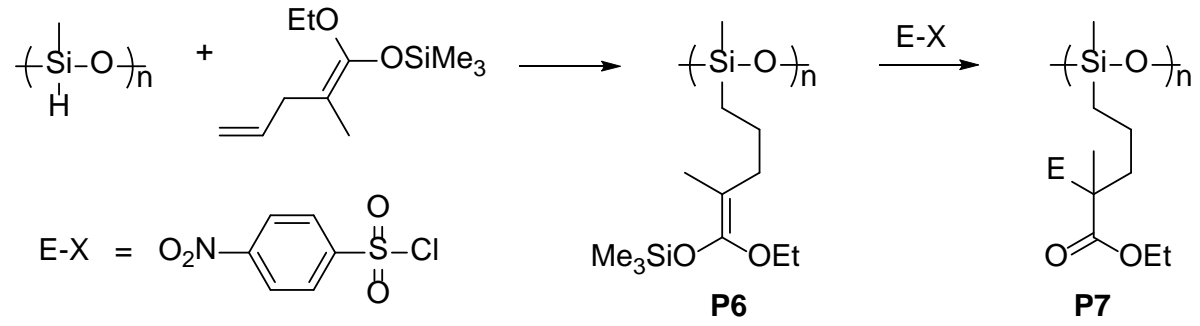

b)
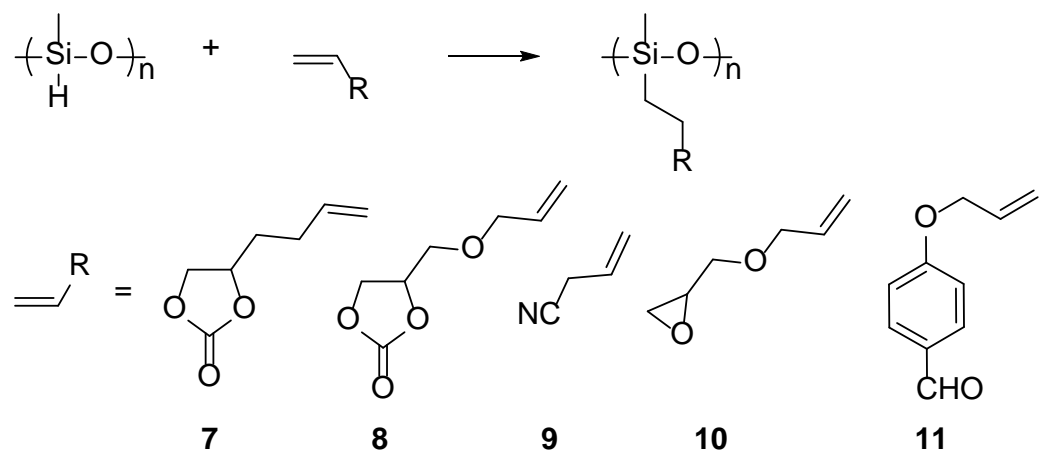

c)
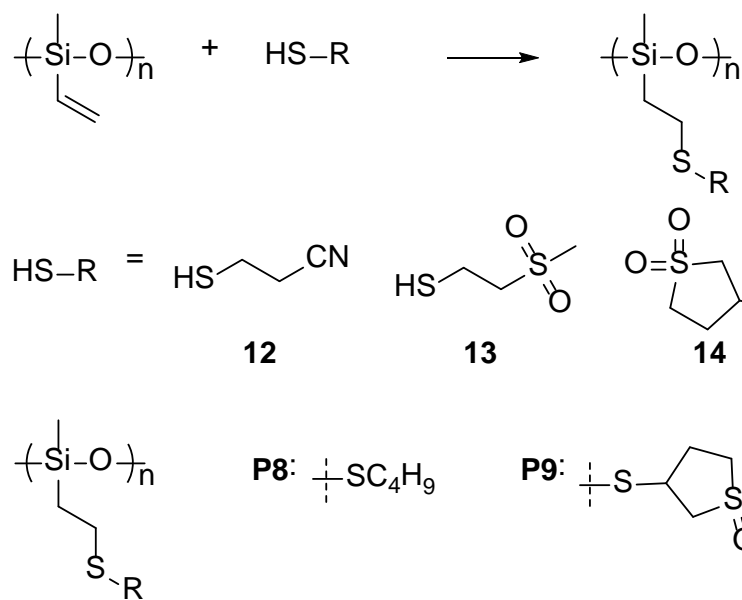<smiles>C[SH](=O)(O)CCS</smiles>

13<smiles>O=S1(=O)CCC(S)C1</smiles>

14<smiles>O=C(O)CCS</smiles>

P10:
P11:<smiles>CS(=O)CCS(C)(=O)=O</smiles>

Scheme 4. Synthesis of $\mathbf{P 6}$ which carries silyl ketene acetal side groups and the subsequent conversion of this polymer into P7 carrying polar 4-nitrobenzenesulphenyl groups (a), ${ }^{114,115}$ functionalization with pendant polar groups of poly(methylhydrosiloxane) via hydrosilylation (b), and functionalization of poly(methylvinylsiloxane) via thiol-ene addition (c). 
a)

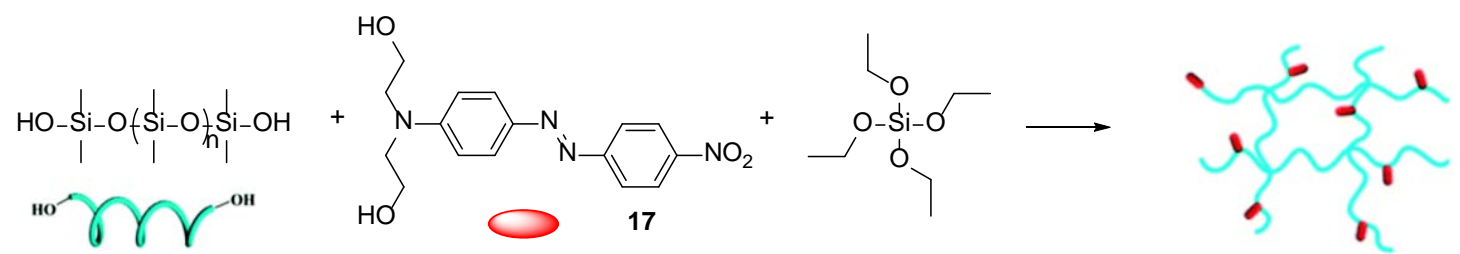

b)

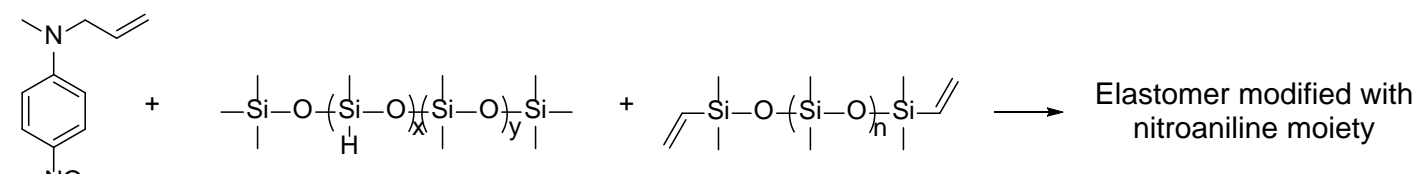
$\mathrm{NO}_{2}$

18

c)
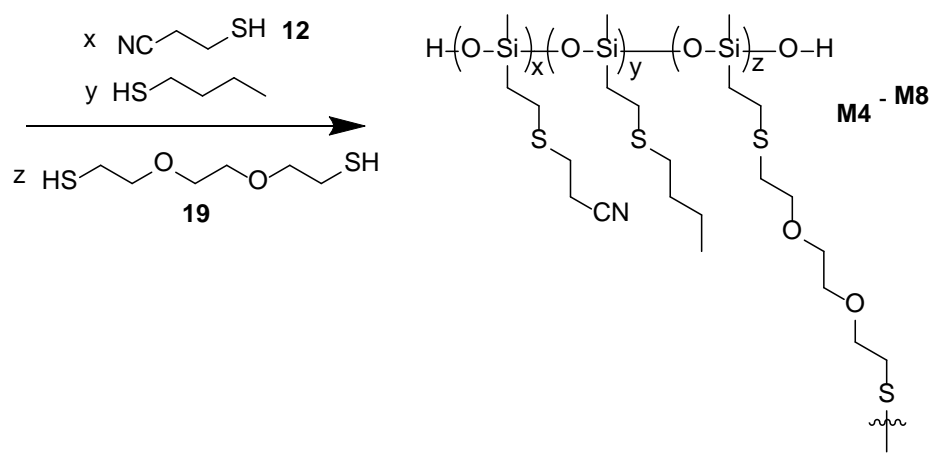

Scheme 5. Synthetic strategy to an azobenzene-grafted PDMS network (a), a one step process to polysiloxane elastomers by Kussmaul et al. starting from a 4-nitroaniline dipole, vinyl endfunctionalized PDMS, and methylhydro-co-dimethyl-polysiloxane cross-linker via hydrosilylation (b), and a one step process to silicone elastomers having different mol\% of polar CN groups prepared via thiol-ene reaction (c). Adapted from Ref. 107 and Ref. 114 with permission from The Royal Society of Chemistry. 
Table 1. Structure, film thickness $d, T_{g}$, dielectric permittivity, actuator breakdown field $E_{\max }$, actuation $s_{\max }$ at $E_{\max }$, elastic modulus at low strain, electromechanical sensitivity $\varepsilon^{\prime} / Y$, actuation $s$ from the measurement and the calculated $s_{z}$ at $10 \mathrm{~V} \mu \mathrm{m}^{-1}$, maximum actuation pressure $p_{\max }$, the maximum elastic energy density and elastic energy density at $10 \mathrm{~V} / \mu \mathrm{m}$ of materials M1-M14.

\begin{tabular}{|c|c|c|c|c|c|c|c|c|c|c|c|c|c|c|c|}
\hline Entry & Polar group & $\begin{array}{c}d \\
{[\mu \mathrm{m}]}\end{array}$ & $\begin{array}{c}T_{g} \\
{\left[{ }^{\circ} \mathrm{C}\right]}\end{array}$ & $\varepsilon^{t}$ & $\begin{array}{c}E_{\max } \\
{\left[\mathrm{V}^{-1} \mathrm{~m}^{-1}\right]}\end{array}$ & $\begin{array}{l}S_{\max } \\
{[\%]}\end{array}$ & $\begin{array}{c}s_{z, \max } \\
{[\%]}\end{array}$ & $\begin{array}{c}Y \\
{[\mathrm{MPa}]}\end{array}$ & $\begin{array}{c}\varepsilon^{t} / Y \\
{\left[\mathrm{MPa}^{-1}\right]}\end{array}$ & $\begin{array}{c}s @ 10 \\
\vee \mu m^{-1} \\
{[\%]}\end{array}$ & $\begin{array}{c}s_{z} @ 10 \\
V \mu m^{-1} \\
{[\%]}\end{array}$ & $\begin{array}{c}p_{\max } \\
{[\mathrm{kPa}]}\end{array}$ & $\begin{array}{c}p @ 10 V / \mu m \\
{[\mathrm{kPa}]}\end{array}$ & $\begin{array}{c}e_{e} @ E_{\max } \\
{\left[\mathrm{J} / \mathrm{cm}^{3}\right]}\end{array}$ & $\begin{array}{c}e_{e} @ 10 \mathrm{~V} / \mu \mathrm{m} \\
{\left[\mathrm{J} / \mathrm{cm}^{3}\right]}\end{array}$ \\
\hline M1 ${ }^{[109]}$ & $\mathrm{CF}_{3}$ & 320 & -92.2 & 6.2. & 7.8 & ${ }^{a} 5.4$ & 10 & 0.019 & 326 & - & - & 3.34 & - & $0.17 \times 10^{-3}$ & 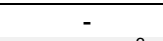 \\
\hline $\mathbf{M} 2^{[131]}$ & & 170 & - & 4.82 & 58 & ${ }^{b} 12$ & 10.7 & 0.368 & 13.1 & $<1.5$ & $<1.5$ & 143 & 4.27 & $7.68 \times 10^{-3}$ & $0.03 \times 10^{-3}$ \\
\hline $\mathbf{M} 3^{[135]}$ & & - & -71 & 5.56 & 10 & ${ }^{\mathrm{c}} 2$ & ${ }^{\mathrm{c}} 2$ & 0.142 & 39.2 & ${ }^{\mathrm{c}} 2$ & ${ }^{\mathrm{c}} 2$ & 4.92 & 4.92 & $0.05 \times 10^{-3}$ & $0.05 \times 10^{-3}$ \\
\hline $\mathbf{M} 4^{[122]}$ & & 150 & -92.6 & 4.3 & 23 & ${ }^{\mathrm{a}} 9.7$ & 16.9 & 0.089 & 48.3 & ${ }^{\mathrm{a}} 2.7$ & 5.2 & 20.14 & 3.81 & $1.70 \times 10^{-3}$ & $0.10 \times 10^{-3}$ \\
\hline $\mathbf{M}^{[122]}$ & & 150 & -78.3 & 6.8 & 18 & ${ }^{\mathrm{a}} 17.5$ & 27.6 & 0.096 & 70.8 & ${ }^{\mathrm{a}} 4.6$ & 8.6 & 19.51 & 6.02 & $2.69 \times 10^{-3}$ & $0.26 \times 10^{-3}$ \\
\hline$M 6^{[122]}$ & & 150 & -67.7 & 9.8 & 13 & ${ }^{\mathrm{a}} 13.5$ & 22.4 & 0.097 & 101 & ${ }^{\mathrm{a}} 6.4$ & 11.7 & 14.66 & 8.68 & $1.64 \times 10^{-3}$ & $0.51 \times 10^{-3}$ \\
\hline$M 7^{[122]}$ & & 150 & -58.2 & 12.9 & 11 & ${ }^{\mathrm{a}} 12.0$ & 20.3 & 0.128 & 100.8 & ${ }^{\mathrm{a}} 9.6$ & 16.8 & 13.82 & 11.42 & $1.40 \times 10^{-3}$ & $0.96 \times 10^{-3}$ \\
\hline $\mathbf{M 8}^{[122]}$ & & 150 & -49.2 & 17.4 & 12 & ${ }^{\mathrm{a}} 21.0$ & 31.7 & 0.155 & 112.3 & ${ }^{\mathrm{a}} 14.1$ & 23.2 & 22.18 & 15.41 & $3.52 \times 10^{-3}$ & $1.79 \times 10^{-3}$ \\
\hline $\mathbf{M} \mathbf{9}^{[143]}$ & & 100 & - & 5.7 & 80 & ${ }^{b} 35$ & 25.9 & 0.52 & 11.0 & ${ }^{b} 1$ & 1 & 323.00 & 5.05 & $41.83 \times 10^{-3}$ & $0.03 \times 10^{-3}$ \\
\hline $\mathrm{M} 10^{[143]}$ & & 100 & - & 6.3 & 50 & ${ }^{b} 35$ & 25.9 & 0.26 & 24.2 & ${ }^{b} 2.5$ & 2.4 & 139.45 & 5.58 & $20.22 \times 10^{-3}$ & $0.07 \times 10^{-3}$ \\
\hline M11 $^{[147]}$ & & - & -57 & 5.6 & 15.6 & ${ }^{b} 11.9$ & 10.6 & 0.097 & 57.7 & ${ }^{\mathrm{b}} 4$ & 3.8 & 12.06 & 4.96 & $0.64 \times 10^{-3}$ & $0.09 \times 10^{-3}$ \\
\hline $\mathrm{M} 12^{[148]}$ & & 400 & -38 & 5.6 & 14 & ${ }^{b} 11$ & 9.9 & 0.092 & 60.9 & $b_{5}$ & 4.8 & 9.72 & 4.96 & $0.48 \times 10^{-3}$ & $0.12 \times 10^{-3}$ \\
\hline $\mathrm{M} \mathbf{3}^{[149]}$ & & 150 & - & 22.6 & 34 & ${ }^{b} 12$ & 10.7 & 2.74 & 8.2 & - & - & 231.32 & 20.01 & $12.38 \times 10^{-3}$ & - \\
\hline M14 ${ }^{[150]}$ & & 500 & -36 & 12.2 & 15 & ${ }^{\mathrm{b}} 2.7$ & 2.6 & 0.34 & 35.9 & ${ }^{\mathrm{b}} 2$ & 2 & 24.39 & 10.8 & $0.32 \times 10^{-3}$ & $0.11 \times 10^{-3}$ \\
\hline
\end{tabular}

${ }^{\mathrm{a}} \boldsymbol{S}_{x y}$ or ${ }^{\mathrm{b}} \boldsymbol{S}_{\text {act }}$ as reported; ${ }^{\mathrm{c}}$ actuators measured in pure shear configuration. Where M1-M8 have a polysiloxan backbone; M9, M10, M12-M14 have a C-C backbone, and M11 has a polyester backbone. 
For Reviews, please insert up to three author biographies and photographs here, max. 100 words each

Dorina M. Opris obtained her B.Sc. in chemistry at Babes-Bolyai University (BBU), ClujNapoca, Romania, in 1997. She then joined Natex S.A. developing flavors and simultaneously did her M.Sc. in chemistry at BBU. From 1999 to 2001 she worked with Prof. Grosu at BBU towards a $\mathrm{PhD}$ and then joined the group of Prof. Schlüter at Freie Universität Berlin, Germany, where she finished her $\mathrm{PhD}$ in 2005. In 2006 she joined Empa, Dübendorf, Switzerland, as PostDoc and later as scientist. Since 2014 she has been the leader of Functional Dielectric Elastomers group, Laboratory of Functional Polymers, led by Prof. Nüesch.

Author Photograph(s) ((40 mm broad, 50 mm high, gray scale))

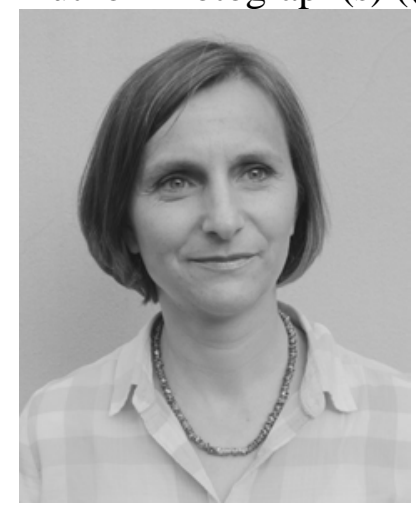


The table of contents entry should be $50-60$ words long

It has been the dream of many scientists to develop stimuli responsive materials that provide forces and shape changes comparable to natural muscles. This dream will become reality one day due to the progress in dielectric elastomer actuators technology.

Keyword (dielectric elastomer actuators, high permittivity elastomers, stimuli responsive polymers, artificial muscles)

Dorina M. Opris*

Polar elastomers as novel materials for electromechanical actuator applications

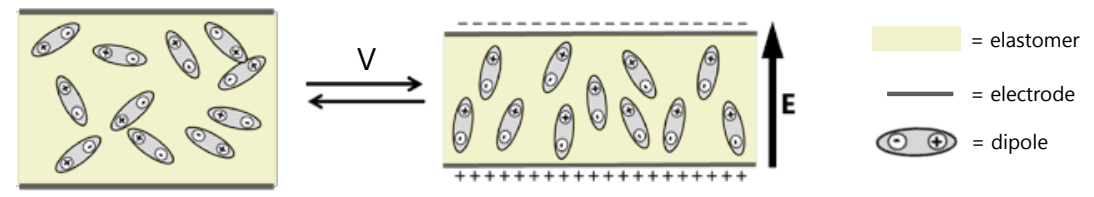

